\title{
Desenvolvimento de Serviços em Redes TCP/IP - Projeto de um Servidor de Modem
}

\author{
Roseli Maria da Silva
}

Orientador:

Prof. Dr. Edson dos Santos Moreira

\author{
Dissertaçâo apresentada ao Instituto de Ciências Matemáticas de \\ Sáo Carlos - USP, como parte dos requisitos para a obtençâo \\ do título de Mestre em Ciéncias - Área: Ciências de \\ Computaçào e Matemática Computacional. \\ USP -São Carlos \\ 1992
}


Aos meus pais João e Odite. 
Quem nada conhece, nada ama. Quem nada pode fazer, nada compreende. Quem nada compreende, nada vale. Mas quem compreende também ama, observa, vê...Quanto mais conhecimento houver inerente numa coisa, tanto maior o amor... Aquêle que imagina que todos os frutos amadurecem ao mesmo tempo, como as cerejas, nada sabe a respeito das uvas.

Paracelso

Odi et amo. Quare id faciam, fortasse requiris.

Nescio, sed fieri sentio et excrucior.

C. V. Gatulo 


\section{Agradecimentos}

ao Prof. Edson dos Santos Moreira pela orientação;

aos professores Nivaldi e Onofre pelo auxílio e sugestôes;

às amigas Alida, Edna, Emi, Rosane e Sueli pelo carinho e atençâo nas horas difíceis:

à Ana Paula, ao Roberto, à Roseli e a Sandra pela amizade e ajuda;

à minha família, pelo apoio e incentivo:

àqueles que de um modo ou de outro contribuiram para a realizaçâo deste trabalho:

a Deus, pois sem ele nada seria possivel.

Este trabalho contou com apoio financeiro da Capes. 


\section{Resumo}

A crescente utilização de sistemas computacionais distribuídos construídos sobre redes de computadores é apresentada. Este projeto considera o ambiente de rede de SUNs existente no Departamento de Ciências de Computaçâo e Estatística do ICMSC - USP. Este trabalho destaca a utilização de mecanismos fornecidos pelo sistema SunOS para o desenvolvimento de novos serviços de rede. $O$ servidor de modem projetado tem por finalidade ilustrar o acréscimo de novos serviços no ambiente SunOS, permitir a interconexâo da rede local com outras redes remotas (via linha telefônica) e a utilização dos serviços oferecidos por outros sistemas possibilitando o compartilhamento do modem e da linha telefônica pelos usuários. A idéia básica do servidor de modem é permitir que qualquer estação da rede tenha acesso a serviços centralizados no servidor. Também são analisados e descritos recursos para o estabelecimento de conexão com outros sistemas e protocolos de comunicação - com ênfase ao conjunto conhecido como TCP/IP. Da maneira que o projeto foi desenvolvido existe uma grande transparência para o usuário da localizaçâo do servidor os serviços fornecidos por meio de servidores como "inetd" e "portmapper" são introduzidos como elementos para fornecer portabilidade, modularidade $e$ transparência aos serviços. 
Abstract

The growing use of distributed systems built over computer networks is presented. Having the design of a modem server as the focusing point, this work is set to describe the mechanisms provided by SunOS operating systems for the development of network services. Communication protocols are described with special attention to the suite of protocols known as TCP/IP. The inetd and portmapper services provided by SunOS are introduced as elements to provide portability, modularity and transparency to services. The design of a modem server is then presented as an example. 


\section{Conteúdo}

1 Introdução 1

2 Redes $\quad 6$

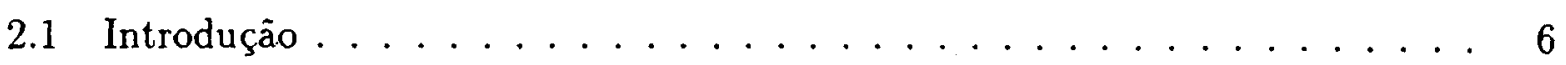

2.2 Redes Locais . . . . . . . . . . . . . . . . . 8

2.2.1 Meios físicos de transmissão de dados . . . . . . . . . . . 10

2.2 .2 Topologia .......................... 10

2.2.3 Métodos de controle de acesso ao meio. . . . . . . . . . . . 12

2.3 Consideraçôes finais. . . . . . . . . . . . . . . . 13

3 Protocolos de Comunicação 14

3.1 Introdução . . . . . . . . . . . . . . . 14

3.2 Modelo de Referência ISO/OSI . . . . . . . . . . . . 15

3.3 Protocolos da camada de transporte. . . . . . . . . . . . . . . 19

3.4 Protocolos da camada de rede . . . . . . . . . . . . . . . . 19

3.5 Protocolos da camada de enlace de dados . . . . . . . . . . . . . . 21

3.5.1 Deteç̧ão dos erros de transmissão . . . . . . . . . . . . . 22

3.5 .2 Correção de erros . . . . . . . . . . . . . . . . 23

3.5.3 Controle de fluxo ....................... 23

3.5.4 Características gerais do funcionamento do enlace de dados . . . . . 24

3.5.5 Protocolos orientados a caráter e orientados a "bit" . . . . . . . 24 
3.5.6 O padrão IEEE $802 \ldots \ldots \ldots \ldots \ldots \ldots \ldots \ldots$

3.5.7 Exemplos de implementaçôes de redes de comunicação $\ldots \ldots . .26$

3.6 Protocolos da camada física . . . . . . . . . . . . . . . . . 29

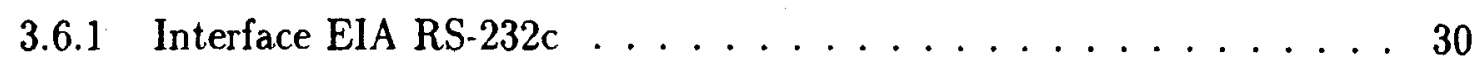

3.7 Modems . . . . . . . . . . . . . . . . . . 31

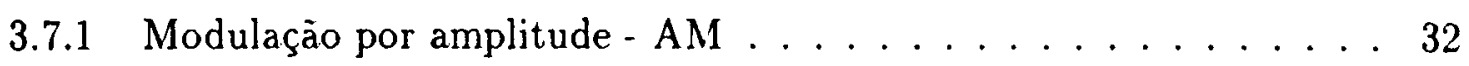

3.7 .2 Modulaçào por freqüência $-F M \ldots \ldots \ldots \ldots$

3.7.3 Modulação por fase $-\mathrm{PM} \ldots \ldots \ldots \ldots \ldots$

3.8 Consideraçôes finais . . . . . . . . . . . . . . . . 34

4 Protocolo TCP/IP $\quad 36$

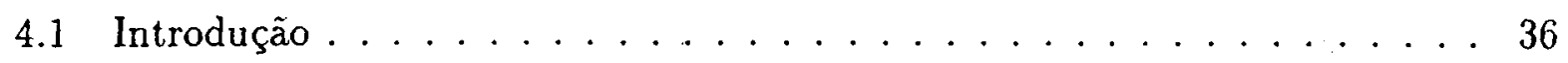

$4.2 \mathrm{O}$ modelo em camadas da Internet $\ldots \ldots \ldots \ldots \ldots$

4.3 Protocolo de Inter-rede . . . . . . . . . . . . . . . . 39

4.4 Protocolos de serviços $\ldots \ldots \ldots \ldots \ldots$. . . . . . . . 41

$4.4 .1 \quad \mathrm{O}$ protocolo TCP $\ldots \ldots \ldots \ldots \ldots \ldots \ldots$

4.4 .2 O protocolo UDP $\ldots \ldots \ldots \ldots \ldots \ldots \ldots$

4.5 Protocolos de aplicação . . . . . . . . . . . . . . . 43

4.6 Considerações finais . . . . . . . . . . . . . . . 45

5 Desenvolvimento de serviços de rede em ambiente SunOS 46

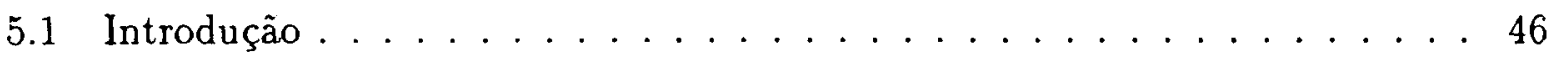

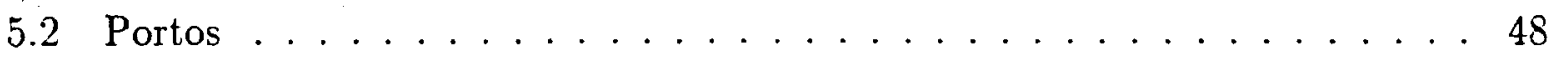

5.3 Implementação de pares cliente/servidor em ambiente UNIX . . . . . 50

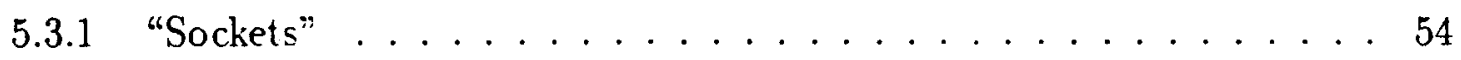

5.3.2 Acesso aos serviços . . . . . . . . . . . . . 61

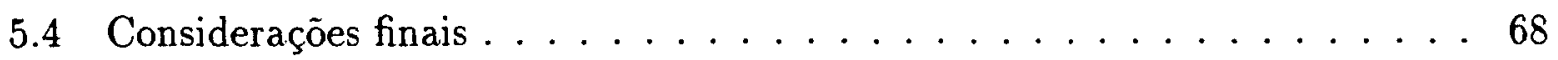


6 projeto do servidor de modem

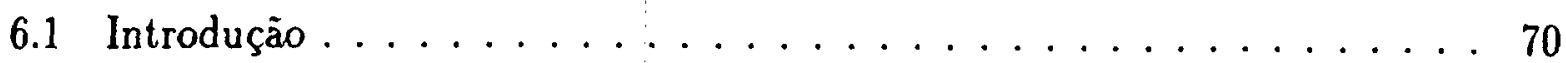

6.2 A funçào do servidor . . . . . . . . . . . . . 70

6.3 Comandos disponíveis . . . . . . . . . . . . . 72

6.4 Acesso ao servidor .......................... 74

6.5 Gerenciamento da conexão . . . . . . . . . . . . . 75

6.6 Manipulação de arquivos no cliente . . . . . . . . . . . 76

6.7 Consideraçôes finais . . . . . . . . . . . . . . 76

$\begin{array}{lll}7 & \text { Conclusões e trabalhos futuros } & \mathbf{7 7}\end{array}$

7.1 Considerações inicias . . . . . . . . . . . . . . . . . 77

7.2 Contribuiçôes deste trabalho . . . . . . . . . . . . . 77

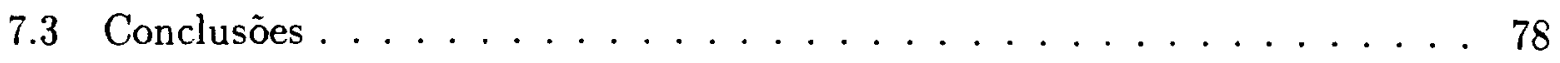

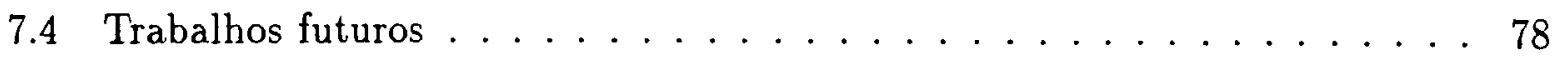

$\begin{array}{lr}\text { Bibliografia . } & 80\end{array}$ 


\section{Lista de Figuras}

1.1 Rede local/Rede pública. . . . . . . . . . . . . . . 3

1.2 Rede local/Servidor. . . . . . . . . . . . . . . 4

1.3 Rede local/usuário remoto. . . . . . . . . . . . . . 4

2.1 Rede de computadores. . . . . . . . . . . . . . . . 7

2.2 Classificação de redes por cobertura geográfica [TAN89]. . . . . . . . . 7

2.3 A rede ANSP [GET92] . . . . . . . . . . . . . . . . . 8

2.4 Rede local. . . . . . . . . . . . . . . . . . . 9

2.5 Topologias básicas de redes locais. . . . . . . . . . . . . . 11

3.1 Modelo ISO/OSI [TAN89]. . . . . . . . . . . . . . 16

3.2 Exemplo de comunicação entre duas máquinas[TAN89] . . . . . . . . . 17

3.3 a) Modelo ISO/OSI e a IEEE 802. b) Padrão IEEE 802. . . . . . . . . . . 26

3.4a Conexâo torneira. . . . . . . . . . . . . . . . 27

3.4 b Conexão T. . . . . . . . . . . . . . . . 27

3.5 Formato padrão do pacote Ethernet. . . . . . . . . . . . . . 27

3.6 O formato padrão dos pacotes. . . . . . . . . . . . . 28

3.7 Uma rede FDDI. . . . . . . . . . . . . . . . . . 29

3.8 Alguns dos principais sinais lógicos do RS-232c . . . . . . . . . . 31

3.9 Comunicaçâo de dados através de modems. . . . . . . . . . . . 32

4.1 As quatro camadas do TCP/IP. . . . . . . . . . . . 38

4.2 Um datagrama IP. . . . . . . . . . . . . . . . . 40 
4.3 Um segmento TCP. . . . . . . . . . . . . . . . 41

4.4 Um datagrama UDP. . . . . . . . . . . . . . . . 43

4.5 Relação entre alguns protocolos da Internet. . . . . . . . . . . . 44

5.1 Estrutura do processo entrada, mostrando o caminho dos dados entre o hardware de rede e um programa de aplicação [COM91b]. . . . . . . . . . 49

5.2 Estrutura do processo saída mostrando o caminho dos dados entre um programa de aplicação e o hardware de rede [COM91b]. . . . . . . . . . 50

5.3 Implementaçào de rede 4.3 BSD UNIX . . . . . . . . . . . . . . 51

5.4 Comparação entre "sockets", TLI e I/Os de arquivos. . . . . . . . . . 53

5.5 Estrutura do endereço do "socket" para os domínios Internet e UNIX. . . . 55

5.6 Possiveis combinações domínio, tipo e protocolos. . . . . . . . . . . . 57

5.7 Chamadas de sistema para "sockets" e a associação dos parâmetros. . . . . 57

5.8 Chamadas de "sockets" utilizadas com protocolos orientados a conexão. . . 60

5.9 Chamadas de "sockets" utilizadas com protocolos sem conexão. . . . . . . 61

5.10 Os campos de configuração do "inetd". . . . . . . . . . . . 64

5.11 Passos executados pelo "inetd". . . . . . . . . . . . . . 65

5.12 Passos para o estabelecimento de conexâo entre o par cliente/servidor $\mathrm{u}$ sando "portmapper" [SUN90a]. . . . . . . . . . . . . . 68

6.1 Diagrama do sistema. . . . . . . . . . . . . . 71

6.2 O par cliente/servidor. . . . . . . . . . . . . 72

6.3 Esquema da conexão. . . . . . . . . . . . . . . . . 74 


\section{Capítulo 1}

\section{Introdução}

$\mathrm{Na}$ área de informática, o desenvolvimento tecnológico conduz a mudanças que acarretam uma crescente descentralização - geográfica e funcional - dos ambientes informatizados. Contudo, recursos computacionais mais potentes, como os periféricos especializados, os bancos de dados e os computadores de grande porte, tendem a permanecer centralizados por serem mais caros. Redes de computadores consistem basicamente na interconexão e compartilhamento desses recursos. Redes locais de computadores podem, portanto, ser consideradas como uma solução a nível local, por exemplo, em uma universidade, uma indústria ou em um escritório de prestação de serviços [TAN89,STA84].

A oferta de serviços disponíveis via rede de computadores é grande e a tendência é que cresça. Como exemplo, podem ser citados o correio eletrônico, o acesso a bases de dados remotas, o acesso a máquinas remotas e a transferência de arquivos [MOU86, QUA86, TAN89]. A seguir são descritos estes serviços:

- Acesso remoto a outras máquinas: o usuário pode ter acesso à máquina remota $\mathrm{e}$ trabalhar interativamente, usando todos os serviços a que tem direito, desde que tenha disponível um código de usuário e uma senha na máquina destinatária. Face à limitada velocidade usada nas conexões existentes no país, percebe-se um tempo de resposta elevado neste tipo de serviço.

- Acesso a bases de dados: permite aos usuários o acesso às informações de uma base de dados, como o serviço de acesso a bancos de dados nacionais e internacionais via INTERDATA/RENPAC da Embratel. Diversas universidades estão implementando seus próprios serviços de recuperaçâo de informações bibliográficas, colocando "on-line" pelo menos as referências sobre o acervo produzido ou disponível na instituiçâo. Contudo, tais implementaçôes não seguem necessariamente padronizaçôes. No exterior, verifica-se um maior grau de integraçâo entre sistemas acadêmicos e comerciais que permitem ao usuário de um sistema formular consultas que sâo direcionadas a outro sistema usando protocolos específicos para a área. A oferta de serviços com linguagem de acesso padronizada por um conjunto de provedores está prevista inicialmente para ser viabilizada através da RENPAC (para assinantes). 
- Transferência de arquivos: usuários podem transferir arquivos entre si. O usuário que inicia a transferência deve possuir direito de acesso aos arquivos envolvidos.

- Correio eletrônico: Um usuário compōe uma mensagem em um computador local, fornece o endereço da caixa postal do receptor $e$ instrui o sistema de correio eletrônico local para enviar a mensagem. O sistema local assume a responsabilidade da mensagem, enviando-a via rede e, finalmente, a mensagem será depositada na caixa postal do receptor.

No Brasil, as empresas do sistema Telebrás oferecem uma infra-estrutura de serviços que incluem desde facilidades de comunicação de dados e textos até comunicação por som e/ou imagem. A Embratel oferece uma série de meios de acesso a estes serviços: SICRAM (Sistema Computadorizado de Retransmissão Automática de Mensagem), TRANSDATA (Canal Privativo de Comunicação de Dados) e RENPAC (Rede Nacional de Comutação de Pacotes) [BRA90]. A instalação da RENPAC, que utiliza circuitos virtuais para a comunicação entre assinantes, teve início nos anos 80 baseada na tecnologia da rede TRANSPAC da França. Os serviços RENPAC dependem do tipo de acesso (dedicado ou comutado) utilizado e do modo de operação dos equipamentos terminais, podendo ser citados RENPAC 3025, RENPAC 3028 e RENPAC 2000.

As características de redes de computadores e de redes de comunicação passaram a ser fatores determinantes da eficiência da utilização de computadores interligados. Recentemente, surgiram técnicas que melhoram a utilização das redes públicas de telefonia para o transporte específico de sinais de dados, além das redes públicas projetadas especificamente para o transporte destes sinais, que oferecem características de qualidade cada vez maiores. Através dos protocolos de comunicação, os dados podem chegar ao destinatário integros, confiáveis e com probabilidade de erros controlável. Se houver erro nos dados transmitidos, as regras de comunicação dos protocolos possibilitam a retransmissão dos dados até que cheguem corretamente [DVO89].

Redes locais de microcomputadores tornaram-se muito populares, podendo ser encontradas em praticamente todo tipo de organizaçâo, desde indústrias, empresas comerciais, até universidades. Contudo, apesar de redes locais poderem funcionar de forma independente, a tendência é que ocorra interconexão entre as redes locais e as redes de longa distância. Um dos protocolos utilizados na interconexão de redes é o chamado conjunto de protocolos TCP/IP, ou apenas TCP/IP [COM91a, POS81a, POS81b, POS83, STE90]. O TCP/IP foi definido na década de 70 para fornecer funções e serviços para a rede Internet. Atualmente existem implementaçôes do TCP/IP disponíveis em computadores na faixa compreendida de supercomputadores a microcomputadores, oferecendo um ambiente de rede robusto, estável e bem entendido pelos usuários e administradores. Além disso, existem várias implementaçôes de dominio público do TCP/IP que podem ser obtidas com facilidade.

Usualmente, no ambiente acadêmico, um usuário de uma rede de computadores trabalha em um hospedeiro, que pode ser desde um microcomputador até um computador de grande porte conectado a uma rede local, que por seu turno pode estar conectada à 
rede do campus. Muitas vezes, recursos específicos como um sistema servidor de arquivos ou um sistema de correio eletrônico podem estar disponíveis localmente em tais redes. A rede do campus, provavelmente, estará conectada a uma rede de longa distância (por exemplo, RENPAC ou Internet), que forneça acesso a recursos remotos, tais como, base de dados especializadas e/ou recursos de supercomputadores.

Sistemas de comunicação baseados em transmissão por via telefônica utilizando modems são usados com sucesso (UUCP, TCP/IP, Phonenet, etc), principalmente por oferecer um meio simples e barato de conexão. No entanto, estes sistemas são projetados para prestar serviços específicos (tais como: correio eletrônico, transferência de arquivos e "login" remoto) entre máquinas previamente determinadas por gerentes de sistemas e executando protocolos específicos.

Este projeto visa fornecer o serviço de conexão telefônica a qualquer estação de uma rede local de computadores que tenham como um dos protocolos disponíveis o TCP/IP através da implementação de um sistema servidor de modem. Um servidor de modem fornece meios de conexão com o modem, serviços de transferência de arquivos, acesso a sistemas remotos e a base de dados remotas. Eventualmente pode permitir que um usuário remoto tenha acesso a recursos locais. Abaixo são apresentadas algumas das possibilidades de utilização de um servidor de modem, ilustradas nas figuras 1.1, $1.2 \mathrm{e}$ 1.3:
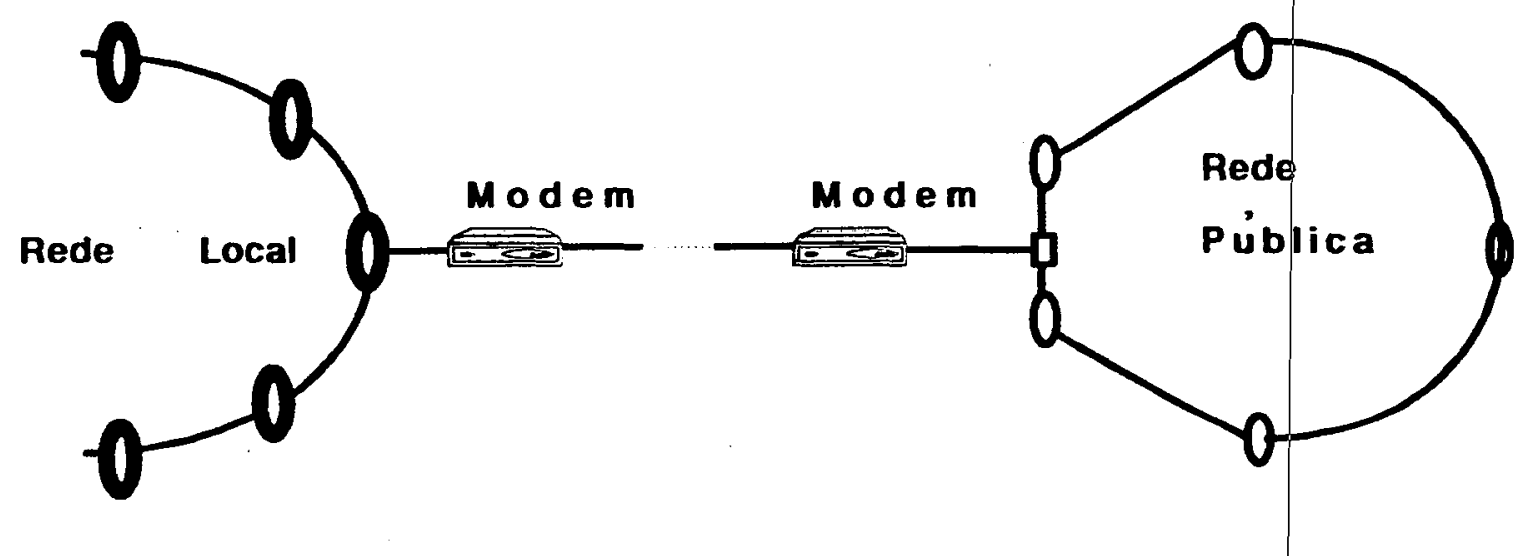

Figura 1.1 Rede local/Rede pública.

- Entre uma rede local e uma rede pública (por exemplo, para a utilização do RENPAC. 2000, figura 1.1).

- Entre uma rede local e um servidor localizado remotamente (base de dados, supercomputadores, etc., figura 1.2).

- Eventualmente, pode-se permitir que usuários remotos tenham acesso aos recursos oferecidos pela rede local (figura 1.3). 


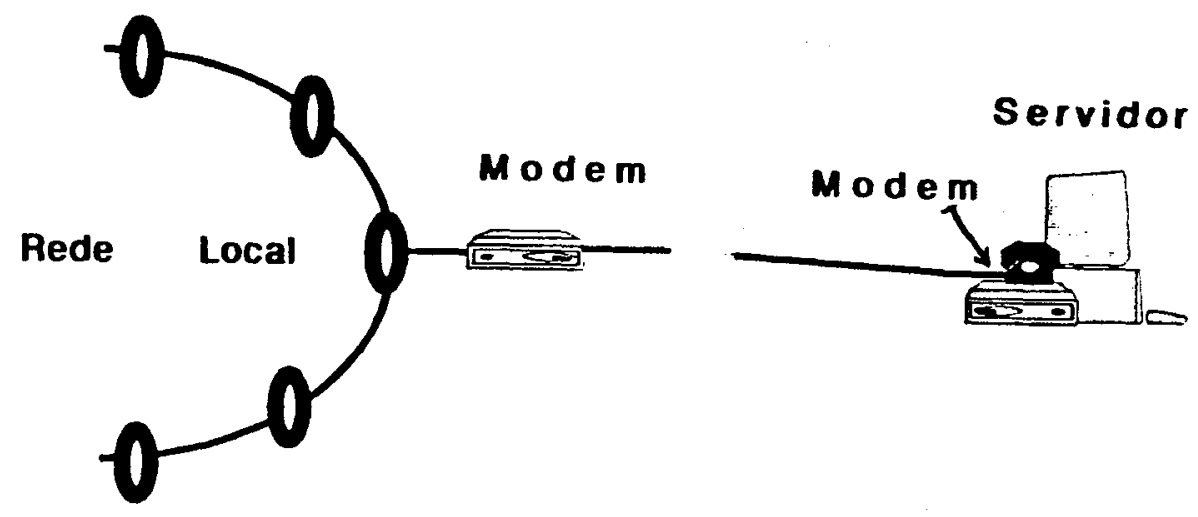

Figura 1.2 Rede local/Servidor.
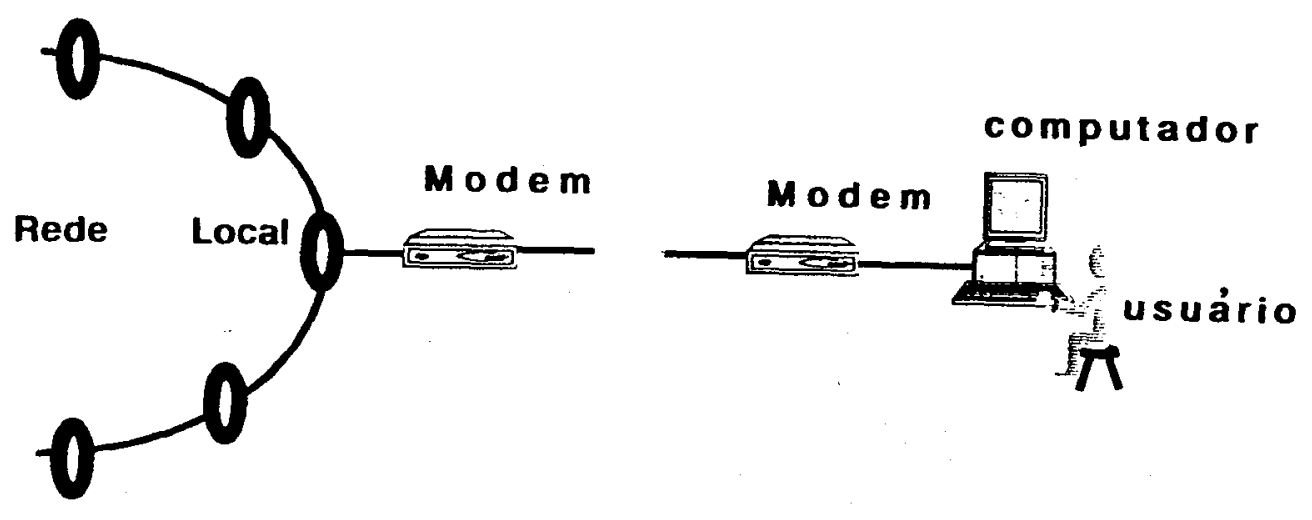

Figura 1.3 Rede local/usuário remoto.

A idéia básica neste trabalho é ilustrar a implementação de serviços de rede no ambiente SunOS através do desenvolvimento de um servidor de modem. O projeto leva em consideração características como modularidade, transparência e portabilidade na descrição da utilização dos mecanismos existentes neste ambiente para o desenvolvimento de serviços de rede.

No capítulo 2, são analisados os conceitos básicos de redes de computadores e, em particular, de redes locais. Como a efetiva conectividade das redes está relacionada com os modelos para a sua interconexão, no capítulo 3, é visto o modelo de referência ISO OSI, além de serem feitas algumas considerações a respeito das possibilidades de implementação 
dos protocolos das camadas física, de enlace de dados, de rede e de transporte (que são de maior interesse neste trabalho). 0 capítulo 4 descreve o conjunto de protocolos TCP/IP, que é o padrão de fato mais usado na interconexão das redes acadêmicas no mundo. No capítulo 5 , é feita uma revisào sobre o modelo cliente/servidor que serve de base para a implementação de serviços de rede. Também são analisados detalhes de implementação e implantação de serviços em redes no ambiente SunOS, dando-se ênfase aos serviços "inetd" e "portmapper". No capítulo 6, é feita a descrição da implantação de novos serviços no ambiente SunOS utilizando o projeto do servidor de modem para exemplificar a implementação de serviços em rede. No capítulo 7 são apresentadas as conclusões e sugestões para trabalhos futuros. 


\section{Capítulo 2}

\section{Redes}

\subsection{Introdução}

O hardware e o software dos sistemas computacionais têm sofrido constante evolução. $\mathrm{O}$ hardware atravessou quatro gerações que foram caracterizadas pela tecnologia dos componentes utilizados na sua implementação. Inicialmente eletromecânicos, passaram pelas válvulas, transistores e finalmente surgiram os circuitos integrados. A evolução do hardware tem se caracterizado pelo aumento da velocidade de processamento e pela redução do espaço físico e do consumo de energia. O software operacional evoluiu dos carregadores de código em linguagem de máquina, passando pelos sistemas operacionais mono-usuário, pelos sistemas multi-usuário em tempo compartilhado até os sistemas operacionais distribuídos. Assim, a disponibilidade de hardware mais acessivel e de maior desempenho possibilita a utilização de recursos computacionais em um modelo no qual o trabalho computacional é feito por um número razoável de computadores separados e interconectados. Estes sistemas são chamados de redes de computadores [TAN89] e esta exemplificado na. figura 2.1. O termo rede de computadores é usado para descrever uma entidade cujos três principais componentes, segundo Landweber [LAN86], são :

- uma coleção de computadores hospedeiros, que fornecem serviços computacionais aos usuários;

- uma rede de comunicação, que consiste de processadores de comunicação de propósito especial;

- um conjunto de protocolos para a comunicação.

Tanenbaum [TAN89] apresenta dois tipos básicos de interconexão para redes:

- Canal ponto a ponto: os nós da rede são interligados aos pares por algum meio físico. É utilizado o princípio "armazena e envia" - quando uma mensagem (unidade lógica 
de informaçâo) é enviada de um nó a outro, é recebida e armazenada por cada nó intermediário até que possa ser remetida;

- Canal de difusâo: neste caso, o canal de comunicação é compartilhado por todos os nós, havendo necessidade de algum controle de acesso ao meio que discipline a sua utilização. Mensagens enviadas por um nó podem ser recebidas por todos, sendo necessário um campo na mensagem especificando o nó destino. $O$ nó que recebe uma mensagem não destinada à ele a ignora.

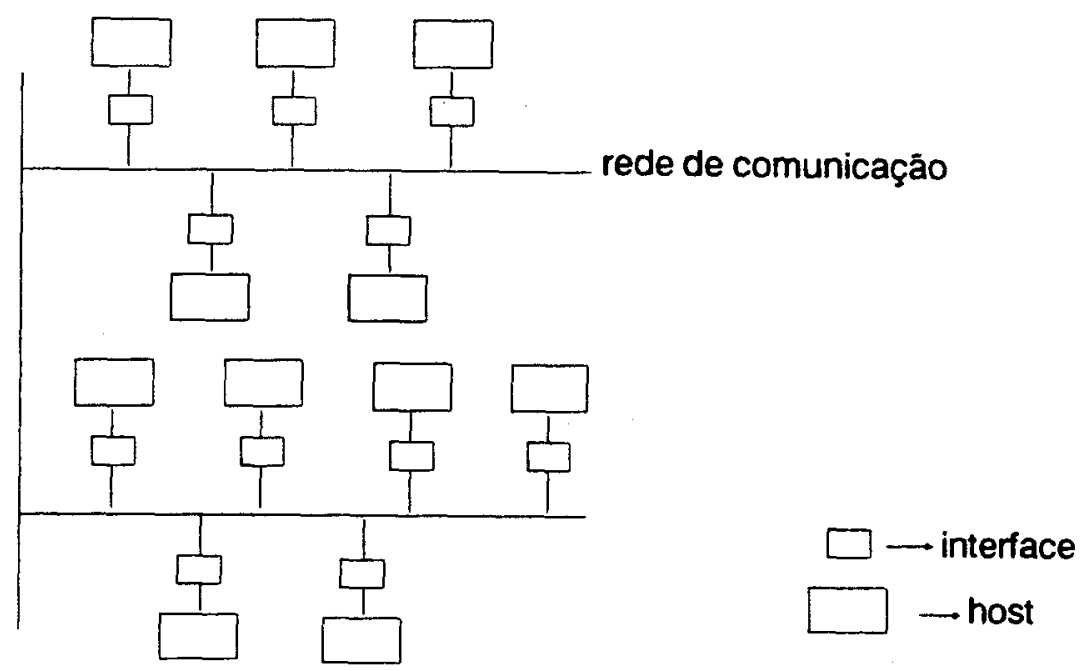

Figura 2.1 Rede de computadores.

Uma das classificações existentes para redes de computadores considera a dimensão da área coberta - a figura 2.2 resume esta classificação.

\begin{tabular}{|l|l|l|}
\hline Dis cancia & Localizagéo & Exemplo \\
\hline $0.1 \mathrm{~m}$ & placa de circuito & data tow \\
\hline $1 \mathrm{~m}$ & sistema & multiprocessador \\
\hline $\begin{array}{l}10 \mathrm{~m} \\
100 \mathrm{~m} \\
1 \mathrm{~km}\end{array}$ & $\begin{array}{l}\text { sala } \\
\text { campus }\end{array}$ & $\begin{array}{l}\text { redes } \\
\text { locais } \\
\text { (LAN) }\end{array}$ \\
\hline $\begin{array}{l}10 \mathrm{~km} \\
100 \mathrm{~km}\end{array}$ & $\begin{array}{l}\text { cidade } \\
\text { pais }\end{array}$ & $\begin{array}{l}\text { redes de longa } \\
\text { distância WWAN) }\end{array}$ \\
\hline $1.000 \mathrm{~km}$ & $\begin{array}{l}\text { continente } \\
\text { planeta }\end{array}$ & $\begin{array}{l}\text { inteconexão } \\
\text { WANs }\end{array}$ \\
\hline
\end{tabular}

Figura 2.2 Classificação de redes por cobertura geográfica [TAN89]. 
Por uma Rede Local ou LAN (Local Area Network) entende-se um suporte de comunicação para interconexão de equipamentos numa área restrita, isto é, uma sala, um prédio ou um campus. As LANs recebem este nome salientando a diferença das WANs (Wide Area Network), que são as redes de longa distância. Entre as LANs e WANs podese considerar as MANs (Metropolitan Area Network) que são as redes metropolitanas [TAN89].

De um modo mais geral, as LANs e WANs podem ser interconectadas e formar uma inter-rede. Uma inter-rede é uma coleção de redes cujo subconjunto de protocolos pode diferir em niveis inferiores, mas usam protocolos similares a nivel de aplicaçào e transferência de dados sobre os componentes da rede. Como exemplo pode ser mencionada a rede Ansp baseada na tecnologia da rede Internet (figura 2.3). Um dos objetivos ao se proporcionar tais ambientes é aumentar a produtividade, a confiabilidade, a conectividade e diminuir os custos [LAN86, QUA86, TAN89].

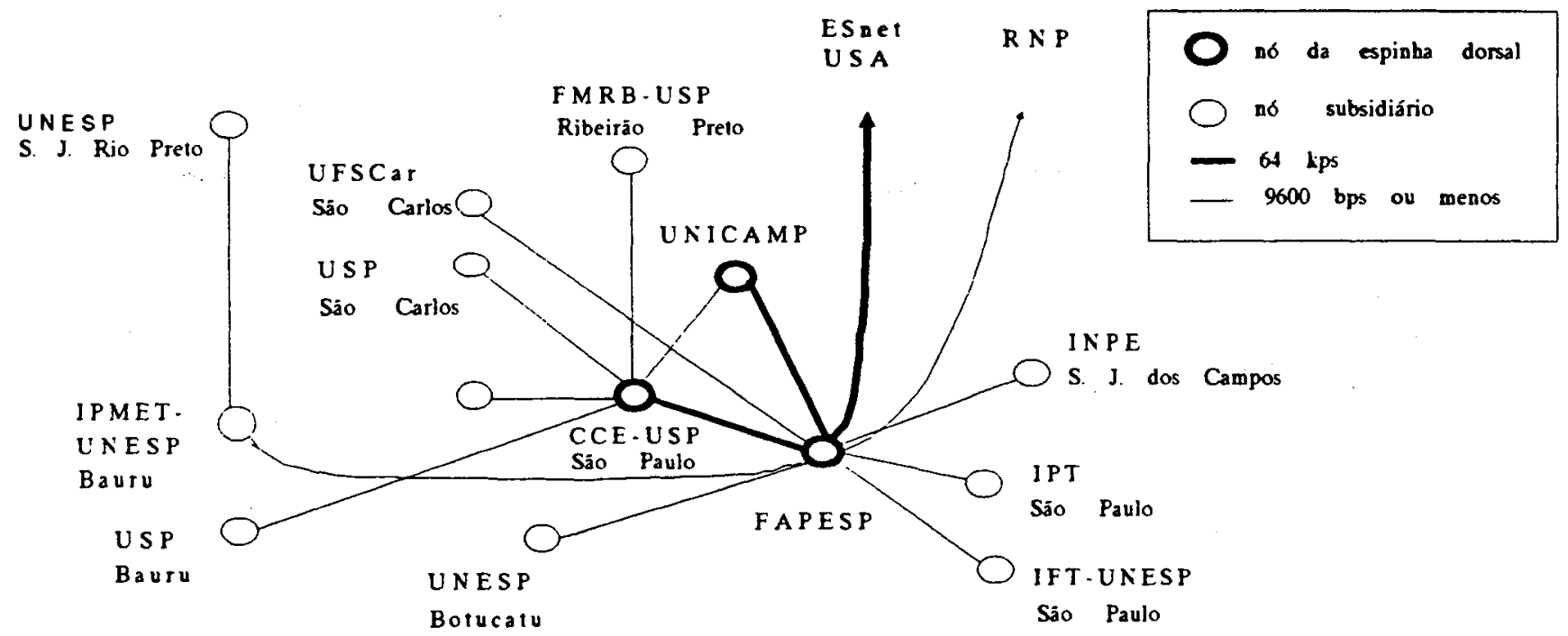

Figura 2.3 A rede ANSP - 1992 [GET92].

\subsection{Redes Locais}

Redes locais (figura 2.4), como un meio de interconexâo de máquinas localizadas geograficamente próximas, podem apresentar altas taxas de transmissâo, baixo custo e serem projetadas especificamente para a finalidade que se desejar: apenas transmissâo de dados, ou transmissão integrada de voz, dados e imagem. A natureza de uma rede é determinada principalmente pelo esquema de interconexão dos seus nós e peló meio físico de transmissão. Existem várias maneiras de se configurar a interconexão dos nós em um ambiente. Cada uma delas apresenta diferentes implicaçôes que podem ser fatores determinantes da relação custo/desempenho global da rede, sendo fundamental manter um certo grau de confiabilidade e simplicidade dos nós [GIO86]. 
ESPINHA DORSAL

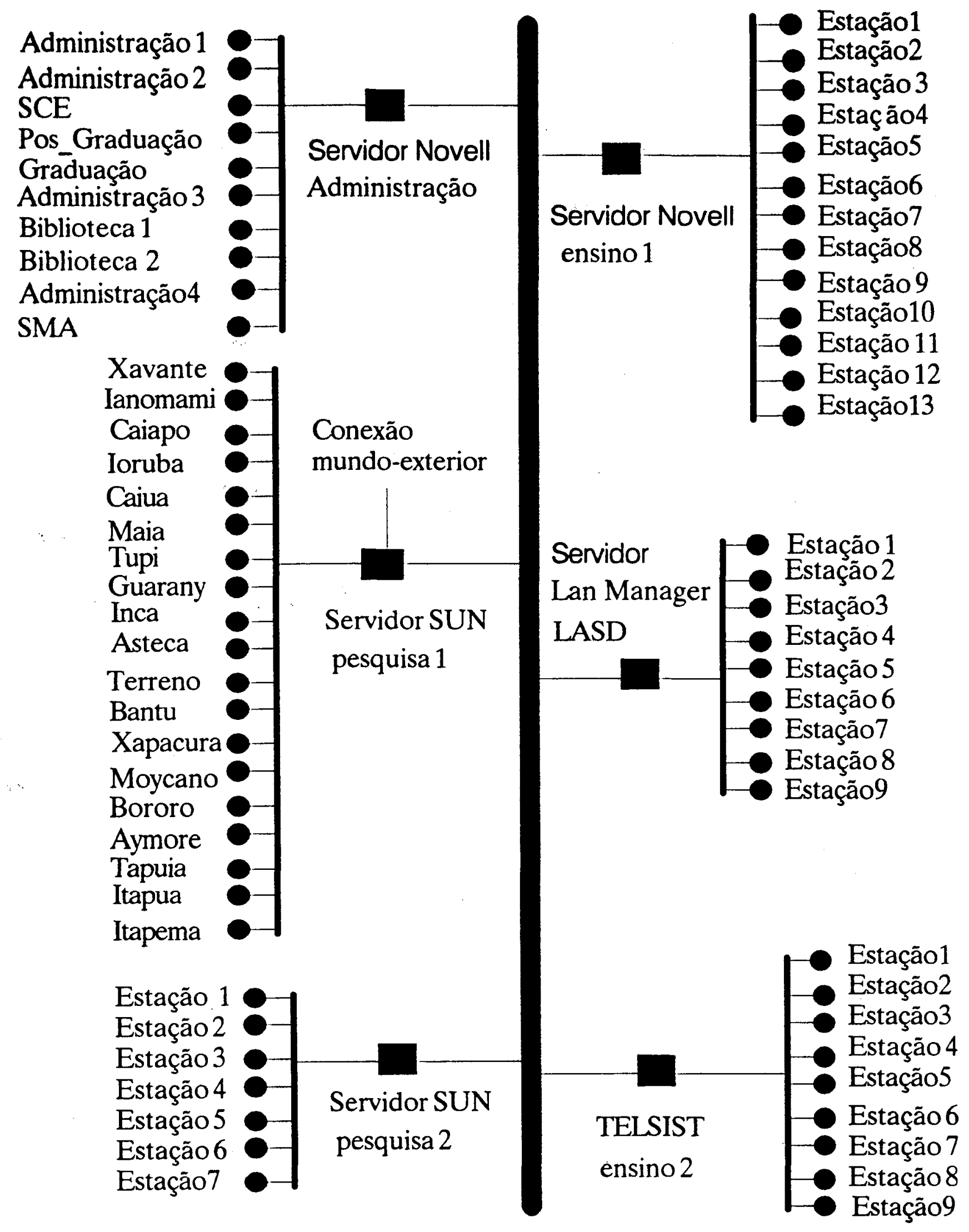

Figura 2.4 Rede local. 
Neste escopo, entende-se por "dispositivos de comunicação" de dados qualquer dispositivo que se comunique com outros via um mejo de transmissão de dados. Como exemplo, podem ser citados terminais inteligentes, computadores, dispositivos convencionais de entrada/saida, modems, telefones e sensores. Em razão da curta distância entre os componentes e do fato de em geral ser propriedade de uma organização ou de um grupo com objetivos afins, soluções mais específicas, e portanto mais simples e eficientes, podem ser encontradas para uma rede local de comunicaçâo [COU88, LAG84, STA84]. O custo de uma rede local é altamente variável, depende das características das aplicações às quais se presta. A topologia, o mejo físico de transmissão e os métodos de controle de acesso ao meio sào os principais elementos que determinam o custo e o desempenho de uma rede local.

\subsubsection{Meios físicos de transmissão de dados}

Este breve resumo apresenta algumas das características dos meios físicos de transmissão mais apropriados para uso em redes locais [LAG86, SAR88, STA84].

O par trançado é o mais comum dos meios físicos de transmissão, usual para baixas velocidades e distâncias de poucos quilômetros. Permite conexão de poucos dispositivos. É próprio para transmissão de sinais digitais e analógicos. Tem uma considerável susceptibilidade a ruídos e interferências, porém, apresenta um custo baixo.

O cabo coaxial apresenta um desempenho melhor, com boa combinação entre altas taxas de transmissão e excelente imunidade a ruído, permitindo um número maior de dispositivos conectados que o par trançado, contudo apresenta um custo maior.

A fibra ótica é um meio promissor em redes locais, apresentando taxas de transmissão da ordem de até 100 vezes mais que os cabos coaxiais e apresenta uma baixa susceptibilidade a ruídos. Entretanto, embora o seu custo seja o mais elevado dos meios mencionados tem caído drasticamente.

\subsubsection{Topologia}

Segundo Stallings [STA84], redes locais sâo freqüentemente caracterizadas em termos de suas topologias. As três topologias básicas sâo estrela, anel e barramento que são analisadas de forma resumida a seguir (figura 2.5 ).

$\mathrm{Na}$ topologia em estrela um elemento central chaveador conecta todos os componentes do sistema e estabelece caminhos dedicados entre pares de estações no momento da comunicação. É um esquema de implementação simples, porém apresenta a grande desvantagem de se basear em um elemento ativo centralizado. Esta topologia é bem adaptada a situações onde o fluxo de comunicação é centralizado, isto é, quando um certo número de nós secundários se comunicam com o nó central. A topologia em estrela é pouco utilizada em redes locais modernas [STA84]. 


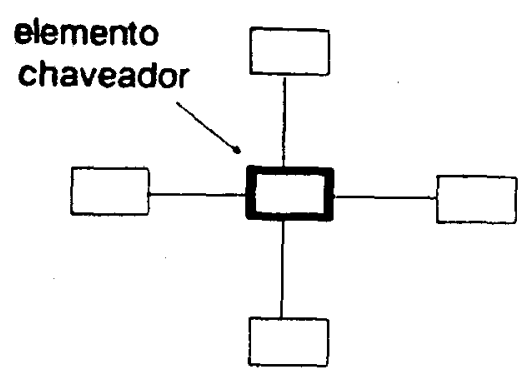

a) Estrela

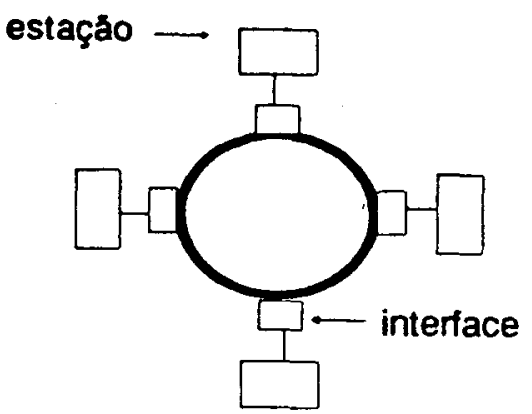

b) Anel

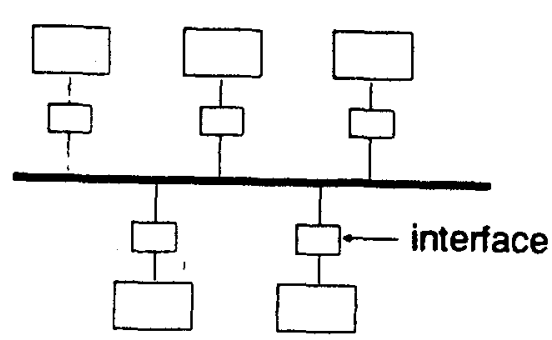

c) Barramento

Figura 2.5 Topologias básicas de redes locais.

Na topologia em anel cada estaçâo é ligada a uma interface de comunicaçào, que se liga com outras em uma conexão ponto a ponto em forma de um laço fechado. $O$ termo conexão ponto a ponto está sendo usado com sentido diferente do termo canal ponto a ponto definido anteriormente. Por conexâo ponto a ponto entende-se que as estaçôes da rede estão conectadas a interfaces interligadas aos pares por mejos físicos de transmissão de dados. As mensagens geradas nesta topologia sào transmitidas unidirecionalmente de interface a interface até atingir a interface da estaçâo destino. A mensagem deve conter os endereços da estaçào fonte e destino. A interface associada à estação destino se encarrega de copiar a mensagem que chega e que lhe é destinada. Os dados circulam no laço passando serialmente pelas interfaces. Uma estação que deseja transmitir coloca os dados em forma de mensagem no anel. Usualmente, a mensagem copiada continua circulando no laço até voltar à interface de origem, que a retira de circulação, fornecendo assim uma forma de confirmaçâo [TAN89]. A única decisâo necessária a cada interface é a capacidade de reconhecer o endereço da estação nos pacotes circulando.

Umas das críticas às redes em anel é que cada interface participa do processo de transmissâo, tornando a confiabilidade da rede dependente da confiabilidade individual das interfaces de comunicaçào. A configuração "star-shaped" [TAN89] é uma proposta que apresenta uma solução para este problema e atualmente é usado em todas as redes em anel modernas. No "star-shaped" é utilizado um fio central onde cada estação é conectada por um par de fios, um para entrada e outro para saída de dados. No fio central existe um elemento chaveador, um relê, que permite isolar parte do anel em caso de falha. A estrutura em anel é relativamente simples e bastante adaptada às redes locais onde o fluxo de comunicação tende a ser descentralizado.

$\mathrm{Na}$ topologia em barramento existe um único meio de transmissão com acesso múltiplo e compartilhado por todos as estações da rede. Os dados são depositados no meio e todas as outras estaçōes têm acesso a eles. Uma estação transmite de cada vez, colocando mensagens que incluem identificação da estação fonte e destino. É uma topologia onde a ocorrência de conflitos de acesso ao meio deve ser tratada. A identificação das mensagens que são destinadas à estação bem como a detecçâo e tratamento de colisões são as principais funçôes da interface de comunicaçâo. Esta topologia elimina a existência 
do elemento central chaveador, sendo facilmente configurável e expansível na maioria dos arranjos físicos. Estas características tornam-na bastante usada em redes locajs [STA84].

\subsubsection{Métodos de controle de acesso ao meio.}

Redes locais são formadas por uma coleção de equipamentos (ou nós) que compartilham o meio de transmissão. Por isso, são necessários métodos de controle de acesso ao meio, que sâo a forma pela qual os nós têm acesso ao uso do canal para transmitir suas mensagens. Os métodos podem ser classificados em dois tipos:

- com controle centralizado, ou seja, existe um nó ou estação com a função específica de decidir quem pode utilizar o meio de transmissão num determinado instante do tempo;

- com controle distribuido entre os nós de comunicação ou estações conectadas à rede, não havendo um nó com função especial de controlar o acesso ao meio de transmissão.

Nas topologias em anel e barramento, um único meio de transmissão é compartilhado pelos nós de comunicaçào. É necessário uma forma de disciplinar a utilização do meio de transmissão num determinado instante para evitar colisões das mensagens [GIO86, STA84, TAN89]. Os métodos de acesso ao meio têm uma forte dependência quanto à topologia empregada. Um resultado das diferentes características topológicas é a existência de métodos de controle de acesso exclusivos a uma determinada topologia. Apesar de alguns métodos de acesso poderem ser implementados em mais de uma topologia, esta não é a regra geral. Mesmo assim, as diferenças topológicas implicam em algumas modificações da técnica em questâo. Os métodos de controle de acesso ao meio incluem CSMA/CD, "token bus", "token ring" e "slotted ring". A seguir serão abordados, de forma sucinta, dois dos métodos de controle ao meio mais usados em redes locais, os métodos CSMA/CD e "token ring".

\section{CSMA/CD}

CSMA/CD ("Carrier Sense Multiple Access with Collision Detection") [TAN89] é um dos método para controle de acesso ao meio físico na topologia em barramento. Uma estação com uma mensagem pronta para enviar primeiro "escuta" o meio físico para ver se o mesmo está livre. Se a estação "detecta" que uma outra estação está enviando uma mensagem naquele momento, ela "escuta" o meio até que ele seja liberado, para então, imediatamente transmitir. Com este tipo de procedimento podem acontecer colisões (duas estações prontas para transmitir podem fazê-lo no mesmo momento). Redes que utilizam CSMA/CD são projetadas para esperar colisões e manipulá-las, retransmitindo as mensagens colididas após um certo intervalo de tempo aleatório. Estas retransmissões sâo manipuladas automaticamente pela interface controladora de redes na estação e são transparentes para o usuário. 


\section{"Token Ring"}

"Token ring" [TAN89] é um dos métodos para controle de acesso em anel. Esta topologia permite a implantaçâo de mecanismos de controle de acesso ao meio com propriedades funcionais como unidirecionalidade da transmissão, nós de comunicação ativos, canal de transmissão fechado. Este método é baseado na existência de um pequeno pacote, um "token", que circula pelo anel. Uma vez iniciado, o "token" circula entre todos os nós de comunicação, alocando o direito de transmissão ao meio compartilhado [STA84]. Uma estação que queira transmitir espera pela passagem do "token", altera o status da "token" para OCUPADO e transmite os dados. Ao completar sua transmissão e quando recebe o "token" com status OCUPADO de volta, a estação insere um "token" com stat us LIVRE. Pode haver a necessidade de um estaçâo monitora capaz de retirar pacotes que circulem indefinidamente e suprir a perda do "token". Esse método tem implicaçōes significativas no desempenho da comunicação, a mensagem pode ter tamanho variável e há a possibilidade de determinar o tempo máximo de espera para o acesso ao meio [GIO86].

\subsection{Considerações finais.}

O aumento na implantação de redes nos últimos anos, motivado principalmente pela necessidade de compartilhar recursos computacionais caros e informaçōes com confiabilidade, preservando a independência das várias estações, tem mudado o cenário da utilização de equipamentos de computação. Sistemas baseados em rede local caracterizados por um ambiente formado de várias unidades interconectadas, relativamente independentes e dispersas ao longo da organização têm sido bastante utilizados e apresentam uma série de vantagens. Entre elas destacam-se a possibilidade de obtençâo de alto desempenho e o compartilhamento efetivo de recursos e informações. As topologias básicas associadas ao desenvolvimento das redes locais de computadores caracterizam-se pelo uso de um único meio físico de transmissão. As topologias em anel e barramento eliminam a necessidade de roteamento intermediário, permitindo a difusão de mensagens entre as estaçôes, entretanto, introduzem a necessidade de disciplinar a utilização do recurso de transmissão comum aos diversos nós interconectados. Apesar das redes locais poderem funcionar de forma independente, a tendência é que ocorra interconexão de redes locais e redes de longa distância, ou de várias redes locais, via redes de longa distância. 


\section{Capítulo 3}

\section{Protocolos de Comunicação}

\subsection{Introdução}

Neste capítulo, são analisados alguns dos protocolos de comunicação. O processo de comunicação entre os diversos sistemas usuários (hardware e software) de uma rede de computadores pressupõe a existência de um conjunto de regras e convençôes que permitam disciplinar a troca de informações. Essas regras comuns constituem os chamados protocolos de comunicação. Protocolos de comunicação regulamentam aspectos que estão relacionados à troca de informações entre usuários, sistemas ou subsistemas da rede, tais como:

- qual a unidade de informação trocada;

- a velocidade de transferência da informação;

- a identificação da origem e do destino da informaçâo;

- controle de anomalias na recepçâo da informação.

Organizaçōes internacionais de padronizaçào, detectando a necessidade de uniformizar (e assim viabilizar) a comunicação entre equipamentos heterogêneos, há alguns anos desenvolvem esforços para especificar uma arquitetura padrão de protocolos de comunicaçâo aceita internacionalmente. Da experiência obtida no projeto de redes, vários principios surgiram possibilitando que novos projetos fossem desenvolvidos de uma forma mais estruturada. Um desses princípios era a idéia de estruturar a rede como um conjunto de camadas hierárquicas, cada uma sendo construída utilizando as funçôes e serviços oferecidos pelas camadas inferiores.

Desta forma, surgiram alguns modelos em camadas. Dois deles se destacam por serem utilizados predominantemente: o conjunto de protocolos TCP/IP e o ISO/OSI. O conjunto de protocolos TCP/IP será analisado no próximo capítulo. O padrâo da ISO (International Standards Organizations) [COU88] é o modelo de referência OSI (Open System 
Interconnect). O modelo ISO/OSI visa servir de base para o desenvolvimento de sistemas abertos, ou seja, sistemas que não fossem exclusivos de nenhum fabricante. Os sistemas abertos devem ser capazes de atender a requisitos de serviços oriundos de outros sistemas, locais e remotos. O ISO/OSI foi elaborado para o uso em redes geograficamente distribuídas e a arquitetura pode ser empregada com qualquer suporte físico de interconexão.

O CCITT - Comité Consultatif International de Télégraphique et Téléphonique - entidade máxima em termos de padronização na área de telecomunicação de dados, aprovou um conjunto de recomendações relacionadas com o funcionamento de redes públicas de comunicação de dados operando na modalidade de comutação de pacotes. Este conjunto de recomendações é encabeçado pela recomendação X.25 [STA84, TAN89], que define o funcionamento dos três níveis inferiores nos equipamentos integrantes de redes públicas de comutação de pacotes. Como um padrão, o X.25 tem recebido o apoio e o endosso dos maiores usuários de telecomunicações e levado vários fabricantes de computadores a implementar este protocolo em seus equipamentos. A utilizaçâo de uma rede pública de comunicação de dados do tipo X.25 já orienta o projeto na direção do modelo de referência ISO/OSI, pois, na verdade, a forma de funcionamento das redes públicas de comutação de dados, que operam na modalidade de comutação de pacotes, constitui o que se denomina níveis inferiores do modelo que serão discutidos posteriormente neste capítulo.

A adoçâo do modelo ISO/OSI pelo C.CITT foi um passo importante na sua consolidação. As administraçôes de serviços de telecomunicações constituem, em todo o mundo, um grande comprador de equipamentos, seja para uso próprio, ou voltada ao oferecimento de serviços telemáticos. Diversos paises já se manifestaram oficjalmente no sentido de adotar o modelo de referência ISO/OSI, podendo-se citar os Estados Unidos, França, Inglaterra, Japão, Brasil e muitos outros. Para a padronização de redes locais será abordada a recomendação IEEE 802 , que corresponde aos niveis físico e de enlace de dados do modelo ISO/OSI.

\subsection{Modelo de Referência ISO/OSI}

A finalidade desse modelo é fornecer uma base comum para a coordenação de novos projetos com o propósito de interconectar sistemas. $O$ objetivo de se estruturar um protocolo em niveis é delimitar e isolar funçôes de comunicaçâo em camadas. O modelo ISO/OSI possui sete camadas de protocolos (figura 3.1), sendo: (1) física, (2) enlace de dados, (3) rede, (4) transporte, (5) sessâo, (6) apresentação e (7) aplicaçâo; nâo sendo especificados exatamente quais protocolos devam ser usados. Apresentam apenas o que cada camada deve fazer a fim de possibilitar a interconexão de equipamentos e redes.

Segundo Tanenbaum [TAN89], a idéia básica da estruturação em camadas é que cada uma das camadas forneça serviços de comunicação à camada imediatamente superior e receba os serviços fornecidos pelas camadas inferiores, que são sucessivamente ampliados e aperfeiçoados, a fim de que na camada de aplicação seja oferecido um conjunto de 
serviços adequados para fornecer diversas aplicações. Uma das críticas feita ao modelo é que as recomendações de protocolos para o modelo ISO/OSI oferecem muitas funções que os usuários não necessitam. Por exemplo, no protocolo X.25, que oferece um serviço de transferência de dados confiável, sucessivos níveis do modelo tratam dos problemas referentes a confiabilidade, sobrecarregando desta forma o sistema. Existem algumas vantagens práticas na utilizaçâo de um modelo em camadas [MOU86]:

- A complexidade do desenvolvimento é reduzida através de abstrações. Nâo importa para uma determinada camada como as demais implementam os serviços fornecidos, só interessa o que a camada oferece como serviço;

- Independência entre as camadas. A camada $N$ preocupa-se apenas em utilizar os serviços da camada $\mathrm{N}-1$ e em fornecer serviços à camada $\mathrm{N}+1$.

\begin{tabular}{|l|}
\hline aplicaçāo \\
\hline apresentação \\
\hline sessão \\
\hline transporte \\
\hline rede \\
\hline enlace de dados \\
\hline física \\
\hline
\end{tabular}

Figura 3.1 Modelo ISO/OSI.

Segundo o modelo de referência [COM91a,TAN89], a camada $\mathrm{N}$ em uma máquina estabelece uma comunicação com a camada $\mathrm{N}$ em outra máquina. As regras e convenções para essa comunicação sâo chamadas de protocolo da camada $N$, e os processos nas diferentes máquinas são chamados processos pares. Entre duas camadas adjacentes existe uma interface, que define as operações primitivas que a inferior fornece à superior. Os dados transferidos numa comunicação entre processos pares não são enviados diretamente, cada camada passa dados e informaçâo de controle para a camada imediatamente inferior até chegar à mais baixa (camada física). Nesta última camada existe uma comunicação física com a camada equivalente em outro sistema. A conversão do lado do sistema receptor processa-se de maneira inversa, dados e informações de controle passam através de cada camada adjacente da máquina receptora até a camada do processo par correspondente.

Os serviços entre as camadas estão disponíveis em endereços únicos, denominados SAP (Service Access Point). A entidade da camada $N+1$ passa através do SAP uma unidade de interface de dados (IDU, Interface Data Unit) para a entidade da camada $\mathrm{N}$. O IDU consiste de um SDU (Service Data Unit) e algumas informações de controle (ICI - Interface Control Information) (figura 3.2 (a)). Para transferir um SDU, a entidade da camada $N$ pode fragmentá-lo em vários pedaços, enviando-o em PDU's (Protocol Data 
Unit) separados juntamente com um cabeçalho. $O$ cabeçalho é usado para ter acesso ao protocolo, identificando qual PDU contem dados ou informaçóes. Os PDU's das camadas de transporte, sessão, apresentação e aplicação são referenciados respectivamente por TPDU, SPDU, PPDU e APDU (figura 3.2 (b)).

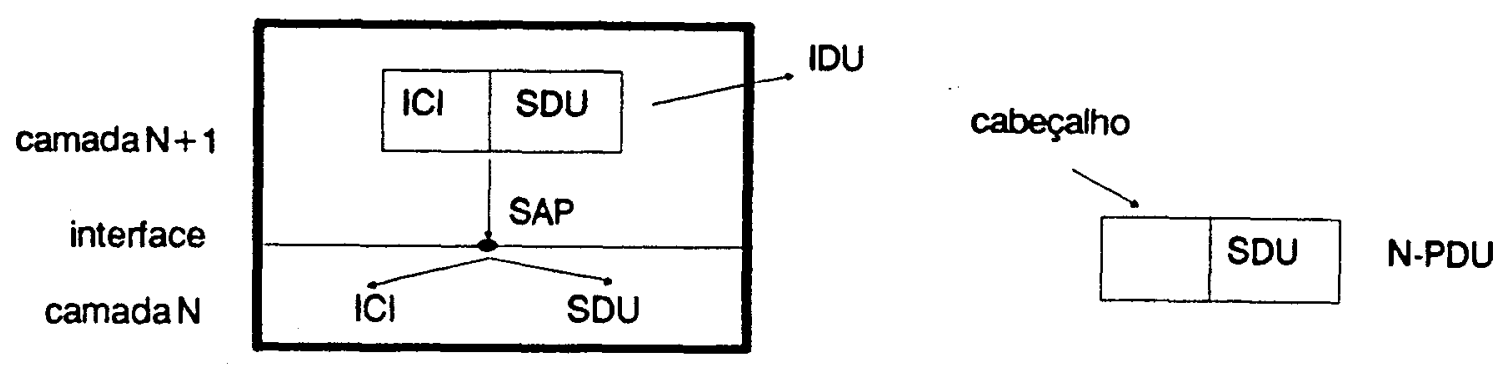

a) Relação entre camadas e interface.

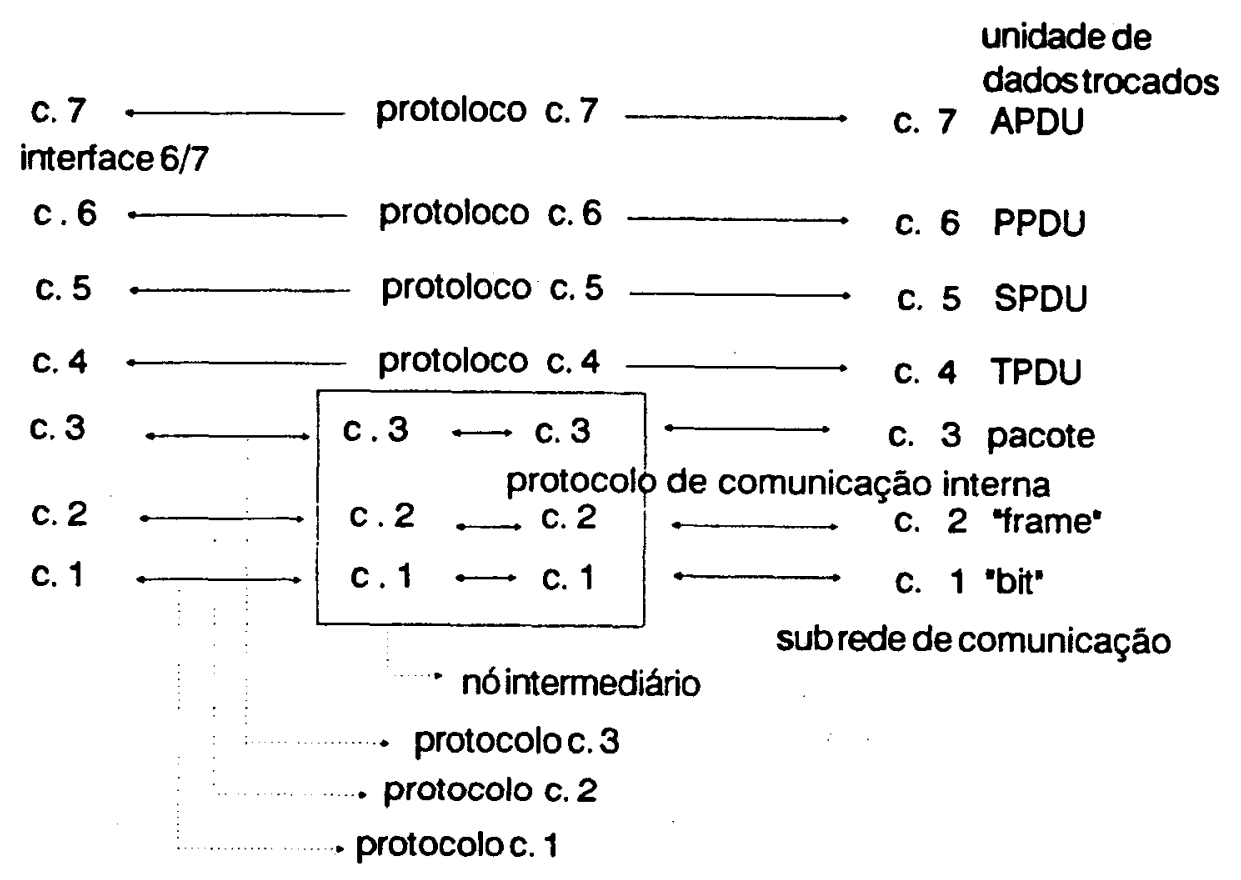

b) A comunicaçāo entre as camadas do modeloISO/OSI.

Figura 3.2 Exemplo de comunicaçâo entre duas máquinas [TAN89].

Camada de aplicação: fornece serviços aos usuários do ambiente ISO/OSI, tais como: correio eletrônico, protocolo de transferência de arquivos, gerenciamento de rede entre outros.

Camada de apresentação: conversões de dados são necessárias para transferir dados entre computadores porque vários tipos de representação de dados podem ser utilizados. Esta camada preocupa-se com a sintaxe e semântica 
dos dados trocados. Realiza transformaçóes nos dados, antes de seu envio, tais como: criptografia, conversão de padrões e compressão do texto.

Camada de sessão: permite aos usuários estabelecer sessões em máquinas diferentes, fornecendo o transporte de dados. Uma sessão permite ao usuário de uma máquina ter acesso remoto a outra máquina ou trocar arquivos entre elas. Fornece um serviço de sincronizaçào, ou seja, quando uma transferência de arquivo é abortada, permite que, ao ser reiniciado, o processo de transferência comece do ponto em que foi interrompido.

Camada de transporte: sua função básica é aceitar dados vindos da camada de sessão, dividi-los em unidades menores (pacotes), se necessário, transferi-los para a camada de rede e assegurar que todos os pacotes cheguem corretamente à máquina destino. Dois modos de comunicação podem ser fornecidos: circuito virtual, onde um canal lógico entre estaçōes origens e destino é estabelecido ou datagrama, onde os pacotes são roteados por cada nó intermediário.

Camada de rede: fornece endereços a nivel de rede para que as entidades da camada de transporte possam se identificar mutuamente. A unidade de informação é o pacote de dados, resultado da segmentação da mensagem. Determina como pacotes são roteados, isto é, mapeia o caminho do pacote ao seu destino através de nós intermediários. Fornece um controle de congestionamento, determinando o melhor caminho para a transmissão de um pacote.

Camada enlace de dados: detecta e corrige os erros que possam ocorrer na troca de informaçôes a nivel da camada física. A unidade de transferência de informação é uma seqüência de "bits" formando um "frame", delimitados por caracteres ou uma seqüencia especial de "bits", que são transmitidos seqüencialmente. Pode ser processado um "frame" de confirmação que é enviado de volta pelo receptor. Fornece um controle de fluxo de dados, de modo a controlar a taxa de transferência de unidades de informação na interface com a camada de rede.

Camada física: define as características mecânicas (tais como, tipo de cabo e conector), elétricas (como representar 0's e 1's), funcionais (duração de um "bit", como a conexão será estabelecida e desfeita) e procedimentos para ativar, manter e desativar conexões físicas para a transmissâo de "bits" entre os processos pares da camada de enlace de dados.

Os protocolos que implementam serviços relacionados com as camadas de transporte, de rede, de enlace de dados e física serão analisados por serem relevantes para este trabalho. São citadas as características que os protocolos implementam, mas nem todos os serviços relacionados a estas camadas são necessariamente ISO/OSI. 


\subsection{Protocolos da camada de transporte}

O serviço de transporte oferece transferência transparente de dados entre usuários do serviço de transporte. Ele libera o usuário de qualquer preocupação sobre como os meios de suporte às comunicações são utilizados para conseguir esta transferência. Esta camada atua na divisão inicial da mensagem em pacotes, seu seqüenciamento e controle do fluxo de comunicação. Esta divisão ocorre num nível mais alto que aquela realizada no nível de enlace, que simplesmente quebra a mensagem a ser transmitida em pacotes nos tamanhos definidos pelo protocolo do nível de enlace. Neste caso, dá-se particular atenção aos sistemas multitarefa, onde a forma pela qual os pacotes estâo numerados é que torna possível que sejam enviados na ordem certa e para a aplicação certa. De fato, um sistema de comunicação prevê nào somente múltiplos nós usando simultaneamente a rede, como múltiplas tarefas sendo executadas em cada nó. Os seus serviços são:

- estabelecimento e encerramento de conexões de transporte;

- fornecimento de classes selecionáveis de serviços;

- transferência de dados com a qualidade solicitada.

Algumas funçôes necessárias para produzir os serviços desta camada são citadas abaixo:

- mapeamento do endereço a nivel de transporte para endereços a nível de rede;

- multiplexação e demultiplexação de conexões;

- segmentação de mensagens em unidades menores, reagrupamento e conseqüente controle de seqüência;

- controle do fluxo de informação.

\subsection{Protocolos da camada de rede}

O nivel de rede é composto pelos protocolos de interconexâo de redes, que são necessários para que várias redes possam falar entre si, referindo-se a endereços e códigos de cada uma. Os endereços tratados não são os dos nós mas os das redes e através deste nível se determina qual o melhor caminho para interligar as redes entre si. A unidade de informação tratada neste nível é denominada pacote. Para prover os serviços citados, a camada de rede deve executar normalmente as seguintes funções:

- seqüenciamento de pacotes; 
- controle de erros;

- controle de fluxo para evitar congestionamento;

- roteamento.

O serviço à nivel de rede inclui dois tipos básicos de serviços:

- serviço orientado a conexâo (circuito virtual): É um serviço onde cada caminho lógico é estabelecido entre a origem e o destino. Durante o tempo de duração do circuito, existirá uma conexão entre a origem e o destino. Os pacotes são entregues em seqüência e com confirmação de entrega. Não precisam levar o endereço integral do destinatário, podem apenas levar uma indicação do caminho ou da conexão à qual estão associados. Neste caso, é preciso estabelecer inicialmente esse caminho, por onde circularão os pacotes e, ao término da transmissão, o circuito deve ser desfeito;

- serviço não orientado a conexâo (datagrama): É um serviço mais simples, onde uma mensagem é tratada de forma individual e entregue ao destinatário pelo caminho mais conveniente para os algoritmos de encaminhamento da rede. Para isso, cada datagrama contém todas as informações de endereçamento necessárias ao seu encaminhamento até o destino. A rede não se preocupa com a ordem na qual os datagramas são entregues e, em geral, não envia à fonte uma confirmação de entrega, não havendo conexão entre fonte e destino.

O protocolo X.25 do CCITT segue o modelo ISO/OSI. É orientado a conexão e usualmente é utilizado para acesso a redes públicas. $O$ protocolo de nível de rede gerencia conexão entre um par de ETDs. Duas formas de conexão são possíveis, circuito virtual e circuito virtual permanente. No circuito virtual são necessários procedimentos de estabelecimento e término de chamadas para liberar e fornecer uma conexão lógica entre dois ETDs. Com um circuito virtual permanente, a rede pública de dados provê conexóes lógicas fim a fim entre dois ETDs numa linha dedicada. A transferência de dados nos dois é basicamente a mesma, porém, no segundo caso, não é necessário estabelecer e desfazer a conexão.

O serviço de circuito virtual será descrito de forma sucinta a seguir. Quando um ETD deseja se comunicar com outro ETD, deve inicialmente estabelecer um circuito virtual entre eles. Para isto constrói um pacote CALL REQUEST e passa-o ao seu ECD. Então a rede entrega o pacote ao ECD destino que o entrega ao ETD associado. Se o ETD destino quiser aceitar a chamada ele envia um pacote CALL ACCEPTED de volta. Quando o ETD origem recebe este pacote de aceitaçâo, o circuito virtual é estabelecido. Daí em diante os ETDs podem usar o circuito virtual para trocar pacotes de dados.

Quando qualquer um dos lados quiser terminar a conexão, basta enviar para o outro lado um pacote CLEAR REQUEST, que deve ser confirmado, enviando de volta um pacote CLEAR CONFIRMATION. Para indicar ao ETD local a chegada de uma chamada 
virtual, o ECD envia um pacote INCOMING CALL e quando o ECD recebe do remoto - CALL ACCEPTED, ele envia para o ETD local um pacote CALL CONNECTED.

Embora o objetivo do serviço de circuito virtual seja o de apresentar um caminho livre de erros entre hospedeiros comunicantes, a própria recomendação prevê a ocorrência de falhas que devem ser tratadas pelos pacotes RESTART e RESET. Assim, deve ser preocupação da camada superior a manutenção da transferência correta de mensagens. Os requisitos da aplicação também influenciam na adoção de procedimentos de controle de erro.

O PAD (Packet Assembler-Disassembler) é uma proposta de padronização para uma interface cuja função é empacotar e desempacotar os dados, que capacite terminais modo caráter, assíncronos, comunicarem-se com o ETD remoto no modo pacote que implementa X.25. O PAD recebe os caracteres originais de um ETD assincrono, armazena-os compondo um pacote formatado de acordo com o protocolo X.25 e os envia pela rede até outro ETD. Ao receber um pacote destinado a um ETD assíncrono, o PAD retira os dados de cabeçalho, enviando os caracteres assincronamente ao ETD, um a um. As especificações para acesso à rede através do PAD estão contidas nas recomendações X.3 que definem os parâmetros do PAD em uma rede pública de dados, na X.28 que define a interface entre um PAD/ETD modo caráter e na X.29 que define a interface PAD/ETD modo pacote.

\subsection{Protocolos da camada de enlace de dados}

Como a camada física não oferece um mecanismo de transporte de dados confiável do ponto de vista de erros de transmissão, uma série de mecanismos deve ser implementada pela camada de enlace de dados para detectar e corrigir possiveis erros, fornecendo uma linha de comunicação que se apresente livre de erros, a despeito da linha física existente introduzir ou não erros na transmissâo [GIO86, TAR86].

Dois tipos básicos de ligação física influem nas características do protocolo de enlace: a ligação ponto a ponto onde dois nós de comunicação estão conectados ao mesmo meio físico e a ligação multiponto onde vários nós estão conectados. A unidade de informação manipulada pela camada de enlace de dados é denominada "frame". Dentre as funçôes da camada de enlace de dados podem ser citadas:

- estabelecer uma conexâo e procedimentos que permitam o uso eficiente dos meios de transmissào, com:

- serviço sem conexão e sem confirmação onde a máquina fonte envia "frames" à máquina destino sem esperar a confirmação de recebimento;

- serviço sem conexão e com confirmação onde cada "frame" é confirmado individualmente e se depois de um certo tempo a estrutura do "frame" não é confirmada ele deve ser enviado de novo; 
- serviço com conexâo e confirmação, onde uma conexão é estabelecida antes que qualquer dado seja transmitido, cada "frame" é numerado, entregue uma única vez e são recebidos na ordem certa;

- definir serviços de interface para a camada de rede determinando como os "bits" da camada física são agrupados em "frames";

- implementar mecanismos de deteç̧ão e recuperaçâo de erros.

Desta forma, a camada superior dispôe de um canal virtual capaz de transmitir suas unidades de informações de forma confiável e correta. Dois tjpos de redes públicas de longa distância são geralmente utilizados para transmissão de dados:

- a rede de comutação de circuitos, onde os usuários enviam os dados através do sistema telefônico;

- a rede de comutação de pacotes, projetada para levar mensagens através de linhas de maior velocidade, por onde são transmitidas as mensagens de diversos usuários.

Uma rede de comutação de pacotes é constituida de computadores, chamados nós de comutação, por linhas de alta velocidade entre esses nós e computadores hospedeiros que utilizam a rede. Mensagens curtas (pacotes), com indicação de destinos, são entregues pelos hospedeiros ao nó de comutação ao qual está conectado. O nó de comutação por sua vez encaminha o pacote para o nó destino pela melhor rota, segundo algum critério de encaminhamento de mensagens, que finalmente entrega o pacote a hospedeiro destino. As principais características da comutação por circuito são:

- A necessidade de estabelecer um caminho entre o usuário remetente e o destinatário antes de se enviar qualquer dado;

- Uma vez estabelecida a conexão, existe um caminho dedicado entre remetente e destinatário para troca de informações;

- Quando a troca de informações se encerra, a conexão é desfeita.

\subsubsection{Detecção dos erros de transmissão}

A inclusão de "bits" adicionais de redundância na mensagem a ser transmitida é o modo usual para detectar se "bits" de informação foram alterados durante a transmissão. Desta forma é possivel a verificaçâo da ocorrência de erro na recepção da mensagem. Um bloco de $\mathrm{k}$ "bits" de informação é codificado em um bloco de n "bits" pelo acréscimo de (n-k) "bits" de redundância e então transmitido. Na recepçâo, o bloco de n "bits" é decodificado e os "bits" de informação entregues ao destinatário. Segundo Giozza, em [GIO86], diversas técnicas têm sido utilizadas para essa finalidade, como por exemplo: 
- Bit de paridade por caráter : consiste em acrescentar um "bit" às palavras do código de representação dos caracteres. $\mathrm{O}$ "bit" de paridade é acrescentado com os valores 0 ou 1, de modo a fazer o número total de "bit" 1 na palavra código, par (paridade par) ou impar (paridade ímpar). O caráter é transmitido e na recepçâo o "bit" de paridade é verificado. Se a paridade não conferir com o valor esperado, então é detectado um erro de transmissão.

- Redundância longitudinal (Longitudinal Redundancy Check): o método consiste em acrescentar à mensagem um caráter (BCC - Block Character Check) que represente uma operaçâo lógica sobre os "bits" dos diversos caracteres que compôem a mensagem. Os "bits" são transmitidos serialmente por coluna. Nesse método são detectados os erros que consistem na inversão de apenas 1 "bit" e também erros do tipo rajada (vários "bits" alterados). Esse método é muito mais poderoso em termos de detecção de erros que apenas o uso do método de paridade por caráter.

- Redundância cíclica (Cyclic Redundancy Check): é mais eficiente na deteç̧ão de erros e é bastante utilizado. Consiste em acrescentar a um bloco de k "bits" de informação (n-k) "bits" de verificação (CRC). Para transmissão, a representação binária da informação é dividida em módulo 2 , por um número predeterminado. $\mathrm{O}$ resto da divisão é acrescentado à mensagem como "bits" de verificação. Na recepção, a mensagem recebida é dividida pelo mesmo número e o resto comparado com o que foi recebido; se nâo coincidir, então detecta-se o erro na transmissão.

\subsubsection{Correção de erros}

Em geral, o método usado para corrigir erros é baseado no pedido de retransmissão do bloco recebido com erros. Existem códigos que permitem a detecção e identificação da posição de erros e, portanto, sua correção no destino sem necessidade de retransmissão. Esses códigos exigem muitos "bits" de redundância, o que limita şua aplicação em transmissão de dados onde a retransmissão é impossível ou muito ineficiente. Em redes locais de computadores, de um modo geral, o método adotado na correção de erros de transmissão é baseado na retransmissào das mensagens [GIO86].

Os objetivos de um mecanismo de retransmissão de mensagens visam garantir a confiabilidade, garantir o uso eficiente dos recursos de transmissão minimizando o atraso nas retransmissôes e ao mesmo tempo evitando retransmissões redundantes de mensagens duplicadas e garantir operação simples que permita a definição do procedimento sem ambigüidade e reduzir a complexidade de implementação.

\subsubsection{Controle de fluxo}

Duas estações conectadas através de um enlace de dados em geral têm diferentes ve locidades de processamento, diversos tamanhos de memória para armazenamento de mensagens, prioridade para tratamento de mensagens recebidas, ou podem estar tratando 
mensagens recebidas de diversos enlaces concorrentemente, sendo necessário implementar mecanismos para controlar o fluxo de informaçōes entre a origem e o destino, evitando transmissões e retransmissōes que não poderâo ser aceitas pelo destino, por exemplo, pela falta momentânea de espaço em suas memórias [GIO86].

Nos protocolos do tipo para e espera, o problema é muito simplificado pelo fato de apenas uma mensagem ser transmitida por vez. A majoria dos protocolos desse tipo não possui procedimentos específicos para controle de fluxo, dependendo para isso, do mecanismo de retransmissão de mensagens, uma vez que as mensagens descartadas pelo destino serão retransmitidas pela origem. Já os protocolos contínuos utilizam mensagens de supervisão e controle do tipo Destino não pode receber e Destino pronto para receber para regular o fluxo de informação e evitar retransmissões desnecessárias, melhorando a eficiência no uso do meio de transmissão.

\subsubsection{Características gerais do funcionamento do enlace de da- dos}

Em geral o funcionamento do enlace de dados é estruturado em quatro fases :

- Fase de estabelecimento do enlace: Esta fase inclui os procedimentos e a troca de mensagens de controle para estabelecer o enlace, usando uma ligação de nível físico já estabelecida;

- Fase de transferência de dados: É constituída dos procedimentos que são o objetivo do protocolo de enlace, a troca de mensagens de dados entre os equipamentos conectados;

- Fase de encerramento do enlace: Consiste nas funções associadas com a desconexão da ligaçâo de enlace, e dependendo do tipo de ligação, sua desconexão é iniciada nessa fase;

- Fase de reinício: Caso ocorram erros durante a transmissão que não possam ser recuperados pelos mecanismos de detecçâo e recuperação de erros, como por exemplo a perda do seqüenciamento das mensagens, é necessário voltar ao estado onde o seqüenciamento possa ser restabelecido. Esta fase inclui os procedimentos para executar essas funçôes.

\subsubsection{Protocolos orientados a caráter e orientados a "bit"}

Protocolos de enlace baseados no caráter são os mais antigos usados em redes de longa distância; tratam a informação e delimitam os blocos usando caracteres de um código fonte estabelecido. Um destes códigos é o ASCII que prevê 10 caracteres especificamente para 
controle de comunicação. Um exemplo é o BSC (Binary Synchronous Communication), desenvolvido pela IBM na década de 60 e ainda utilizado [GIO86].

Os protocolos mais recentes não utilizam caracteres de código para delimitação dos blocos e supervisão da troca de mensagens. Em vez disso, tanto as mensagens de texto como as de supervisão são envelopadas em um "frame" delimitado por um "flag". A distinção entre mensagens de texto e supervisão nesses protocolos é feita pela configuração de "bits" do campo de controle no cabeçalho do "frame". Um exemplo é o HDLC (High Level Link Control Procedures) que é um resultado do esforço de padronização desenvolvido pela ISO para o nivel de enlace.

\subsubsection{O padrão IEEE 802}

O modelo IEEE 802 resultou de um projeto do Instituto de Engenheiros Elétricos e Eletrônicos dos EUA, no sentido de estabelecer uma arquitetura compatível ao modelo ISO/OSI, mas orientada ao desenvolvimento de redes locais. Essa adaptação do modelo ISO/OSI subdivide a camada de enlace de dados em duas subcamadas, como mostrado na figura 3.3. A subcamada LLC (Logical Link Control) fornece às superiores dois tipos de serviços de entrega das unidades de dados:

- tipo 1 - sem conexão, sem confirmação e sem qualquer controle de fluxo ou recuperação de erro.

- tipo 2 - com conexão pré-estabelecida, confirmaçâo, controle de fluxo, recuperação de erros e seqüenciação.

A subcamada MAC (Medium Access Control) fornece serviços que permitem disciplinar o compartilhamento de um meio de transmissâo, comum aos sistemas usuários da rede. Os métodos de controle de acesso ao meio são especificados nesta subcamada. A subcamada MAC permite a especificaçâo da subcamada LLC com um certo grau de independência da topologia, do meio de transmissão e do método de controle de acesso ao meio utilizado na rede local. A camada física ( $\mathrm{PHY}$ ) especifica os protocolos que se encarregam de prover os serviços básicos de transmissão e recepção de "bits" através de conexôes físicas entre duas estaçôes. A subcamada LLC especifica os serviços que permitem uma comunicação confiável de seqüência de "bits" ("frames") entre as estações. Nesta camada, são implementados os serviços de recuperação de erros de transmissão e de controle de fluxo. As camadas superiores têm funções e serviços que se aplicam às redes de computadores de uma maneira geral.

A necessidade de atender satisfatoriamente ao maior número possivel de aplicaçôes orientou o estabelecimento de mais de um padrão de protocolos para redes locais segundo o padrão IEEE 802, particularmente, no que se refere à camada física e à subcamada MAC: 
Padrão IEEE 802.1: especifica funçôes e protocolos de gerenciamento de redes e interfaces com as camadas superiores, ou seja, é um documento descrevendo em detalhes a relação entre os padrões IEEE 802 e a arquitetura ISO/OSI.

Padrão IEEE 802.2: especifica um protocolo de controle de enlace lógico para uso com qualquer um dos outros padrões referentes ao tipo de controle de acesso e do meio de transmissão associado.

Padrão IEEE 802.3: especifica um padrão para redes em barramento, utilizando CSMA/CD como método de acesso ao meio.

Padrão IEEE 802.4: especifica um padrão para redes em barramento, utilizando passagem de "token" como método de acesso ao meio.

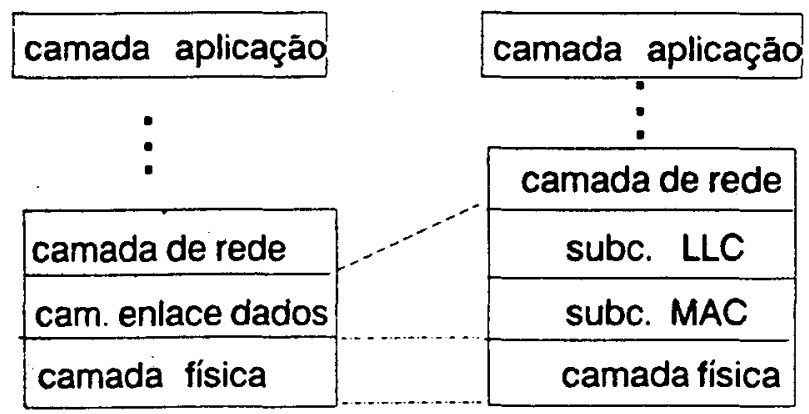

(a)

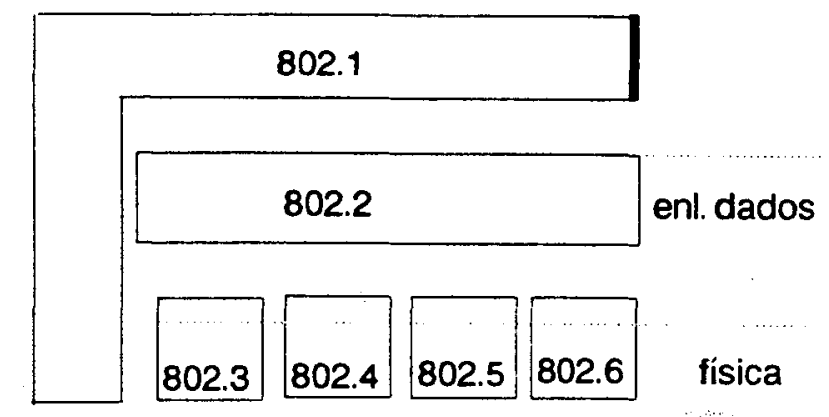

(b)

Figura 3.3 a. Modelo ISO/OSI e IEEE 802. b. Padrào IEEE 802.

Padrão IEEE 802.5: especifica um padrão para redes em anel, utilizando passagem de "token" como método de acesso ao meio.

Padrão IEEE 802.6: especifica um padrão para redes metropolitanas.

Todos estes padrões IEEE 802 apresentados acima atualmente procuram incorporar alternativas para o uso de fibras ópticas. O padrão FDDI (Fiber Distributed Data Interface), desenvolvido pela organizaçâo de padronização ANSI nos EUA, é o primeiro padrão desenvolvido especialmente para redes locais com fibras ópticas e segue a arquitetura IEEE 802.

\subsubsection{Exemplos de implementações de redes de comunicação}

(a) Ethernet

Segundo Comer em meados dos anos 70 a Xerox desenvolveu um sistema chamado Ethernet [MET76]. Em 1980, um esforço conjunto das organizações Intel, Xerox e DEC resultou na especificação conhecida como Blue Book Ethernet, ou padrão DEC/INTEL/XEROX [COM91a]. Essa especificação foi modificada resultando no padrào IEEE 802.3. As redes Ethernet operam em taxa de 
transmissão de $10 \mathrm{Mbps}$, tem topologia em barramento e o método de acesso ao meio usado é o CSMA/CD. Na figura 3.4 os dojs tipos de conexão (torneira ou T) são mostrados.

Transceptor

(torneira)

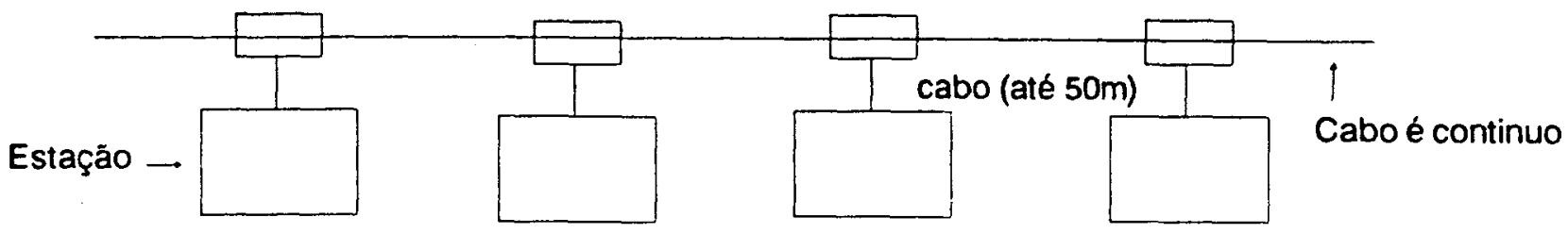

Figura 3.4a Conexão torneira.
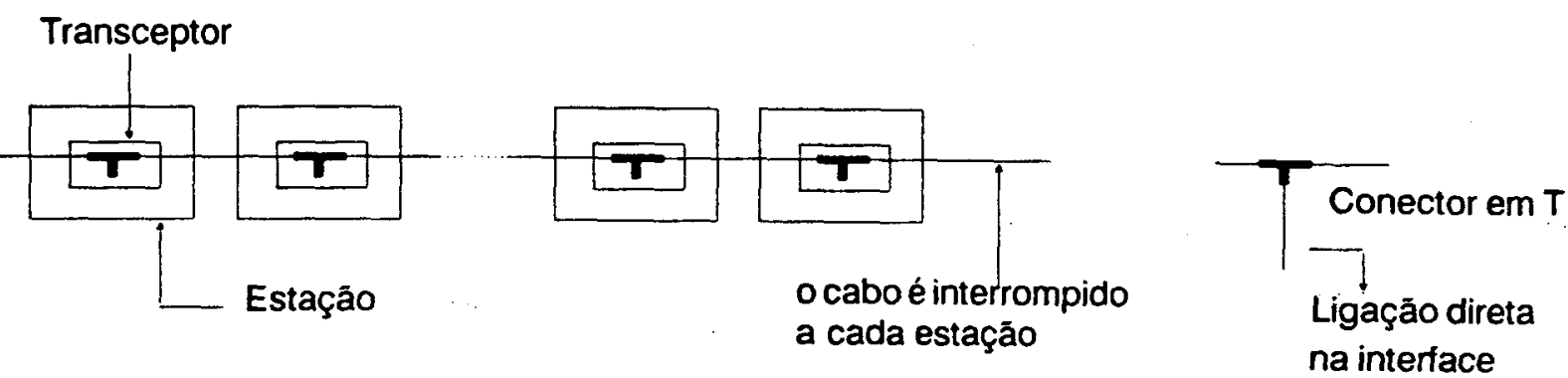

Figura 3.4b Conexão T.

$\mathrm{Na}$ configuração usual pode-se observar um "transceptor" preso ao "ether" e um cabo "transceptor" cuja função é conectá-lo à placa de interface que possui um "chip" responsável por diversas funções de gerenciamento da rede. O comprimento máximo permitido ao cabo Ethernet é $500 \mathrm{~m}$, caso seja necessário atingir distâncias maiores é preciso utilizar repetidores ("repeaters"), que propiciam a regeneração do sinal. Em situaçôes com alta carga de trabalho apresenta baixa eficiência. Os endereços Ethernet têm 6 bytes (todos os "bits" marcados em 1 enviam a mensagem a todas as estações). O formato padrão do pacote (com o comprimento em bytes) e a descriçâo dos campos serão mostrados a seguir [COM91a], figura 3.5:

Preâmbulo
\begin{tabular}{|c|c|c|c|c|c|c|}
\hline 8 & 6 & 6 & 6 & 2 & $46-1500$ & 4 \\
\hline
\end{tabular}

Figura 3.5 Formato padrâo do pacote Ethernet.

- Preâmbulo - 0 e 1 alternados, que ajudam a sincronização do destinatário;

- Tipo - tipo do protocolo utilizado ou comprimento dos dados;

- Verificação - ajuda a interface detectar transmissão com erro.

(b) "Token Ring"

O protocolo "token ring" foi desenvolvido pela IBM e posteriormente foi escolhida como um dos padróes internacionais para redes locais, o IEEE 802.5 
[TAN89,STA84]. Utilizam a topologia em anel e o método de controle de acesso em anel baseado em passagem de "token". Pode operar com várias taxas de transmissão, $4 \mathrm{Mbps}$ e muitos outros. Usa o sistema de sinalização "Manchester enconding", com voltagem alta e baixa, com magnitude absoluta de 3.0 a 4.5 volts. Um "bit" chegando na interface é copiado para um "buffer" de 1 "bit", onde pode ser inspecionado e até modificado. Esta copia introduz um atraso de 1 "bit" em cada interface. A interface do anel tem dois modos de operação: escuta - os "bits" são apenas copiados para a saida - e transmite - a interface quebra a conexão, permitindo a entrada dos dados no anel. Os "bits" circulam e são removidos pela estação transmissora. Apresenta alta eficiência quando ocorrem altas cargas de trabalho. Abaixo é mostrado o formato padrão dos pacotes ("token" e dados), figura 3.6, com o comprimento em bytes e a descrição dos campos [TAN89]:

- começo e fim - delimita o pacote;

- controle de acesso - indica "token" vazjo ou cheio, prioridade e permite a reserva do próximo "token" com uma dada prioridade;

- controle do pacote - distingue entre pacotes de dados e controle;

- status do pacote - contem os "bits" A e C, os quais permitem a estação transmissora obter informações sobre a recepção do pacote:

$\mathrm{A}=0$ e $\mathrm{C}=0$ : destino nâo presente ou desligado.

$\mathrm{A}=1$ e $\mathrm{C}=0$ : destino presente mas pacote não aceito.

$A=1$ e $C=1$ : destino presente e pacote copiado.

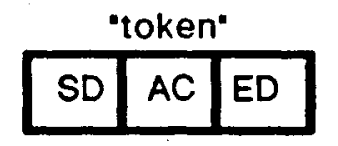

End. destino End. origem Dados Verificação

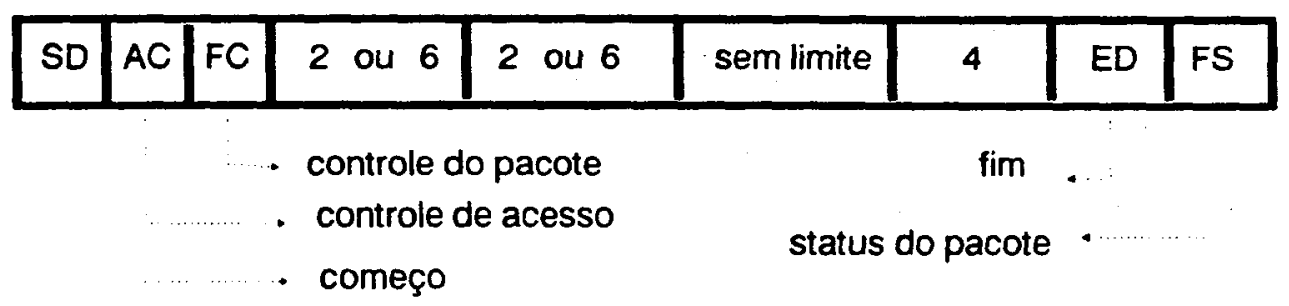

Figura 3.6 O formato padrão dos pacotes.

\section{(c) FDDI}

O comitê ASC X3T9.5 foi o responsável pela padronização do protocolo FDDI desenvolvido pela ANSI nos E.U.A. [ROS90]. Atualmente alguns documentos ANSI FDDI já foram transformados em documentos ISO/OSI. As redes FDDI operam em taxa de transmissão de $100 \mathrm{Mbps}$ com fibra óptica e esta baseado em "token ring". Dois tipos de conexão estão previstas no padrão, na classe A a estação liga-se diretamente ao anel e na classe B, a estação liga-se ao anel 
através de um concentrador. A arquitetura FDDI especifica até a primeira subcamada do nivel de enlace (subcamada MAC), aceitando como subcamada superior o protocolo LLC padrão IEEE 802.2. Cada nó FDDI é composto das subcamadas PHY (PHYsical layer protocol), PMD (Physical layer Medium Dependent), MAC (Media Access Control) e SMT (Station ManagemenT).

São especificados basicamente dois tipos de tráfego. $\mathrm{O}$ tráfego sincrono oferece banda garantida e tempo de acesso máximo para transmissão, podendo ser usado em aplicações em tempo real. $O$ tráfego assincrono pode ser utilizado para serviços que precisem ter acesso ao canal de comunicação com características de banda e acesso menos restritivas. Visando incorporar caracteristicas de redes metropolitanas (MAN), foi realizada uma otimização no padrão FDDI para implementação do serviço de comutação de circuitos. A figura 3.7 mostra uma rede FDDI.

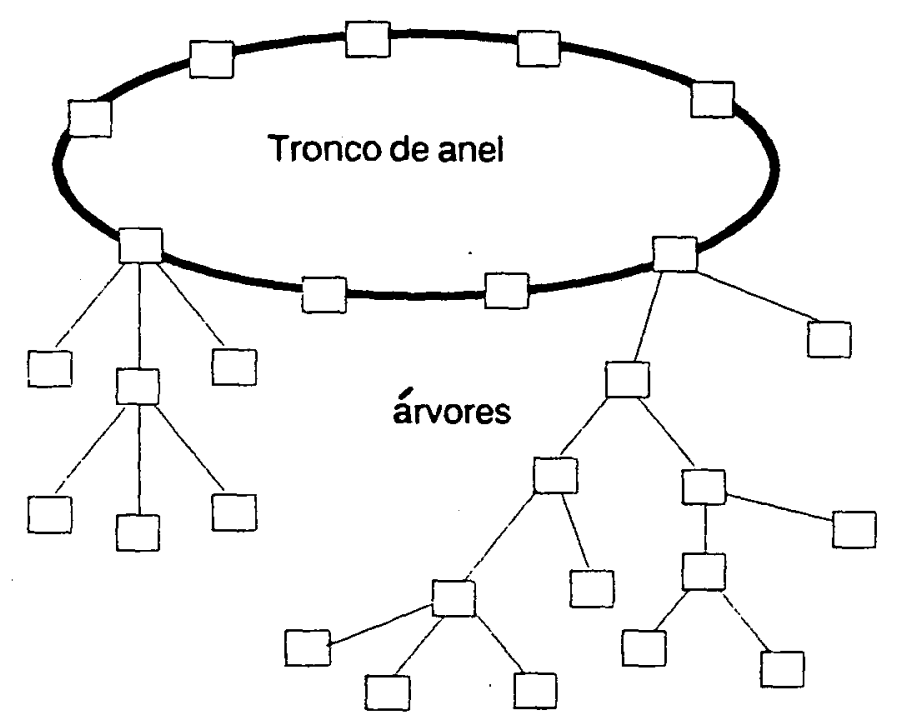

Figura 3.7 Uma rede FDDI.

\subsection{Protocolos da camada física}

Como dito anteriormente, a camada física do modelo ISO/OSI é a responsável pela transferência de "bits" através do meio físico de transmissão [COU88, TAN89]. Um protocolo do nível físico define os seguintes atributos de um sistema de comunicação de dados:

- A conexão de uma ligação entre os dispositivos;

- As características dos sinais elétricos, eletromagnéticos ou ópticos entre os dispositivos de comunicação;

- A provisão para conectores mecânicos (como as dimensões e número de "plugs" e pinos); 
- O tipo de sinais de temporização (que habilita os dispositivos a sincronizar cada sinal do outro);

- A descrição de como os canais físicos são usados.

A maioria dos dispositivos de processamento de dados possue capacidade de transmissão de dados limitada através de portos seriais padrões. Normalmente, geram sinais digitais usando dois niveis de voltagem para codificar os dados. Esta camada deve cuidar das características elétricas, mecânicas, funcionais e procedurais das interfaces de transmissão.

Com relação à padronização, existem dois padrôes recomendados: se a ligação for feita por circuitos analógicos, como uma linha telefônica, a conexão será através de um modem, utilizando interfaces com os padrôes RS-232c, X.21 bis, RS-449 ou com a recomendação CCITT V.24; se forem utilizados circuitos digitais, será usada a ligação segundo a recomendação CCITT X.21. A seguir, a interface RS-232c será vista como um exemplo de uma interface da camada física .

\subsubsection{Interface EIA RS-232c}

Neste contexto, dispositivos como computadores e terminais, são designados como ETD (Equipamento Terminal de Dados) e os Equipamentos de Comunicação de Dados (como por exemplo o modem) são denominados ECD. O ECD fornece conexão para o usuário ETD com os circuitos de comunicação de dados. As atuais conexões entre os ETDs e ECDs são chamadas portos e contêm a lógica necessária para conectá-los. O circuito de comunicação de dados é o caminho físico entre os ECDs. Existem diversos nomes usados pela indústria para descrever o circuito, por exemplo: canal, linha ou ligação.

As características mecânicas pertencem à conexão física real entre o ETD e o ECD, um cabo deve ligar o ETD ao ECD (provavelmente com um conector em cada extremidade). Neste ponto são analisadas as especificações físicas, como números de pinos do conector, tamanho do conector e todas as outras dimensões. As caracteristicas elétricas determinam qual a voltagem que determina por exemplo o binário 1, qual a taxa de transmissão permitida e qual deve ser o tamanho do cabo. As características funcionais determinam quais os circuitos são conectados a cada um dos pinos e o que significam. As características procedurais especificam o protocolo, isto é, a seqüência legal de eventos entre os equipamentos.

A interface RS-232c, elaborada nos EUA pela EIA (Eletronic Industries Association), constitui-se num padrão para o interfaceamento serial entre um ETD e o ECD associado [TAN89]. Este padrâo adquire um caráter internacional através das recomendações CCITT V.24 e V.28 que especificam, respectivamente, as características funcionais e elétricas de uma interface semelhante. Quanto às características mecânicas, a interface RS-232c é associada a um conector de 25 pinos nos formatos macho e fêmea. Este conector forneca apenas os principais sinais da norma CCITT V.24 (que especifica um total 
de 52 sinais). Em relação às caracteristicas elétricas, é uma interface para transferência serial de dados onde o binário 1 é uma voltagem menor que -3 volts e o binário 0 é uma voltagem maior que +4 volts. Quanto às características funcionais, os principais sinais lógicos trocados entre o ETD e o ECD são mostrados na figura 3.8. E finalmente, as características procedurais estabelecem o par ação e reação. Por exemplo, caso o ETD esteja ligado a um modem e emita um "request to send", o modem responde com um "clear to send" se for possível receber o dado.

\begin{tabular}{|c|c|c|c|}
\hline \multicolumn{4}{|c|}{ Intertace EIA RS - 232C } \\
\hline Pino & Sigla & ETDECD & Função \\
\hline 1 & FG & & terra de proteção \\
\hline 2 & TD & - & dados transmitidos \\
\hline 3 & RD & - & dados recebidos \\
\hline 4 & RTS & - & pedido para transmissăo \\
\hline 5 & CTS & - & pronto para transmissăo \\
\hline 6 & DSR & - & ECD pronto \\
\hline 7 & & & terra de sinalizaçáo \\
\hline 8 & DCD & - & detecçăo de portadora \\
\hline 20 & DTR & - & ETD pronto \\
\hline
\end{tabular}

Figura 3.8 Alguns dos principais sinais lógicos do RS-232c.

\subsection{Modems}

Um dos componentes básicos em um sistema de comunicaçâo de dados, do ponto de vista de hardware, é o modem. É necessária a conversão de sinais quando computadores enviam dados sobre linhas telefônicas. Modems são dispositivos moduladores/demoduladores que realizam a interface do mundo digital dos computadores e terminais com o mundo analógico das facilidades de transmissão. A figura 3.9 mostra os elementos básicos da comunicação de dados. Os modems podem ser unidades isoladas (externos) ou fazer parte de um equipamento terminal (internos).

Normalmente os modems operam em um dos dois modos básicos possiveis, "halfduplex" ou "full-duplex". No modo "half-duplex", os modems compartilham a linha telefônica, revertendo a direção de transmissão periodicamente. Devem ser utilizadas regras bem definidas para controlar este modo de operação. O modo "full-duplex" é fornecido por dois tipos de linhas telefônicas, que usam tipos diferentes de modem. Um tipo de serviço é a linha privativa de 4 fios, que pode ser alugada da companhia telefônica e que consiste de dois canais - um para cada direção. Desta maneira, cada modem age como uma combinação de dojs modems, um para transmissão e outro para recepção, operando sobre canais essencialmente separados. Também é possível ter-se comunicação em modo 
"full-duplex" sobre linhas telefônicas discadas, onde os sinais transmitidos e recebidos coexistem na mesma linha.

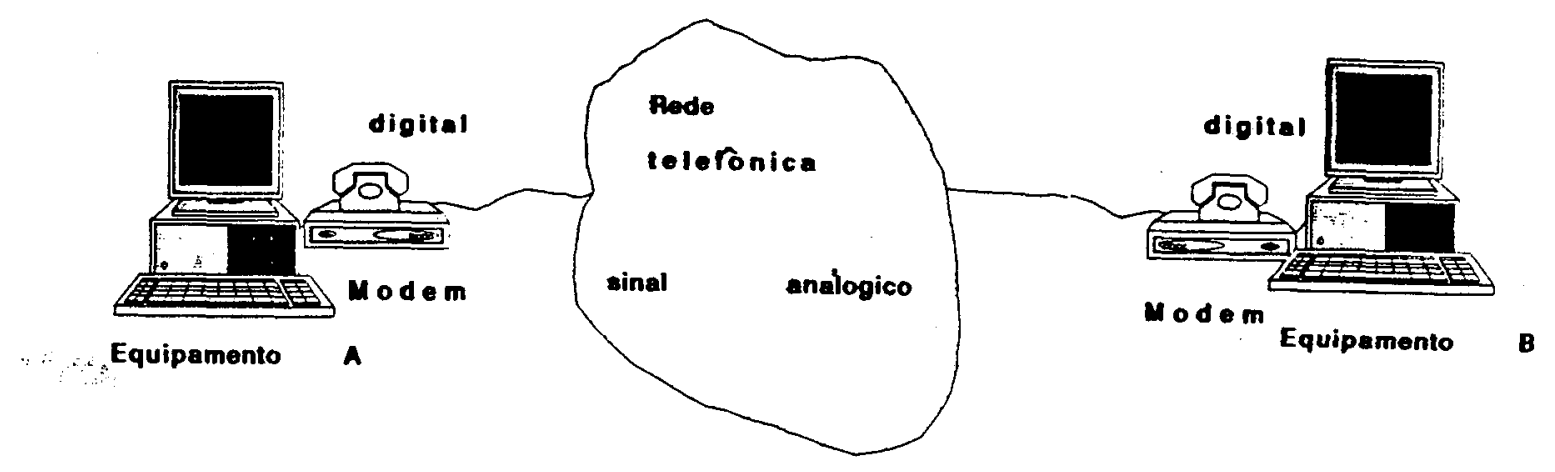

Figura 3.9 Comunicação de dados através de modems.

Há vários tipos possíveis de modulação, basicamente variando freqüência, fase ou amplitude de uma portadora. Cada método afeta os dados sobre um sinal portador que é alterado para transmitir as propriedades da seqüencia de dados digitais. A seguir é feita uma breve descriçâo dos três métodos básicos de modulação.

\subsubsection{Modulaçāo por amplitude - AM}

Modems AM alteram a amplitude da portadora de dados de acordo com a seqüência de "bits" digitais. A freqüência e fase de uma portadora são mantidas constantes e a amplitude é aumentada ou diminuida para representar um dígito 0 ou um dígito 1 . $\mathrm{Na}$ sua forma mais simples a portadora do sinal pode ser chaveada "on" ou "off" para representar o estado do dígito binário. O sinal AM é representado como:

$s(t)=A \cos \left(2 \Pi f_{c} t+\theta_{c}\right)$ para binário 1

$s(t)=0$ para binário 0

onde $s(t)$ é o valor da portadora no tempo, $A$ é a amplitude máxima da voltagem da portadora, $f_{c}$ é a frequêencia da portadora e $\theta_{c}$ é a fase da portadora.

$\mathrm{O}$ uso de $\mathrm{AM}$ para comunicação de dados tem diminuído porque um esquema multinivel precisa usar muitos de poucos níveis de sinal. Quando o número dos niveis de sinal aumenta a distância entre os niveis diminui. Transmissores AM muitas vezes saturam uma faixa estreita e, em alguns casos, devem ser usados com menos poder que o seu máximo para diminuir o problema de saturação. 


\subsubsection{Modulação por freqüência - FM}

A modulação por frequêencia altera a freqüência da portadora de acordo com a seqüência de "bits" digitais. A amplitude é mantida constante. Na sua forma mais simples um binário 1 é representado por uma certa freqüência e o binário 0 por outra. Muitas variações de modems FM estão disponiveis. O mais comum é o modem FSK (Frequency Shift Keying) que usa quatro freqüências na faixa de banda da linha telefônica. O modem FSK transmite, respectivamente, sinais 1070 e $1270 \mathrm{~Hz}$ para representar o binário 0 (SPACE) e binário 1 (MARK) e recebe sinais 2025 e $2225 \mathrm{~Hz}$ como um binário 0 (SPACE) e binário 1 (MARK). Como dito anteriormente, esta abordagem possibilita transmissões "full-duplex" sobre linhas telefônicas. $\mathrm{O}$ chaveamento da troca de frequêencia é expressado como:

$$
\begin{aligned}
& s(t)=A \cos \left(2 \Pi f_{1} t+\theta_{c}\right) \text { para binário } 0 \\
& s(t)=A \cos \left(2 \Pi f_{2} t+\theta_{c}\right) \text { para binário } 1
\end{aligned}
$$

FSK tem sido uma técnica largamente usada por modems para baixa velocidade que são relativamente baratos e simples. Entretanto seu uso sobre linhas analógicas está caindo, com mais fabricantes implementando ECDs com técnicas de modulaçào por fase.

\subsubsection{Modulação por fase - PM}

Modems PM alteram a fase do sinal para representar um 1 ou 0 . $O$ método de modulação por fase também é chamado PSK (Phase Shift Ki $\epsilon$ ing). Uma abordagem comum para PSK é comparar a fase do estado do sinal atual com o estado do sinal anterior (também conhecido como DPSK - it differencial PSK). Esta técnica usa uma faixa de banda mais eficiente que FSK porque coloca mais informaçōes em cada sinal. Também requer equipamento mais elaborado para geração e representaçâo dos dados. O sinal PSK esta representado como:

$$
s(t)=A \cos \left(2 \Pi f_{c} t+\theta\right)
$$

onde $\theta$ é igual a mudança de fase.

PSK pode ser empregada para fornecer modulaçâo multinivel. A técnica é chamada modulação de quadratura de sinal. Por exemplo, um modem que transmita 2 "bits" por "bauds" codifica a seqüência de dados binários, como segue:

$$
\begin{aligned}
& 11: \theta=45^{\circ} \\
& 10: \theta=135^{\circ} \\
& 01: \theta=225^{\circ} \\
& 00: \theta=315^{\circ}
\end{aligned}
$$


$\mathrm{O}$ receptor de cada modem sofre influência do sinal do seu próprio transmissor. Estes sinais podem ser confundidos pelo receptor do modem; portanto, eles devem ser separados. Normalmente isto é feito no dominio freqüência, com cada sinal usando partes disjuntas da banda de um canal telefônico. Canais telefônicos de voz foram projetados para passar frequência na banda de cerca de $300 \mathrm{~Hz}$ a $3 \mathrm{kHz}$. Modems "full-duplex" até $2400 \mathrm{bps}$ dividem esta banda em duas bandas mais estreitas (Phase Encoding). Para transmissão a velocidades maiores, técnicas de compactação são utilizadas. A escolha das frequêencias utilizadas pelos modems depende de um acordo prévio sobre qual banda de frequências cada modem usa para transmitir e receber. Este acordo normalmente é feito do seguinte modo: o modem que origina a chamada transmite na banda inferior e recebe na banda superior e o modem resposta faz o oposto.

\subsection{Considerações finais}

Num esforço de fornecer serviços padronizados e compatíveis através do mundo, organizaçôes têm cooperado através do CCITT para formular recomendaçōes para prover vários tipos e níveis de serviços. Partindo das experiências no desenvolvimento de alguns protocolos como TCP/IP e SNA, a ISO elaborou um modelo básico de referência para interconexão de sistemas abertos denominados OSI. A finalidade desse modelo é fornecer uma base comum para a coordenaçâo de novos projetos de interconexão de redes. Várias recomendaçôes para operação de redes de comutação de pacotes têm sido adotadas, tais como a recomendaçào X.25, especificando a interface ou protocolo a ser seguido pelos assinantes que têm acesso à rede pública. É interessante notar que os serviços oferecidos por redes e os protocolos são conceitos distintos e separados. Protocolo é um conjunto de regras que determinam o formato e significado de "frames", pacotes ou mensagens que são trocados entre entidades (software ou hardware) pares em uma camada. As entidades utilizam protocolos para implementar os seus serviços definidos. Cada um é livre para trocar seus protocolos desde que não altere, de forma visível, os serviços para seus usuários.

Apesar de ter sido objeto de um grande esforço colaborativo a nivel internacional desde 1980, o impacto sobre redes acadêmicas da arquitetura ISO/OSI [TAN89] ainda é relativamente pequeno, especialmente quando comparado com TCP/IP. Esta situação certamente se modificará com o tempo, especialmente levando-se em consideração iniciativas governamentais como US-GOSIP (U.S. Government'Open Systems Interconnection Profile), que exigiram "suporte para ISO/OSI" dos seus fornecedores a partir de novembro de 1990. Algumas das principais redes compondo a Internet já estão se modificando para admitir o uso simultâneo dos protocolos TCP/IP e do modelo ISO/OSI e desta forma a transição para ISO/OSI está encaminhada (pelo menos para a comunidade Internet). Porém, para que isto se dê com rapidez, é necessário que existam disponiveis implementaçôes de todos os niveis dos protocolos ISO/OSI nos sistemas usados pelos usuários finais. Rose em [ROS90] propôs a implementação do serviço de transporte ISO/OSI em termos de circuitos virtuais TCP (vide capítulo 4). Além disso, o projeto ISODE (ISO Development Environment) reune as contribuiçôes de diferentes grupos de implementadores dos 
protocolos de aplicação ISO/OSI para formar um pacote disponivel livremente através de repositórios de software na Internet. $O$ projeto ISODE continua evoluindo e já incluí implementaçôes dos principais aplicativos ISO/OSI e também um ambiente completo para o desenvolvimento de novos aplicativos. 


\section{Capítulo 4}

\section{Protocolo TCP/IP}

\subsection{Introdução}

Utilizado há majs de dez anos nos Estados Unidos da América, o conjunto de protocolos TCP/IP, ou simplesmente TCP/IP, foi implementado pelo DoD (Department of Defense) com o fim de integrar seus computadores em uma única rede, a Internet. A divulgação da tecnologia de inter-redes TCP/IP deve-se em parte a duas iniciativas tomadas por agências do governo dos EUA. Em 1983, o Departamento de Defesá adotou a tecnologia para sua rede privada (MILNET) e exigiu que todos os sistemas por ele adquiridos a fornecessem. Uma outra iniciativa foi o financiamento pela DARPA do desenvolvimento de uma versão extremamente bem difundida do sistema operacional Unix (4.2 BSD) que é também a base de Ultrix (da DEC) e SunOS (da SUN Microsystems). Neste sistema está incluida uma interface ("sockets") [STE90] para poder usar os protocolos TCP ou UDP, o que pode facilitar o desenvolvimento de software aplicativo empregando estes protocolos.

A tecnologia de inter-redes TCP/IP foi explicitamente desenvolvida, com financiamento do DARPA (Defense Research Products Agency), para permitir a interoperação de serviços entre computadores ligados a redes físicas de tecnologias distintas. Entre as tecnologias abrangidas incluiam-se: redes locais de diferentes tipos, conexôes seriais ponto a ponto e redes X.25. O modelo admitia a interligação direta ou indireta de um número arbitrário de redes distintas, e exigia de uma rede participante o suporte para um serviço de entrega de pacotes. A partir desta base, criava-se uma rede virtual ou inter-rede, utilizando um esquema global de endereçamento e oferecendo um serviço de entrega não confiável de datagrama entre qualquer par de computadores a ela ligados [COM91a].

Duas ou mais redes vizinhas estavam ligadas através de pelo menos um computador comum a elas, chamado de roteador, cuja função era retransmitir numa das redes, os datagramas recebidas em uma outra. Em cada rede o datagrama era transmitido utilizando o mecanismo de transmissão de pacotes próprio a ela. A escolha da rota a ser seguida em cada transmissão de pacotes era a principal função do roteador e era determinada pelo endereço do destinatário final do datagrama. O protocolo de inter-redes usado era chamado 
de Internet Protocol, ou IP, e os endereços globais eram chamados de endereços IP. Os serviços em uma inter-rede IP faziam uso de dois protocolos de transporte: o Transmissiom Control Protocol (TCP), que implementa serviço conectado e confiável, através de um circuito virtual, e o User Datagrama Protocol (UDP), que implementa um serviço de entrega de datagramas não confiável. Serviços que usavam TCP incluíam desde correio eletrônico (usando o Simple Mail Transport Protocol - SMTP), transferência de arquivos (usando o File Transfer Protocol - FTP) até "login" remoto (usando TELNET). Serviços que usavam o UDP incluiam o Domaim Name Service (DNS) e o Trivial File Transfer Protocol (TFTP).

Adicionalmente, há mais de dez anos, a tecnologia TCP/IP vinha sendo usada para interligar um número sempre maior de redes de todos os tipos. Nos primeiros anos, a ARPANET funcionava como sua espinha dorsal, por onde passava a maior parte do tráfego de longa distância, mas a partir de 1985 vinha sendo substituída neste papel pela espinha dorsal da NSFnet, criada pela National Science Foundation para interligar centros de supercomputação financiadas por ela e prover acesso remoto aos pesquisadores. Até 1988, a espinha dorsal da NSFnet funcionava usando canais com a mesma capacidade que a ARPANET, $56 \mathrm{Kbps}$. Passou-se em 1988 ao uso de canais de cerca de $500 \mathrm{Kbps}$ e em 1989 para cerca de $1.5 \mathrm{Mbps}$, sendo que até 1992 seria feita a migração para uma nova espinha dorsal funcionando em $45 \mathrm{Mbps}$ (uma parte está funcionando desde 1990).

Um dos argumentos a favor do uso do TCP/IP é que ele oferece um ambiente de rede maduro, robusto, estável e bem entendido pelos usuários e administradores. Os equipamentos mais modernos de computação que estão sendo adquiridos por pesquisadores são estações de trabalho, geralmente das marcas Digital, Hewlett-Packard, IBM ou Sun. Todas estas estaçôes vêm com interfaces Ethernet/IEEE 802.3, e geralmente são usadas em rede local, empregando os protocolos TCP/IP. Frequentemente a mesma rede local interliga estações de trabalho, "mainframes" e computadores pessoais. Uma única instituição poderá ter várias redes deste tipo interligadas através de linhas seriais, ligando equipamentos em redes diferentes ou por meio de pontes ou roteadores, formando assim uma inter-rede interna. A montagem desta inter-rede é tecnicamente "fácil", quando todas as redes componentes já utilizam os protocolos TCP/IP. No contexto desta inter-rede interna, estarão disponiveis os serviços "login" remoto, transferência de arquivos e correio eletrônico.

Deve-se ainda destacar os possiveis papéis numa inter-rede TCP/IP para computadores pessoais (PCs) usando o sistema operacional MS-DOS. Um PC pode participar diretamente numa rede local, por exemplo, Ethernet ou "Token Ring", se possuir interface de rede. Também pode estar ligado a outro equipamento como "terminal", através de uma linha serial. Um PC ainda pode servir de roteador entre duas redes locais através de interfaces Ethernet ou linhas seriais. Já estão publicamente disponíveis no meio acadêmico diversas implementaçōes de software para PCs com MS-DOS que implementam os protocolos TCP/IP, "Serial Line IP" (SLIP), roteadores e protocolos de aplicação tais como TELNET, FTP e NFS [COM91a]. Também existem alguns produtos comerciais com a mesma finalidade. Softwares deste tipo tornam imediatamente aproveitável como entidade ativa numa inter-rede TCP/IP o equipamento mais comum que existe hoje no país, 


\subsection{O modelo em camadas da Internet}

O software TCP/IP está organizado nas quatro camadas conceituais: aplicação, transporte, inter-rede, rede - mostradas na figura 4.1 e uma quinta camada física (hardware). As camadas conceituais são descritas e analisadas posteriormente [COM91a, POS81a, POS81b].

\begin{tabular}{|l|}
\hline aplicaçāo \\
\hline transporte \\
\hline inter-rede \\
\hline interface de rede \\
\hline
\end{tabular}

Figura 4.1 As quatro camadas do TCP/IP.

\section{Camada de aplicação}

Nesta camada os usuários executam programas de aplicação que têm acesso a Internet. Uma aplicação interage com os protocolos da camada de transporte para enviar e receber dados. Cada programa de aplicaçâo escolhe suas próprias formas de dados que podem ser desde uma seqüência de dados até a uma cadeia de bytes. De qualquer modo, expede os dados para a camada de transporte para que os remeta.

\section{Camada de transporte}

A principal obrigação desta camada é oferecer comunicação entre programas de aplicação. Muitas vezes chamado um serviço fim a fim de entrega de datagramas. O serviço de entrega fim a fim do sistema Internet possui dois padrões de protocolo de serviço, o protocolo TCP e o protocolo UDP. Estas duas classes de serviços são oferecidas para atender aplicações em ambientes onde existam diferentes graus de confiabilidade, taxa de erro e atraso. Através do TCP, essa camada pode regular o fluxo de informação e pode assegurar que os dados cheguem sem erro e na seqüência correta, fornecendo transporte confiável. Para funcionar desta forma espera por uma confirmação de recebimento e se necessário retransmite o pacote. Pode ser necessário segmentar a mensagem origem em unidades menores denominadas pacotes. Um outro tipo de transporte disponivel, através do UDP, é não confiável, com sistema de entrega de pacotes sem conexão. Neste caso, os datagramas podem ser entregues em qualquer ordem e nâo é feito nenhum tratamento para detecção e tratamento de erros.

Embora a figura 4.1 use um único bloco para representar a camada de aplicação, uma máquina de propósito geral pode ter múltiplos programas de aplicaçâo tendo acesso à 
rede ao mesmo tempo. A camada de transporte deve aceitar dados de vários programas usuários e enviá-los para a camada de rede. Para fazê-lo, acrescenta informaçóes adicionais para cada pacote, incluindo códigos que identifiquem que programa de aplicação o enviou e que programa de aplicação deve recebê-lo. A máquina receptora usa o código do destinatário para identificar o programa de aplicação que deve recebê-lo.

\section{Camada inter-rede}

Esta camada gerencia a comunicaçào entre máquinas. Aceita um pedido da camada de transporte para enviar um pacote. O termo pacote é usado genericamente aqui para significar os dados de uma transação entre um hospedeiro e sua rede; deve conter os endereços origem e destino, juntamente com os dados. Somente endereços IP são usados. O pacote é encapsulado num datagrama, o cabeçalho é preenchido e é utilizado um algoritmo de roteamento para determinar se entrega o datagrama diretamente ou o envia para roteadores. Depois transfere o datagrama para a interface da rede apropriada para a transmissão. Esta camada também trata datagramas que são recebidos, verificando a sua validade, apagam o cabeçalho e usam algoritmos de roteamento para decidir se o datagrama deve ser processado localmente ou expedido. Para datagramas endereçados a máquina local, o software da camada inter-rede escolhe entre os protocolos de transporte aquele que pode tratar o pacote. Finalmente, a camada inter-rede envia e trata as mensagens do ICMP (Internet Control Message Protocol). O ICMP é o protocolo que possibilita o envio de mensagens de controle e manipulação de erros.

\section{Camada de interface de rede}

Esta camada é responsável por receber datagramas e transmiti-los através de uma rede específica. Essa camada, algumas vezes também chamada de camada de enlace de dados, fornece os meios de um hospedeiro ter acesso à rede, descrevendo o protocolo para um hospedeiro conectar-se a uma rede e não o protocolo usado na rede. A interface da rede pode ser um mecanismo para conectar a rede ou um complexo subsistema que usa seu próprio protocolo de enlace de dados para conectar-se a rede.

\subsection{Protocolo de Inter-rede}

O protocolo desta camada denomina-se IP e segundo Comer em [COM91a], os serviços Internet estão construidos sobre um sistema de entrega de pacotes não confiável e sem conexão cuja unidade básica de transferência é o datagrama IP, ou simplesmente datagrama. O datagrama é dividido em cabeçalho e área de dados. $\mathrm{O}$ protocolo IP implementa duas funções básicas, endereçamento e fragmentação. $\mathrm{O}$ módulo inter-rede usa o endereço transmitido no cabeçalho para entregar o datagrama ao seu destinatário. A seleção do caminho que deve ser percorrido pelo datagrama é chamado de roteamento. $\mathrm{O}$ módulo também usa campos do cabeçalho do datagrama, mostrados na figura 4.2, para fragmentar e remontar os datagramas quando for necessário uma transmissão em pacotes menores pela rede. 
Opera estando implementado em cada hospedeiro e em cada roteador conectado à rede. O IP trata cada datagrama como uma entidade independente não relacionada com nenhum outro. Usa quatro informaçôes chaves para fornecer seus serviços; os campos tipo de serviço, tempo de vida, opção e checagem do cabeçalho. Em suma, o protocolo IP não fornece comunicação confiável (não existe confirmação entre os nós, não é feito controle de erros de dados, somente a checagem do cabeçalho; não é feita retransmissão e não existe controle de fluxo). Problemas na comunicação podem ser relatados via o ICMP, que é implementado no módulo IP. Abaixo, os campos do datagrama são descritos de forma sucinta [COM91a].

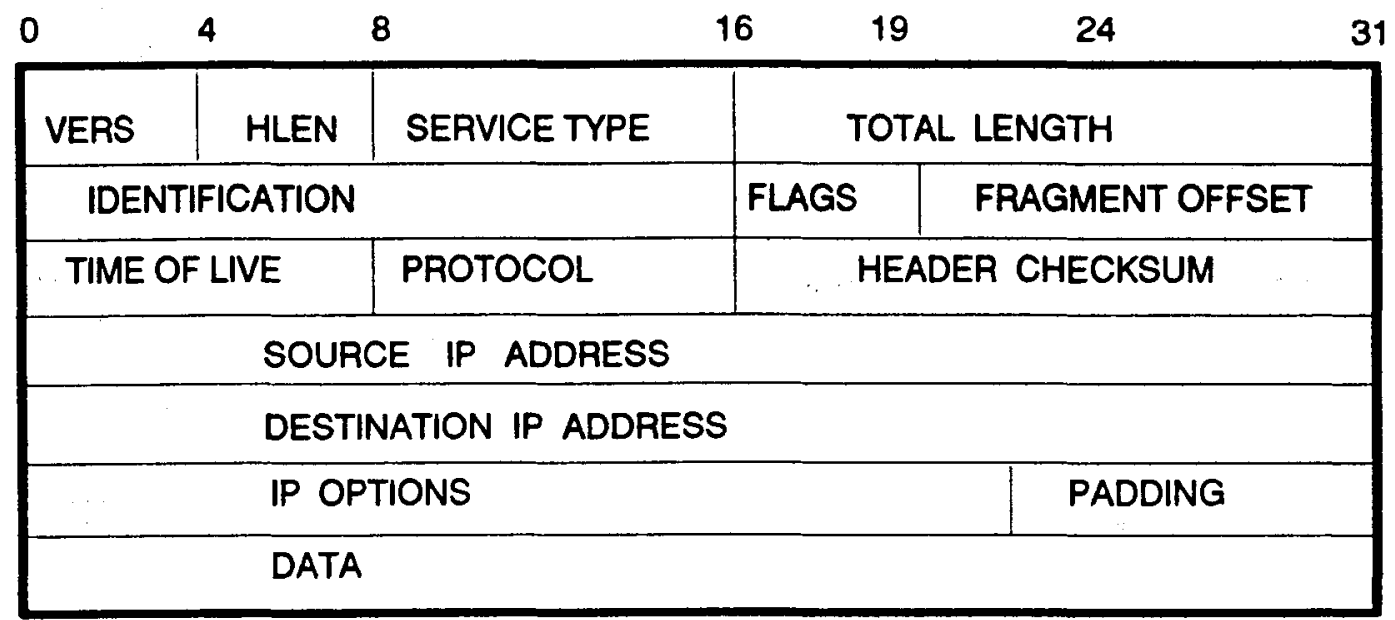

Figura 4.2 Um datagrama IP.

- VERS: versão do formato do cabeçalho (atualmente na versão 4).

- HLEN: comprimento do cabeçalho medido em palavras de 32 bits.

- SERVICE TYPE: especifica a qualidade do serviço desejado.

- TOTAL LENGTH: comprimento total do datagrama em bytes.

Observação: A fragmentação e remontagem dos datagramas são controlados pelos próximos três campos.

- IDENTIFICATION: um inteiro que identifica o datagrama (em caso de fragmentação deve ser copiado em todos os fragmentos).

- FLAGS: controla a fragmentação.

- FRAGMENT OFFSET: especifica o número do fragmento.

- TIME TO LIVE: tempo, em segundos, que o datagrama pode permanecer na Internet. 
- PROTOCOL: protocolo utilizado no próximo nivel.

- HEADER CHECKSUM: garante a integridade dos valores do cabeçalho.

- SOURCE IP ADDRESS: endereços Internet (4 bytes).

- DESTINATION IP ADDRESS: endereços Internet (4 bytes).

- IP OPTIONS: pode aparecer ou não num datagrama, utilizado em testes.

- PADDING: usado para assegurar que o cabeçalho termine com uma palavra de 32 bits.

- DATA: área de dados.

\subsection{Protocolos de serviços}

Nos niveis mais baixos, redes TCP/IP fornecem um serviço de entrega de pacotes não confiável onde os pacotes podem ser perdidos ou destruidos. Neste nível, são oferecidos serviços através de dois protocolos de transporte: o Transmissiom Control Protocol (TCP), que implementa um circuito virtual, e o User Datagrama Protocol (UDP), que implementa um serviço de datagrama não confiável.

\subsubsection{O protocolo TCP}

\begin{tabular}{|c|c|}
\hline \multicolumn{1}{|c|}{8} & 16 \\
\hline source port & \multicolumn{2}{|c|}{ destination port } \\
\hline \multicolumn{3}{|c|}{ sequence } & number \\
\hline \multicolumn{2}{|c|}{ acknowledgement number } \\
\hline hlen reservedcode bits & \multicolumn{2}{|c|}{ window } \\
\hline checksum & urgent pointer \\
\hline \multicolumn{3}{|c|}{ options (if any) } \\
\hline \multicolumn{3}{|c|}{ data } \\
\hline \multicolumn{2}{|c|}{ padding } \\
\hline
\end{tabular}

Figura 4.3 Um segmento TCP.

O TCP é um protocolo para comunicação em ambas as direções. Permite que vários programas de aplicação numa máquina comuniquem-se de forma concorrente com programas de aplicação em outras máquinas em um ambiente multirede. É orientado a 
conexão, no sentido de que antes de transmitir dados, precisa estabelecer uma conexão lógica entre os participantes. É implementado utilizando o protocolo IP que fornece meios para endereçamento do TCP origem ao destinatário em diferentes rede. O TCP implementa controle de fluxo de dados, onde o transmissor recebe uma mensagem especificando a quantidade de dados que o receptor pode receber. Contém mecanismos para fornecer transmissões confiáveis que incluem números de seqüência, digitos de verificação, temporização, reconhecimentos e procedimentos de retransmissão. Um segmento TCP está dividido em duas partes, o cabeçalho e a área de dados, como pode ser visto na figura 4.3. Os campos do cabeçalho são descritos abaixo.

- SOURCE PORT e DESTINATION PORT: identifica o número do porto do programa de aplicação nas máquinas conectadas.

- SEQUENCE NUMBER: identifica a posição na cadeia dos bytes do segmento de dados.

- ACK. NUMBER: identifica a posição do byte mais alto recebido.

- HLEN: contém um número inteiro que especifica o tamanho do cabeçalho em múltiplo de 32 bits.

- RESERVED: reservado para uso futuro.

- CODE BITS: determina o conteúdo e propósito do segmento.

- WINDOW: tamanho do "buffer".

- URGENT POINTER: indica a prioridade da entrega dos dados.

- OPTIONS: usado para comunicar-se com o software TCP na outra ponta da conexão.

- CHECKSUM: verifica a integridade do cabeçalho e dos dados.

- PADDING: usado para assegurar que o cabeçalho termine com uma palavra de 32 bits.

- DATA: área de dados.

O principal propósito do TCP é fornecer um serviço confiável, com conexão entre pares de processos. Para fornecer estes serviços sobre um sistema de comunicação inter-redes menos confiável, é necessário ter facilidades implementadas nas áreas de transferência de dados básicos, confiabilidade, controle de fluxo, multiplexaçâo, conexão, precendência e segurança. 


\subsubsection{O protocolo UDP}

O protocolo UDP fornece um serviço não confiável e sem conexão baseado no protocolo IP para o transporte de mensagens entre máquinas, adicionado da habilidade de discriminar entre múltiplos processos destinos, chamados portos, que podem ser determinados em um hospedeiro. O UDP inclui a verificação na máquina origem dos dados que estão sendo enviados. O UDP diferencia os portos em uma máquina utilizando um número que identifica o porto a que cada mensagem UDP está associada. Alguns números de portos estão especificados e outros números de portos sâo deixados disponiveis para programas aplicativos.

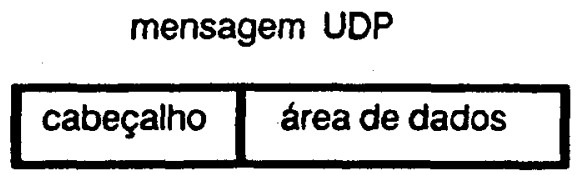

a)

\begin{tabular}{|l|l|}
\hline 0 & 16 \\
\hline port org. & port destino \\
\hline tamanho & checksum \\
\hline
\end{tabular}

b)

Figura 4.4 Um datagrama UDP.

Cada mensagem do UDP, denominada datagrama do usuário, é formada por duas partes, o cabeçalho e a área de dados (fig. 4.4a). O cabeçalho está dividido em quatro campos de 16 bits que especificam o porto de/para onde a mensagem foi enviada, o tamanho da mensagem e um "checksum" (fig. 4.4b). O UDP basicamente utiliza os serviços da camada do protocolo IP e conceitualmente estão em camadas independentes, mas na prática, existe uma forte interação entre eles.

\subsection{Protocolos de aplicação}

Vários protocolos de aplicaçâo têm sido estabelecidos pela Internet, alguns dos mais importantes são descritos a seguir [COM91a]. O relacionamento entre alguns dos protocolos Internet é mostrado na figura 4.5 [COM91a, POS81b].

\section{TELNET}

Protocolo para terminal remoto TELNET permite a um usuário num terminal estabelecer uma conexào TCP para ter acesso a um servidor em outra máquina que possibilite enviar mensagens da máquina local diretamente a máquina remota e vice-versa. $O$ TELNET fornece um sistema de autenticaçâo que permite aos usuários identificarem-se no sistema remoto. Pode-se citar três serviços básicos [POS83]: 
- define um terminal remoto que fornece uma interface entre o sistema remoto (servidor remoto) e os programas clientes.

- inclue um mecanismo que permite ao cliente e ao servidor negociar opções (por exemplo, especificar se os dados passados na conexão TCP será um texto binário ou ASCII).

- TELNET trabalha do mesmo modo para conectar terminais a programas remotos ou conectar dois terminais locais.

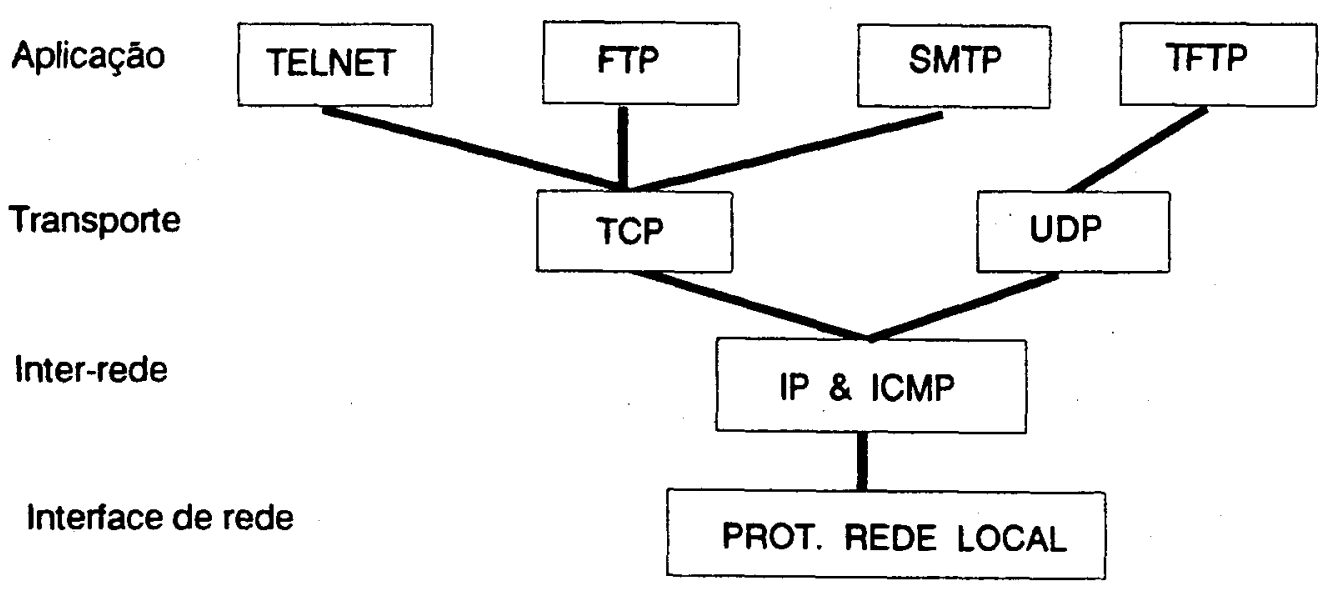

Figura 4.5 Relação entre alguns protocolos da Internet.

\section{FTP}

Protocolo de transferência de arquivo FTP (File Transfer Protocol) permite a um usuário autorizado ter acesso a um sistema remoto, identificar-se, listar diretórios remotos, copiar arquivos de/para máquinas remotas e executar alguns comandos remotamente [CRO82]. Segundo [COM91a], o FTP é mais complexo que o TELNET, pois: permite a um usuário ter acesso a múltiplas máquinas numa única sessão, mantém uma conexão TCP separada para controle e transferência de dados e usa o protocolo TELNET para controlar sua conexão de controle.

\section{SMTP}

Protocolo simplificado de transferência de correspondência, SMTP (Simple Mail Transfer Protocol), espècifica como dois sistemas de correspondência eletrônica podem interagir e o formato da mensagem de controle que eles utilizam para a transferência. A função básica do SMTP é fornecer um mecanismo de negociaçâo básica para a passagem de mensagem de uma máquina para outra. Como o FTP, o SMTP é construido sob os serviços do TCP [POS82]. 


\section{TFTP}

O TFTP (Trivial File Transfer Protocol) é o protocolo padrão para transferência de arquivos com capacidade e sobrecarga mínimas, visando aplicaçōes que não necessitam de interações complexas entre o cliente e o servidor. TFTP depende somente do serviço de entrega de datagramas não confiável e sem conexão (UDP) e pode ser usada em máquinas onde pode ser difícil ou impossivel gerenciar múltiplas conexões TCP concorrentes. Por ser pequeno pode ser usado em por estaçôes de trabalho sem disco que o tenham na ROM e usam-no para obter uma imagem inicial da memória no momento em que sejam ligadas.

\subsection{Considerações finais}

A evolução das tecnologias de fabricaçào de computadores e de telecomunicações possibilita a distribuiçâo eficaz de recursos computacionais. $O$ custo decrescente de computadores pessoais e estações de trabalho vem permitindo um maior acesso a esses recursos e o problema inicialmente identificado de isolamento entre os usuários de computação pessoal pode ser resolvido através da ligação em redes destes equipamentos, possibilitando o compartilhamento destes equipamentos, informaçôes e serviços, a custos inferiores e com desempenho e conveniência maiores que os possiveis com a partilha de tempo em grandes sistemas. Com a possibilidade da utilização do TCP/IP para interconexâo destes equipamentos as inter-redes TCP/IP vêm quase de graça.

A Internet baseia seus protocolos na idéia de que a confiabilidade é um problema a ser analisado pelas estaçôes origem e destino, sendo a camada de transporte a que detecta algum erro e soluciona o problema. A liberdade resultante da verificação torna o software da Internet mais fácil de compreender e implementar [COM91a]. O conjunto de protocolos TCP/IP tornou-se um padrão de fato, pois a experiência prática da Internet interligando sistemas heterogêneos conduziu a esta situaçâo. O TCP/IP fornece a base para a Internet, contribuindo para a realização dos serviços fornecidos por essa rede. 


\section{Capítulo 5}

\section{Desenvolvimento de serviços de rede em ambiente SunOS}

\subsection{Introdução}

O padrão mais comum de interação entre aplicações cooperantes é conhecido como o paradigma do cliente/servidor. Segundo Comer em [COM91a], servidor é qualquer programa que ofereça um serviço. Servidores recebem pedidos que chegam pela rede, os processam e retornam os resultados aos requisitantes. Um programa torna-se cliente quando ele envia um pedido para um servidor e espera por uma resposta. Os servidores podem executar tarefas simples ou complexas. Esse paradigma apresenta a possibilidade de crescimento modular, pois tanto clientes como servidores podem ser introduzidos gradualmente. Os clientes e servidores podem executar em máquinas separadas ou compartilhar a mesma máquina. Dependendo da situação um mesmo processo pode ter comportamento de servidor ou de cliente [COM91a]. A comunicação entre processos nesse paradigma toma a forma de pedido-resposta, e um suporte possível para essa comunicação constitui as chamadas de procedimento remotos (Remote Procedure Call - RPC) [MUL89]. A comunicação entre os processos cliente e servidor pode tomar a forma de simples transmissão de mensagens. Essas transmissões podem ser bloqueantes (o processo cliente fica bloqueado até o servidor poder receber o pedido) ou não bloqueantes (o pedido enviado pelo processo cliente é armazenado em um "buffer", permitindo retransmissão em caso de falha) [COU88].

Vários serviços, fornecidos normalmente pelo sistema operacional em arquiteturas centralizadas, são implementados em sistemas distribuidos através de servidores remotos, disponiveis a todo o sistema [COU88]. A maior conseqüência desse método é a redução da complexidade do núcleo do sistema operacional, com influência direta na maior confiabilidade do sistema. Os principais serviços usualmente oferecidos nas redes acadêmicas incluem correio eletrônico, sistemas servidores de arquivos, acesso a máquinas remotas, acesso a bancos de dados remotos, intercâmbio interativo de mensagens em tempo real, 
transferência de arquivos e conferências computadorizadas [COU88, LAN86]. Abaixo são apresentados alguns servidores responsáveis por serviços da rede:

- Servidor de arquivos: É um dos servidores mais importantes e complexos num sistema distribuido. Segundo Giozza em [GIO86], o seu objetivo é oferecer aos usuários armazenamento e acesso de informação. A integridade de dados é uma das maiores preocupações dos servidores de arquivos [COU88]. Entre suas atribuições destacam-se [TAN85]: gerenciar um sistema de arquivos que possa ser utilizado pelo usuário (em substituição ou em adjção ao sistema de arquivos existente localmente em sua máquina) e garantir a integridade dos dados (detectando e implementando uma política de proteção em casos de falha do sistema, de acessos concorrentes e acessos não autorizados).

- Servidor de carga de sistema: Segundo Tanenbaum [TAN85], esse servidor fornece programas às máquinas da rede quando elas iniciam a operação. Normalmente tem seu próprio disco local, usado para armazenar o conjunto de programas fornecidos para as estações quando solicitados. Quando uma estação é ligada, ela executa o programa de controle residente, que segue a seqüência de "boot".

- Servidor de correio eletrônico: Um servidor de correio eletrônico é composto de duas partes principais, a interface do usuário e o sistema que transfere a mensagem. Quando um usuário quer enviar uma mensagem, primeiro ele a compõe e formata através do serviço de correio eletrônico, que ativa o sistema encarregado de enviar a mensagem ao destinatário. O sistema que transfere a mensagem é um processo responsável por obter o endereço do destinatário, enviar, armazenar, retransmitir e entregar a mensagem ao destinatário. Ele contem informações sobre usuários, redes e outros servidores.

O desenvolvimento de serviços em redes de computadores está diretamente ligado aos recursos disponiveis no ambiente onde estão sendo projetados. $\mathrm{O}$ usuário pode ter acesso a serviços, através de aplicativos, sem ter conhecimento sobre como estão implementados e da forma que utilizam a rede (nâo fazendo distinção entre operações locais e remotas). A major parte dos softwares que implementa o protocolo TCP/IP reside no sistema operacional (de onde pode ser compartilhada por todos os aplicativos executados na máquina), isto é, o sistema operacional tem uma única copia do código, entretanto, vários programas podem solicitar o código. Sistemas operacionais gerenciam a memória principal (onde os programas executam), o meio de armazenamento secundário (onde ficam armazenados os arquivos do sistema), recursos e dispositivos periféricos [COM91b].

Neste escopo, um processo é considerado uma computação feita de forma independente. Cada processo executa de forma independente fornecendo um aparente paralelismo. Em geral, quando se diz que os processos executam de forma concorrente, um esquema de prioridades está sendo usado para disciplinar a execuçâo dos processos (o que permite ter processos com precedência sobre outros). O sistema tem, por exemplo, processos TCP/IP e um processo para cada programa de aplicação. 
Algumas abstrações de sistemas operacionais são úteis para entender os mecanismos do TCP/IP. O uso de abstrações para isolar partes do software do conjunto de protocolos torna mais fácil o seu entendimento. $O$ sistema operacional UNIX fornece os mecanismos semáforo (usado para sincronização entre os processos) e porto (que permite que processos troquem mensagens entre eles através de uma fila finita) que permitem a implementação da abstração "sockets" usada na comunicação entre processos [LEF89]. 0 ambiente XINU [COM91b] é usado na próxima seção para ilustrar os detalhes e o funcionamento interno do mecanismo porto.

\subsection{Portos}

A abstração porto ("port") fornece um ponto de reunião por onde o processo pode passar dados. Pode-se pensar no porto como uma fila de mensagens adicionada de dois semáforos que controlam o seu acesso. Um programa cria um porto pela chamada da função "pcreate" e especifica o tamanho da fila como um argumento ("pcreate" retorna um argumento que é usado para referenciar o porto). Uma vez o porto tendo sido criado, processos chamam as funçōes "psend" e "preceive" para, respectivamente, depositar e remover itens. O mecanismo porto usa semáforos para coordenar os processos que usam a fila. Por exemplo, se um processo tenta enviar/extrair uma mensagem e o porto está cheio/vazio, o processo pode ser bloqueado até que outro processo extraia/deposite mensagens.

Processos implementando protocolos usam ambos, filas e portos para passar pacotes entre eles. Por exemplo, o processo de entrada IP envia segmentos TCP para o porto do qual o processo TCP os extrai. Enquanto isso, no ponto da entrada de dados da rede (interface de rede) continuam chegando datagramas em uma fila da qual o processo IP os extrai. Quando os dados passam pelas filas o sistema deve usar um mecanismo de passagem de mensagens ou semáforos para sincronizar as ações dos processos independentes.

A figura 5.1 resume o fluxo sobre a entrada de dados entre a interface de rede e o aplicativo. Os dispositivos de rede colocam em fila todos os pacotes que chegam e os conduzem para filas de datagramas IP. $O$ processo IP extrai pacotes das filas, entregandoos para o software de alto nível do protocolo apropriado. Quando o IP encontra um datagrama UDP invoca o processo UDP que deposita o datagrama entrante no porto apropriado (do qual será lido pelos programas de aplicação). Já, quando IP encontra um segmento TCP, passa o datagrama para o porto do qual o processo de entrada TCP o extrai [COM91b].

A figura 5.2 resume o fluxo de informação entre um programa de aplicação e o hardware de rede durante o processo de saída de dados. $\mathrm{Na}$ figura tem-se um programa de aplicação (executando como um processo separado), rotinas (system calls) para passagem de streams de dados para TCP (ou datagramas para UDP). Na saída UDP, é executado o processo UDP que aloca um datagrama UDP, encapsula-o e envia-o para o processo IP (que o despacha para o endereço destino apropriado). 


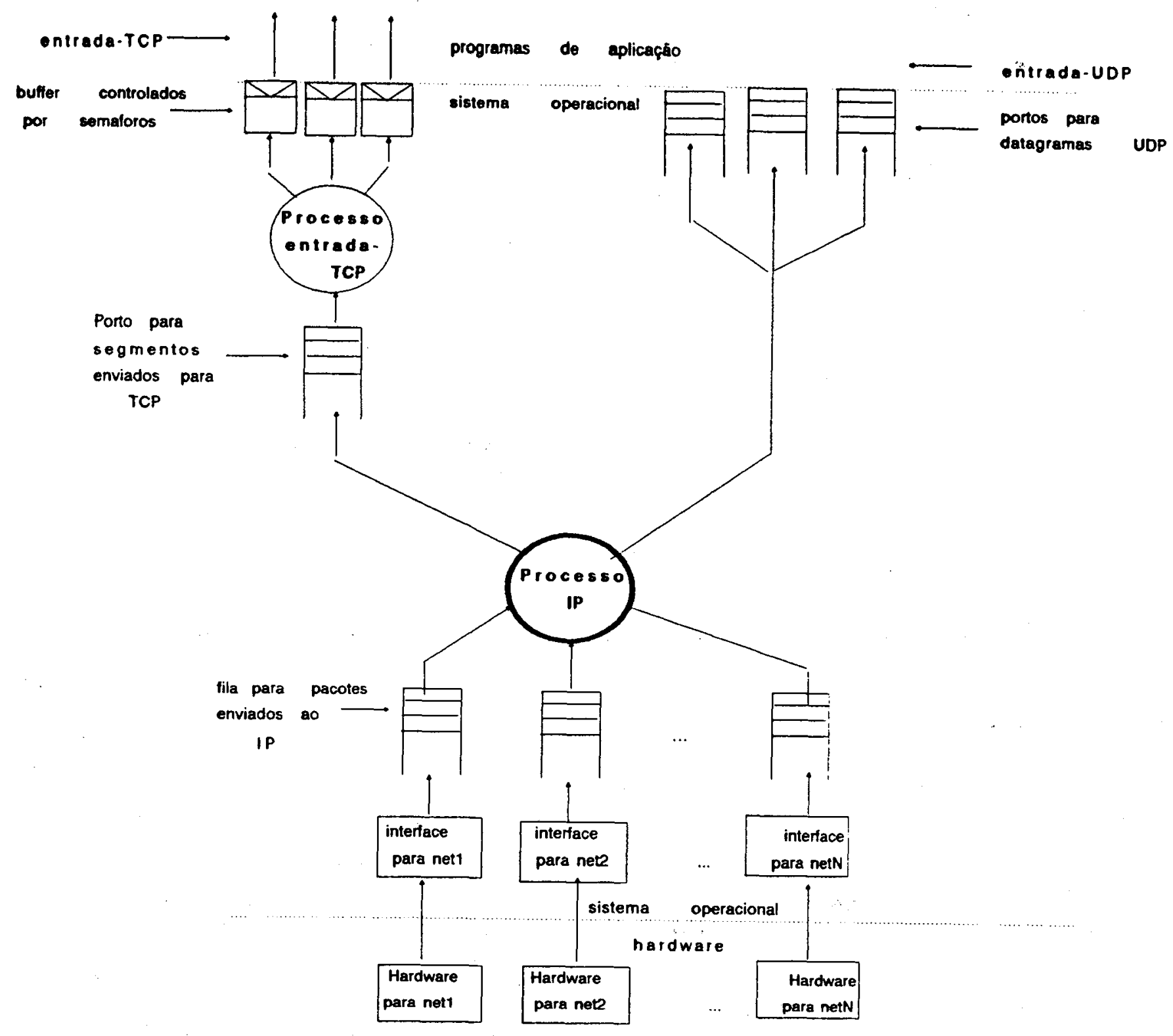

Figura 5.1 Estrutura do processo entrada, mostrando o caminho dos dados entre o hardware de rede e um programa de aplicação [COM91b].

$\mathrm{Na}$ saida TCP, o processo do programa de aplicação chama uma rotina do sistema para transferir dados entre o sistema operacional e o seu lugar no "buffer". O processo de aplicação informa ao processo saída TCP que novos dados estão aguardando para serem enviados. Quando um processo saída TCP executa, divide os streams de dados em segmentos e os encapsula como um segmento TCP. Finalmente, o processo TCP enfileira os segmentos no porto de onde serão extraídos e enviados pelo IP [COM91b]. Note que o processo IP é a parte central do conjunto sendo compartilhado em ambos os processos (entrada e saída). 


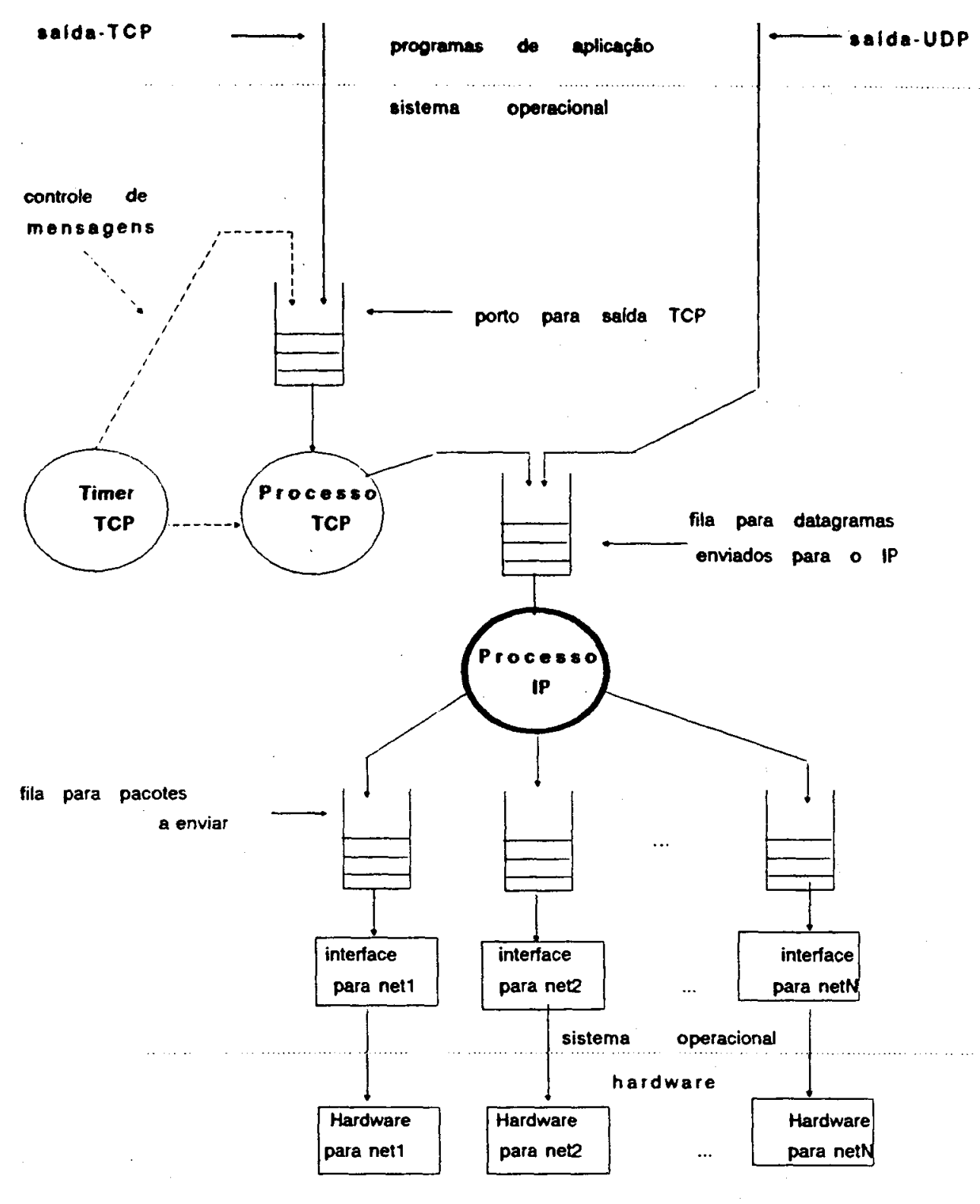

Figura 5.2 Estrutura do processo saída mostrando o caminho dos dados entre um programa de aplicação e o hardware de rede [COM91b].

\subsection{Implementação de pares cliente/servidor em ambiente UNIX}

Como visto acima, o sistema operacional deve prover mecanismos que permitam a comunicação entre processos envolvidos na comunicação. A atual implementaçâo do kernel do UNIX separa o sistema em três camadas, como mostrado na figura abaixo [STE90]: 


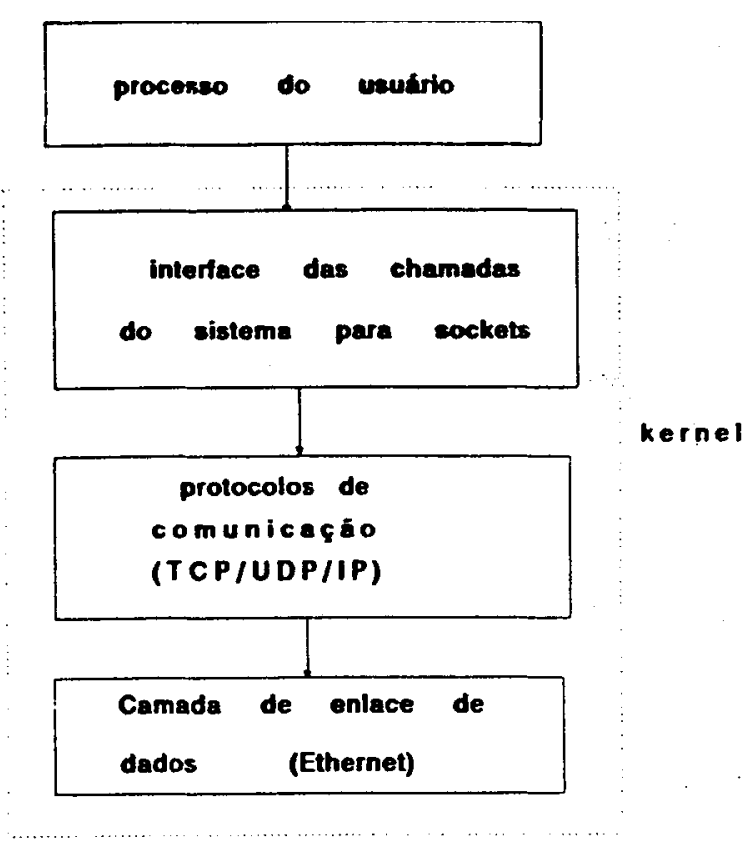

Figura 5.3 Implementação de rede 4.3 BSD UNIX.

Interfaces para programas de aplicação estão disponjveis para permitir a comunicação com os protocolos. Duas das interfaces mais usadas no ambiente UNIX são os "sockets" de Berkeley e as TLIs (Transport Layer Interface) do System V. Facilidades para comunicação entre processos (IPC - interprocess communication) e protocolos de rede foram as principais adições ao sistema UNIX introduzidas pela versão 4.2 BSD de Berkeley [LEF89]. Estas facilidades foram projetadas para suportar os itens abaixo [LEF89]:

- Transparência: Comunicações entre processos não devem depender dos processos estarem ou não na mesma máquina.

- Eficiência: A aplicabilidade das facilidades de comunicação entre processos estão limitadas por seu desempenho.

- Compatibilidade: Existindo processos UNIX simples ("naive"), eles deveriam poder ser usados no ambiente distribuído sem necessidade de mudanças. Processo "naive" é caracterizado como um processo que executa seu trabalho lendo do arquivo de entrada padrão e escrevendo no arquivo de saída padrão. Um processo sofisticado é um que gerencie outros processos ou use conhecimento sobre dispositivos específicos, por exemplo um terminal.

Durante o desenvolvimento do projeto das facilidades de comunicação entre processos foi detectada a necessidade dos seguintes requisitos [LEF89]:

- O sistema deveria suportar comunicação com redes que usam diferentes convençôes de nome, conjuntos de protocolos e hardware. A noção de domínio de comunicação 
foi definida por esta razão. 0 domínio de comunicação incorpora a semântica padrão da comunicação e nomeação. Redes diferentes podem ter modos diferentes de especificar o nome de um ponto de comunicação. As propriedades dos nomes também podem variar (em uma rede um nome pode ser um endereço fixo de um ponto de comunicação, em outra pode ser usado para localizar um processo que pode movê-lo de posição). A semântica de comunicação pode incluir o custo associado com o transporte confiável de dados, o suporte para transmissão "multicast", a habilidade para passar acesso direto, entre outros. Para discriminar propriedades de comunicação, as aplicações podem selecionar o domínio apropriado às suas necessidades.

- Uma abstração unificada para um ponto final de comunicação é necessária para tornar possivel a sua manipulaçâo como um descritor de arquivos UNIX. $\mathrm{O}$ "socket" é um objeto abstrato pelo qual mensagens sâo enviadas e recebidas. "Sockets" são criados com um domínio de comunicação assim como os arquivos são criados dentro de um sistema de arquivos.

- Os aspectos semânticos da comunicação devem estar disponíveis de uma forma controlada e uniforme. Aplicaçôes devem ser capazes de requisitar modos diferentes de comunicação (como circuito virtual e datagrama). Contudo estas maneiras devem ser fornecidas de uma forma consistente com o domínio de comunicação.

- Processos devem ser capazes de localizar pontos finais de comunicação para que eles possam ser encontrados sem serem relacionados. Por exemplo, o nome do "socket" é interpretado somente dentro do contexto do domínio de comunicação em que foi criado.

No sistema UNIX, um processo tem um conjunto de descritores de entrada/saída. Descritores podem referenciar arquivos, dispositivos ou canais de comunicaçãa. $\mathrm{O}$ uso de descritores tem três fases: criação, uso para leitura e/ou escrita e destruição [SUN90a]. A idéia básica é fazer IPC similar a entrada/saída (I/O) de arquivos. Entretanto, a comunicação em rede envolve muito mais detalhes que a comunicação entre arquivos. Abaixo serão citados alguns pontos que devem ser considerados na comunicação em rede [STE90]:

- O relacionamento cliente/servidor típico é assimétrico - em uma conexão é necessário determinar qual dos lados é o servidor e qual é o cliente. $\mathrm{O}$ servidor normalmente espera uma requisiçâo de serviço do cliente "escutando" um endereço bem conhecido;

- Uma conexão de rede pode ser orientada à conexão ou sem conexão;

- Nomes são mais importantes em redes do que em operações com arquivos;

- São necessários mais parâmetros para ser especificada uma conexão de rede do que a entrada/saída de arquivos;

- A interface de rede deve suportar múltiplos protocolos de comunicação. 
Uma comparação entre a complexidade adicional imposta para a entrada/saída de rede em relaçâo a entrada/saída de arquivos é exemplificada através da figura 5.4 que mostra os passos necessários para o uso de "sockets", TLI e I/O de arquivos em uma transferência orientada a conexão.

\begin{tabular}{|c|c|c|c|c|}
\hline & & Sockets & TUI & IOs de arquivos \\
\hline \multirow{6}{*}{ Servidor } & aloca espaço & & t_alloco & \\
\hline & cria end point & socket0 & t_openo & mknod 0 open 0 \\
\hline & associa endereço & bind 0 & tbind 0 & \\
\hline & especifica fila & listen0 & & \\
\hline & espera por conexao & accepto & t_listen0 & \\
\hline & coloca novo fd & & $\begin{array}{l}\text { t_openo t_bindo } 0 \\
t \text { accept } 0\end{array}$ & \\
\hline \multirow[t]{6}{*}{ Cliente } & aloca espaço & & t_alloco & \\
\hline & cria end point & socket 0 & t_openo & openo \\
\hline & associa endereço & bind 0 & t_bindo & \\
\hline & conecta c/ server & connect 0 & t_connect0 & \\
\hline & transfere dados & $\begin{array}{l}\text { read } 0 \text { write } 0 \\
\text { recv } 0 \text { send } 0\end{array}$ & $\begin{array}{l}\text { read0 write } 0 \\
\text { t_rcv0 t_snd0 }\end{array}$ & $\begin{array}{l}\text { read } 0 \\
\text { write } 0\end{array}$ \\
\hline & datagramas & $\begin{array}{l}\text { recutrom } 0 \\
\text { sendto } 0\end{array}$ & $\begin{array}{l}\text { t_rcvudata0 } \\
\text { t_sndudata0 }\end{array}$ & \\
\hline & finalizaçao & $\begin{array}{l}\text { close } 0 \\
\text { shutdown } 0\end{array}$ & $\begin{array}{l}\text { t_close } 0 \\
\text { t_sndrel } \\
\text { t-snddis } 8\end{array}$ & $\begin{array}{l}\text { close0 } \\
\text { unlink0 }\end{array}$ \\
\hline
\end{tabular}

Figura 5.4 Comparaçâo entre "sockets", TLI e I/Os de arquivos.

Os serviços de rede foram implementados no ambiente SunOS através de servidores remotos, disponiveis a todo o sistema [SUN90a]. A introduçâo de novos serviços torna-se possivel pelo acréscimo de novos servidores. Exemplos de processos servidores no SunOS são o "portmapper", o "inetd" e o serviço de nomeação de rede (NIS).

O NIS é um servidor de páginas amarelas que fornece serviço de nomeação ao sistema operacional SunOS. É um mecanismo para identificar e localizar objetos e recursos acessiveis à comunidade. O principal propósito do serviço de nomeação é desacoplar o suporte lógico da implementação física do objeto. As bases de dados do NIS, melhor conhecidas como mapas, são distribuídas entre várias máquinas e são atualizadas a partir de uma base central de uma maneira automática e confiável, assegurando assim que os clientes compartilham as mesmas bases de dados de um modo consistente através da. rede. Existem duas variedades de servidores NIS - mestre e escravo. A máquina designada como servidor mestre contém o conjunto de mapas que podem ser atualizados quando necessário. O servidor escravo mantém uma cópia completa do conjunto de mapas do NIS. Sempre que os mapas do servidor mestre são atualizados, este propaga as 
atualizações aos servidores escravos. Os clientes do NIS executam processos que requisjtam dados dos mapas através de um processo de ligação ("biding process"). 0 processo cliente usa um "broadcast-rpc" para iniciar a ligação com um servidor NIS.

\subsection{1 "Sockets"}

A interface "sockets" implementada por SunOS contém mecanismos de IPC derivados da implementação UNIX de Berkeley. Comunicação entre processos baseada em "sockets" foi introduzida na versâo $4.2 \mathrm{BSD}$ e foi incorporada depois no SunOS. O projeto dessas facilidades foi o resultado de mais de dois anos de discussões entre pesquisadores e foram incorporadas muitas das idéias de pesquisas da época - ao mesmo tempo que mantinham a filosofia UNIX de simplicidade e concisão [SUN90a]. Antes, somente o mecanismo "pipe" permitia que dois processos se comunicassem - na mesma máquina. Na versão 4.3 do UNIX de Berkeley, o "socket" foi projetado como um subsistema totalmente independente do sistema de arquivos do UNIX. Todos os "sockets" são classificados de acordo com sua semântica de comunicação. Classes são definidas pelo subconjunto de propriedades que um "socket" suporta. Estas propriedades são [LEF89]:

- Entrega de dados ordenados;

- Entrega de dados não duplicados;

- Entrega confiavel de dados;

- Preservação dos limites da mensagem;

- Suporte para mensagens de controle com precedência ("out-of- band");

- Comunicação orientada a conexão.

No ambiente SunOS, "sockets" são identificados de acordo com propriedades de comunicação visiveis ao usuário. Considera-se que os processos se comuniquem apenas entre "sockets" do mesmo tipo. Os principais tipos de "sockets" disponíveis atualmente são mostrados abaixo [SUN90a]:

- Um "socket stream" fornece um fluxo de dados bidirecional, confiável, ordenado, não duplicado e não limitado para a mensagem;

- Um "socket" datagrama suporta fluxo de dados bidirecional que não garante ser confiável, ordenado ou duplicado. Ou seja, um processo recebendo mensagens através de um "socket" datagrama pode encontrar mensagens duplicadas e possivelmente em ordem diferente daquela em que foram enviados. Uma característica importante de um "socket" datagrama é que os limites dos registros de dados são mantidos. "Sockets" do tipo datagrama modelam rigorosamente as facilidades encontradas em muitas das redes de comutação de pacotes contemporâneas ( por exemplo, Ethernet); 
- Um "socket raw" fornece acesso a usuários para protocolos de comunicação básicos que suportam a abstração "socket". Estes "sockets" são normalmente orientados a datagramas embora suas características dependam da interface fornecida pelo protocolo. "Sockets raw" têm sido fornecidos principalmente para o desenvolvimento de novos protocolos de comunicação, não sendo exatamente para uso geral.

\section{Chamadas de sistema para "sockets"}

Abaixo são descritas algumas das chamadas de sistema para "sockets" necessárias para realizar programação em rede. Antes, contudo, são necessárias algumas considerações sobre o endereçamento de "sockets". Os arquivos "sys/types.h" e "sys/socket.h" devem ser incluídos em todas as chamadas do sistema para "sockets" [STE90].

$\#$ include $<$ sys $/$ types.h $>$
$\#$ include $<$ sys $/$ socket.h $>$

struct sockaddr_in

\begin{tabular}{|c|}
\hline dominio Internet \\
\hline porto (2-byte) \\
\hline $\begin{array}{c}\text { net iD. host ID } \\
\text { (4-byte) } \\
\text { (não usado)) }\end{array}$ \\
\hline
\end{tabular}

struct,sockaddr_un

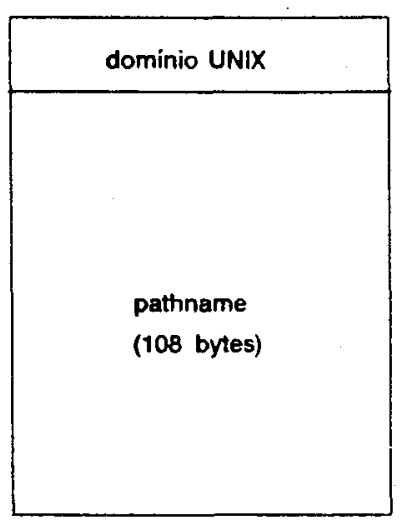

Figura 5.5 Estrutura do endereço do "socket" para os domínios Internet e UNIX.

Muitas das chamadas de sistemas disponiveis em UNIX BSD precisam de um ponteiro para a estrutura do endereço do "socket" como um argumento [SUN90a]. A definição desta estrutura está em <sys/socket.h>:

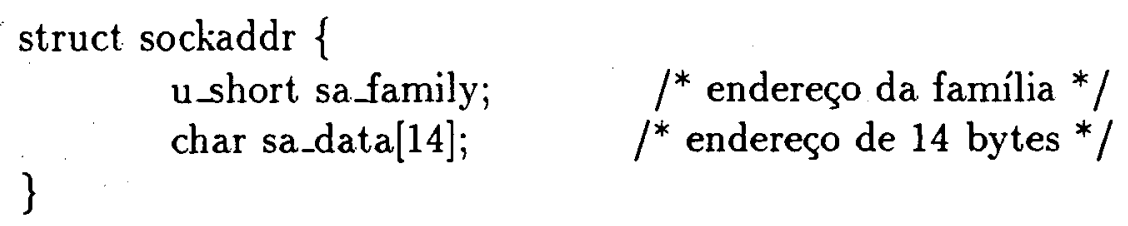

O conteúdo do endereço especifico do protocolo é interpretado de acordo com o tipo de endereço. A figura 5.5 mostra a estrutura do endereço do "socket" para os domínios Internet e UNIX. Para o domínio Internet a estrutura abaixo é definida em <netinet/in.h>: 


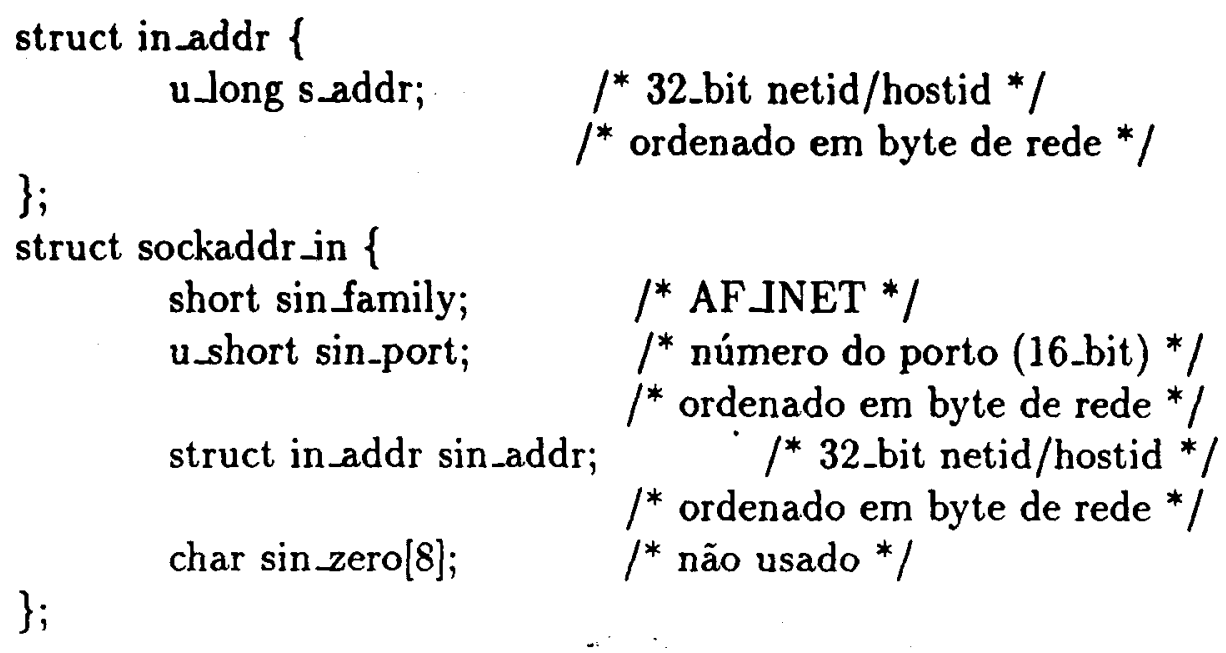

Para o domínio UNIX a seguinte estrutura é definida em <in/un.h>:

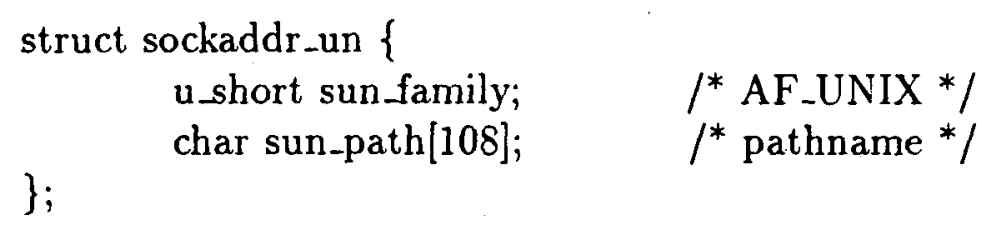

As chamadas de sistema fazem uso de dois argumentos: o endereço da estrutura genérica sockaddr e o tamanho da atual estrutura do protocolo especificado.

Chamada de sistema socket cria um "socket".

O primeiro passo para manipular entrada/saída de rede é criar um "socket" através da chamada de sistema socket, especificando o tipo de protocolo de comunicação desejado no domínio Internet ou UNIX. A figura 5.6 mostra as possíveis combinações de domínio, tipo e protocolos.

int socket(domain, type, protocol); int domain, type, protocol;

domain:
AF_UNIX
(protocolos UNIX)
AF_INET
(protocolos Internet)

type:

SOCK_STREAM

SOCK_DGRAM

(socket stream)

(socket datagrama)

protocol:

IPPROTO_UDP

IPPROTO_TCP

(protocolo UDP)

(protocolo TCP) 


\begin{tabular}{|l|l|c|c|}
\hline dominio & 40O & Protocolo & $\begin{array}{c}\text { Piotocolo } \\
\text { slval }\end{array}$ \\
\hline AF_INET & SOCK_DGRAM & IPPROTO_UDP & UDP \\
AF_INET & SOCK_STREAM & IPPROTO_TCP & TCP \\
AF_INET & SOCK_RAW & IPPROTO_ICMP & ICMP \\
AF_INET & SOCK_RAW & IPPROTO_RAW & ('rRW') \\
\hline
\end{tabular}

Figura 5.6 Possiveis combinações de domínio, tipo e protocolos.

A chamada retorna um valor inteiro similar ao descritor de arquivos, um descritor de "socket" (sockfd). Para obter este descritor de "socket" deve_se especificar o domínio do endereço e o tipo de "socket" (stream,datagrama,etc). A chamada socket especifica o parâmetro protocol para uma associação entre os elementos da quíntupla protocol, local_addr, local_process, foreign_addr, foreign_process. Antes do descritor do "socket" ter um valor real é necessário especificar os outros quatro parâmetros. A figura 5.7 mostra as chamadas de sistema típicas para os casos entre diferentes pares cliente/servidor e entre protocolos orientados a conexão e sem conexão.

\begin{tabular}{|l|l|l|l|}
\hline & protocol & localaddr, local-process & foreign-addr,foreign-process \\
\hline senvidor orientado a conexáo & socketo & bindo & listeno, accepto \\
\hline cliente orientado a conexáo & socketo & \multicolumn{2}{|c|}{ connecto } \\
\hline servidor sem conexáo & socketo & bindo & recufromo \\
\hline cliente sem conexáo & socketo & bindo & sendtoo \\
\hline
\end{tabular}

Figura 5.7 Chamadas de sistema para "sockets" e a associação dos parâmetros.

A chamada de sistema bind associa um nome ao "socket".

int bind (sockfd, addr, addrlen);

int sockfd,addrlen;

struct sockaddr *addr;

O segundo argumento é um ponteiro para o endereço do protocolo específico e o terceiro é o tamanho da estrutura do endereço. São três os possíveis usos do bind: 
- Registro de servidores e seus endereços bem conhecidos no sistema. Ambos os tipos de servidores - orientados a conexão e sem conexão - precisam usá-lo para poder aceitar requisições do cliente;

- Um cliente pode registrar um endereço específico para si mesmo;

- Um cliente usando um protocolo sem conexão precisa assegurar-se que o sistema associou-o a um único endereço.

Os parâmetros local_addr e local_process são completados pela chamada bind no conjunto de parâmetros.

A chamada de sistema connect conecta o processo cliente a um descritor de "socket" depois de uma chamada socket para estabelecer uma conexão com o servidor:

$$
\begin{aligned}
& \text { int connect(sockfd, servaddr, addrlen); } \\
& \text { int sockfd,addrlen; } \\
& \text { struct sockaddr *servaddr; }
\end{aligned}
$$

A chamada socket retorna o descritor sockfd. Os segundo e terceiro argumentos são ponteiros para um endereço de "socket" e seu tamanho, como descrito anteriormente. A associação dos quatro parâmetros: local_addr, local_process, foreign_addr e foreign_process da quíntupla é feita tipicamente através da conexão. As figuras 5.8 e 5.9 ilustram a utilização do connect.

A chamada de sistema listen é usada por processos servidores orientados a conexão para indicar quantas conexôes estâo dispostos a receber:

$$
\begin{array}{r}
\text { int listen(sockfd, backlog); } \\
\text { int sockfd, backlog; }
\end{array}
$$

Usualmente, é executada após as chamadas socket e bind e imediatamente antes da chamada accept (que será vista a seguir). O argumento backlog especifica a reserva de quantos pedidos de conexão podem ser enfileirados (enquanto espera que o servidor execute a chamada accept). Este argumento, geralmente, é especificado como 5 ( o maior valor permitido atualmente).

A chamada de sistema accept é usada por processos servidores orientados a conexão para estabelecer a conexão com o processo cliente:

$$
\begin{aligned}
& \text { int accept( sockfd, peer, addrlen); } \\
& \text { int sockfd, *addrlen; } \\
& \text { struct sockaddr }{ }^{*} \text { peer; }
\end{aligned}
$$


A chamada accept faz a primeira conexão requisitada da fila e cria um outro "socket" com as mesmas propriedades do sockfd. Se não existirem requisiçôes pendentes então bloqueia o servidor até um que cliente requisite um serviço. Esta chamada de sistema pode retornar três valores: um código inteiro (com uma indicação de erro ou um novo descritor de "socket"), o endereço do processo cliente ("peer") e o tamanho do seu endereço (addrlen). O novo descritor de "socket" retornado pelo accept refere-se a associação completa da quíntupla \{protocol, local_addr, local_process, foreign_addr, foreign_process\}.

As chamadas de sistema read, send, sendto, write, recv e recvfrom são usadas para leitura/escrita de informações sobre "sockets":

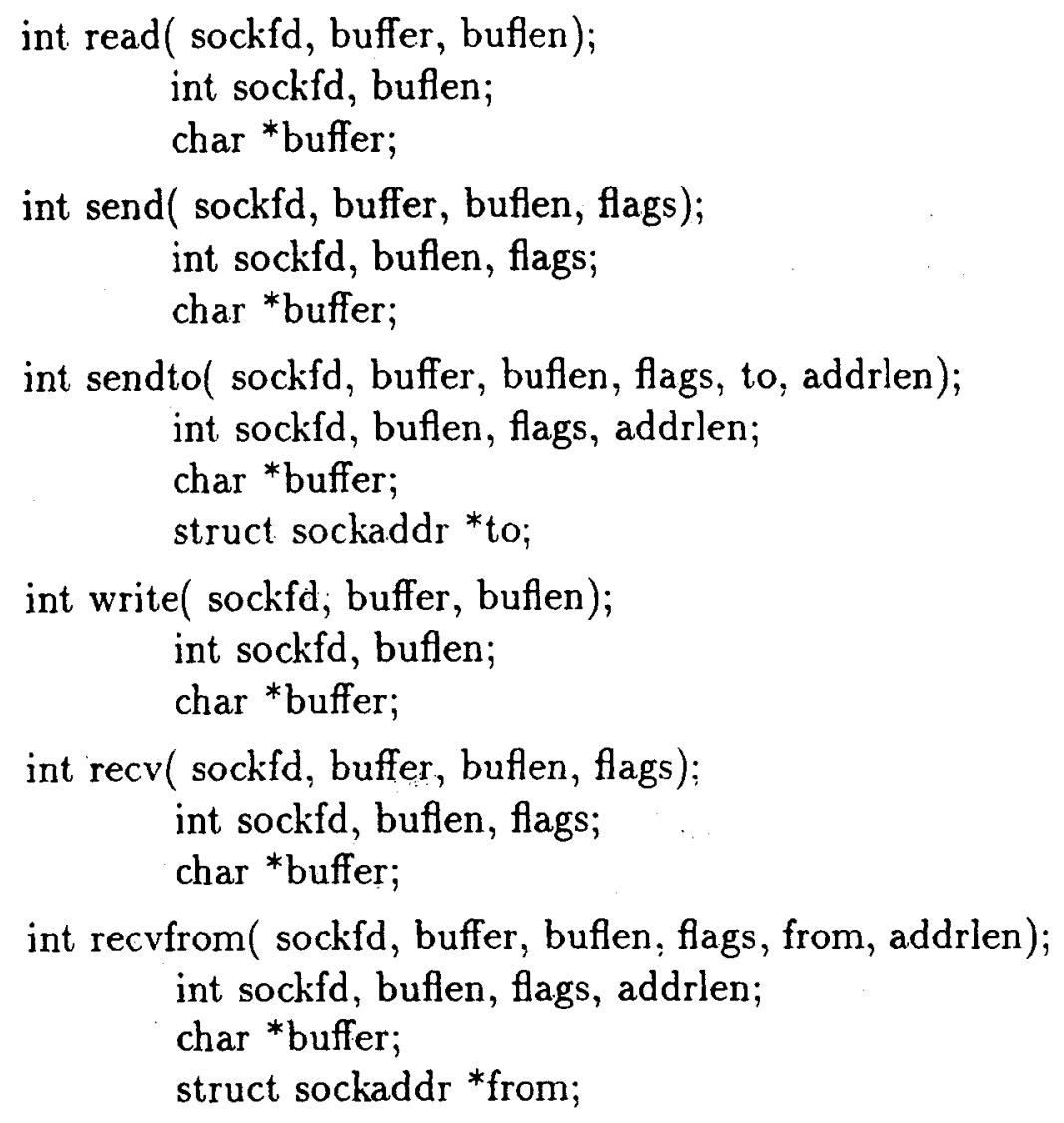

Os três primeiros argumentos sockfd. buffer e buflen em todas as chamadas de sistemas para leitura/escrita em "sockets" são similares aos parâmetros para leitura/escrita em arquivos. $\mathrm{O}$ argumento flags possibilita estabelecer prioridade para os dados. $\mathrm{O}$ argumento to/from de sendto/recvfrom especifica o destinatário/remetente dos datagramas enviados/recebidos. Todas as chamadas retornam o tamanho do dado que estão escrevendo/lendo como um valor de função. Enfim, os parâmetros das chamadas para leitura/escrita refletem as diferenças de suas funçôes.

A chamada de sistema close é usada para fechar um "socket":

int close(sockfd); int sockfd; 
Se o "socket" existente estiver associado com o protocolo TCP o sistema deve assegurar que nenhum dado que não tenha sido transmitido ou reconhecido seja enviado pelo kernel. Normalmente o sistema retorna do close imediatamente, mas o kernel pode tentar enviar algum dado já enfileirado.

\section{Servidor}

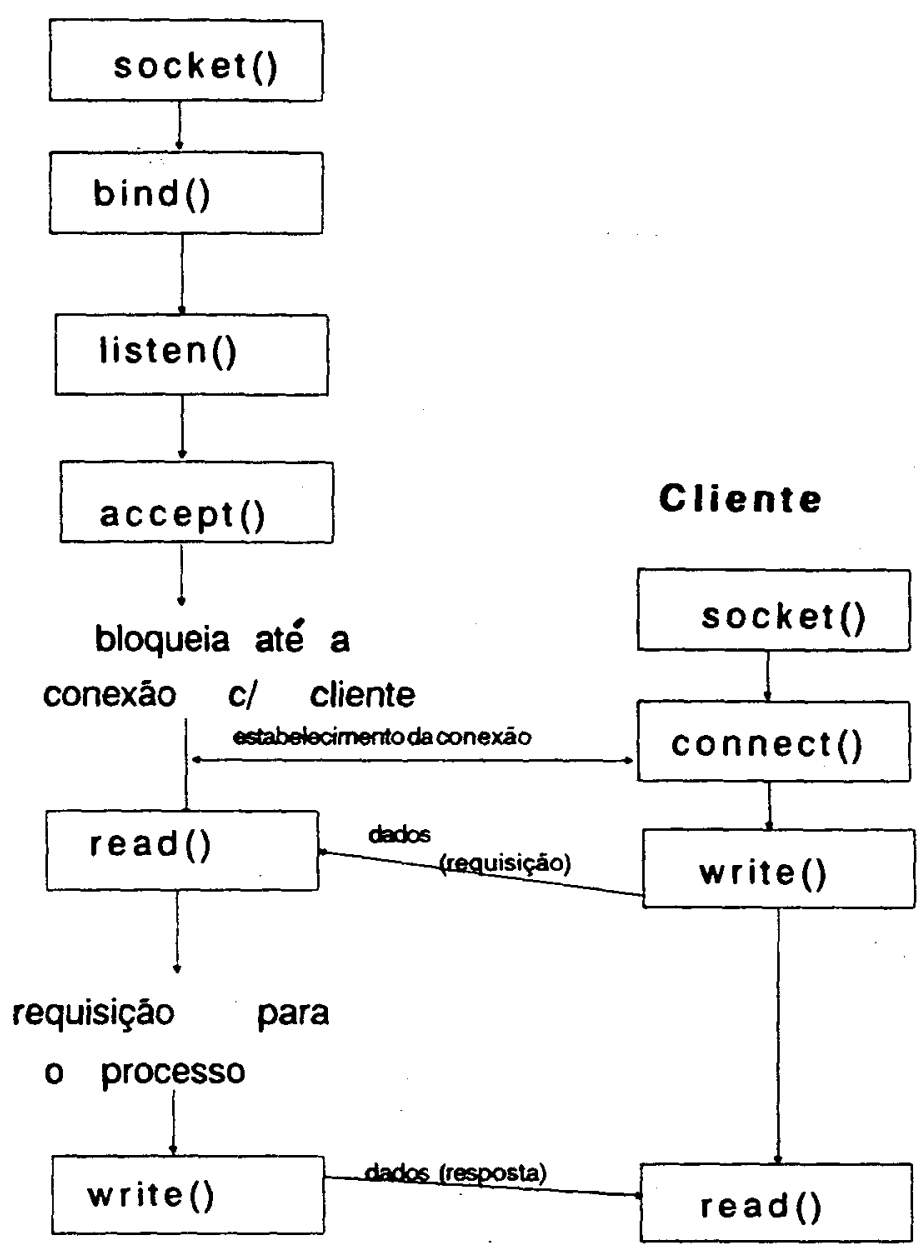

Figura 5.8 Chamadas de "sockets" utilizadas com protocolos orientados a conexão.

A figura 5.8 mostra uma seqüência típica que ocorre para se estabelecer uma transmissão orientada a conexão. Primeiro o servidor é iniciado, depois, em algum momento, um cliente é iniciado e conecta-se ao servidor.

As chamadas do sistema são diferentes quando o par cliente/servidor usa um protocolo sem conexâo. A figura 5.9 mostra as chamadas do sistema usadas. 0 cliente não estabelece a conexâo com o servidor. Ao invés disso, o cliente envia um datagrama para o servidor usando a chamada sendto que tem o endereço destino como um dos seus parâmetro. O servidor não tem que aceitar uma conexâo do processo cliente, ao invés disso, usa justamente a chamada recvfrom que espera até que dados cheguem de algum cliente. $\mathrm{O}$ 
recufrom retorna o endereço do processo cliente junto com o datagrama, então, o servidor pode enviar sua resposta ao processo correto.

\section{Servidor}

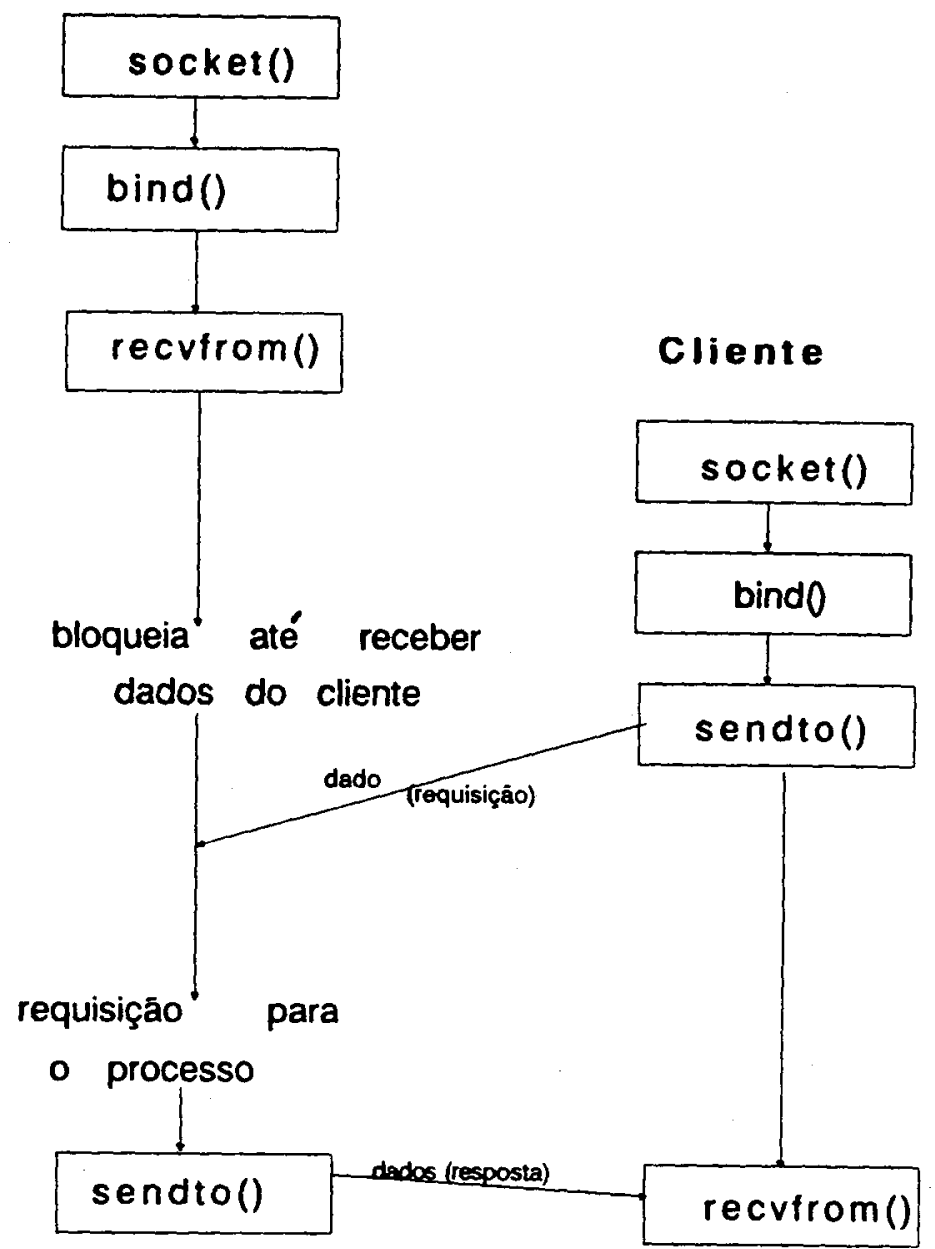

Figura 5.9 Chamadas de "sockets" utilizadas com protocolos sem conexão.

\subsubsection{Acesso aos serviços}

$\mathrm{Na}$ rede TCP/IP estão disponíveis, basicamente, dois tipos de conexão com a rede, através de circuito virtual e entrega de datagramas. Códigos que sejam usados por vários programas concorrentes são significativamente mais complexos que códigos que façam parte de um único programa. Programas clientes precisam de uma forma de encontrar os programas servidores, ou seja, eles necessitam de um modo para procurar e encontrar o número do porto dos programas servidores. Os serviços de transporte da rede nâo fornecem isto, eles fornecem transferência de mensagem processo à processo sobre a rede. De que forma um processo aguarda uma mensagem sobre um porto muda de um sistema operacional para outro, mas todos oferecem mecanismos que suspendem a execução de 
um processo até que uma mensagem chegue ao porto. Assim, mensagens não são enviadas para processo receptores mas para portos nos quais os processos receptores esperam por mensagens. Em geral, a mensagem contêm um endereço de transporte, ou seja, número da rede, número do hospedeiro e o número do porto.

O nome de um hospedeiro Internet para mapeamento de endereços é representado pela estrutura hostent:

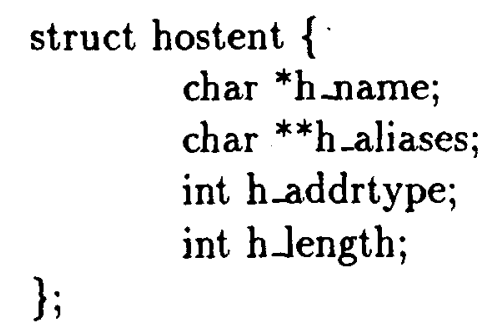

Os elementos da estrutura são:

h_name Nome oficial do hospedeiro.

h_aliases Um "array" de nomes alternativos para o hospedeiro.

h_addrtype $\quad O$ tipo de endereco sendo retornado; geralmente AF.INET.

h_length O tamanho, em bytes, do endereco.

h_addr_list Um ponteiro para uma lista dos enderecos de rede para o "host" nomeado.

A rotina gethostbyname obtem o nome de um "host" Internet e retorna uma estrutura hostent, enquanto a rotina gethostbyaddr mapeia endereços da estrutura hostent. A base de dados para estas rotinas é fornecida pelo arquivo /etc/hosts ou pelo uso do servidor de nomes resolver do NIS.

Para protocolos definidos no mapa protocols.bynames e no arquivo/etc/protocols do NIS a estrutura protoent define o mapeamento dos nomes dos protocolos usados com as rotinas getprotobyname e getprotobynumber:

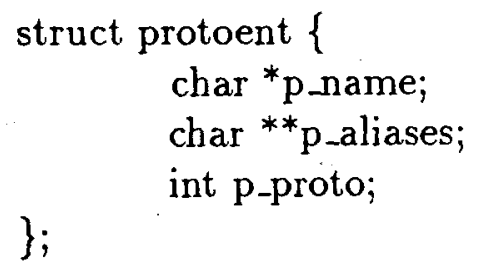

Os elementos desta estrutura são:
p.name
O nome oficial do protocolo.
p_aliases
Uma lista de nomes alternativos para o protocolo.
p_proto
$\mathrm{O}$ número do protocolo. 
Obter informações a respeito de serviços registrados é um pouco mais complicado que conseguir informações sobre hospedeiros ou protocolos. É esperado que um serviço resida em um porto específico e empregue um protocolo de comunicação particular. Esta visão é consistente com o dominio Internet, mas é inconsistente com outras arquiteturas de rede [SUN90a]. Serviços disponíveis estão contidos no mapa services.byname e no arquivo /etc/services do NIS. O serviço de mapeamento é descrito pela estrutura servent:

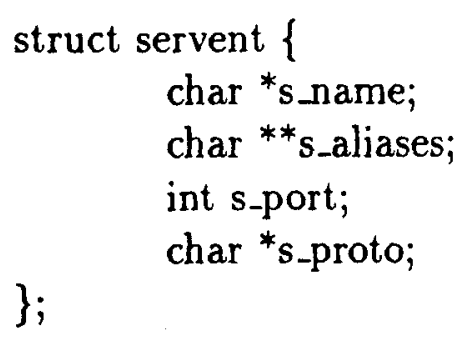

Os elementos desta estrutura são:
s_name
O nome oficial do serviço.
s_aliases
Uma lista de nomes alternativos para os serviços.
s_port
$\mathrm{O}$ número do porto onde o serviço reside.
s.proto
O nome do protocolo usado quando se contacta o serviço.

A rotina getservbyname mapeia nomes de serviços para uma estrutura servent especificando o nome do serviço. Por exemplo a chamada serv-port = getservbyname( "telnet", "tcp"); retorna o servidor telnet que usa o protocolo TCP.

Com o suporte das rotinas apresentadas anteriormente, um programa de aplicação Internet raramente tem que negociar diretamente com endereços. Isto permite que serviços sejam desenvolvidos, tanto quanto possivel, de modo independente da rede. Contudo, eliminar todas as dependências da rede é muito difícil. Sempre existe alguma dependência no programa, se for necessário ao usuário fornecer o endereço de rede quando solicitar serviços. Para se ter acesso a serviços da rede podem ser usados o "inetd" e o "portmapper" que são vistos a seguir.

\section{Inetd - O super servidor da Internet}

O esquema onde aplicaçôes cliente requisitam serviços de um prọcesso servidor implica no estabelecimento de comunicação de forma assimétrica. Em um sistema 4.3 BSD típico já existem alguns "daemons" esperando apenas pela chegada de uma requisição (por exemplo: "daemons" FTP, TELNET, TFTP e etc). Nas versōes anteriores a 4.3 BSD cada um dos servidores tinha um processo associado a ele. Todos os servidores tinham que criar um "socket", associar um endereço bem conhecido ao "socket" e esperar por uma conexão e então executar um "fork". Enquanto o processo filho executava o serviço, o processo pai ficava aguardando uma outra requisiçâo. A versão $4.3 \mathrm{BSD}$ fornece um super servidor Internet: o processo "inetd". Este "daemon" pode ser usado por um servidor que usa TCP ou UDP. $O$ "inetd" oferece as duas características abaixo: 
- Permite que um único processo ("inetd") fique esperando múltiplas requisições de conexâo ao invés de serem mantidos os processos para cada serviço potencial (isto reduz o número total de processos no sistema).

- Simplifica a escrita de processos servidores que manipulam requisiçôes e outros detalhes da comunicação em rede que passam a ser manipulados pelo "inetd". Todos os detalhes que foram descritos para o estabelecimento e manutenção da comunicação em rede por um servidor típico devem ser feitos pelo "inetd" antes que o servidor seja chamado.

\begin{tabular}{|l|l|}
\hline \multicolumn{1}{|c|}{ Campo } & Descriçăo \\
\hline service-name & deve estar em /etc/services \\
socket-type & stream ou dgram \\
protocol & deve estar em /etc/protocols (tcp ou udp) \\
wait-flag & waŕt ou nowart \\
login-name & de /etc/passwo (nomalmente root) \\
server-program & pathname completo para exec \\
server-program-arguments & máximo de 5 argumentos \\
\hline
\end{tabular}

Figura 5.10 Os campos do arquivo de configuração do "inetd".

Porém existe um preço a pagar por isso. O "inetd" tem que executar um "fork" e um "exec" para invocar o processo servidor vigente enquanto que um servidor contido em si mesmo somente tem que executar um "fork" para manipular cada requisição. Entretanto, este trabalho adicional é o preço da simplificação do servidor e da redução no número total de processos no sistema.

Quanto ao seu funcionamento, o processo "inetd" estabelece a si mesmo como um servidor e então lê o arquivo /etc/inetd.conf para inicializar a si próprio. Este arquivo especifica todos os serviços para os quais o super servidor está "atento", ("escutando" por ele) e o que fazer quando uma requisição de serviço chegar. Cada linha do arquivo contém os campos mostrados na figura 5.10.

Algumas das linhas exemplo são mostradas abaixo:

\begin{tabular}{lllllll}
$\ldots . .$. & & & & \\
$\mathrm{ftp}$ & stream & tcp & nowait & root & /etc/ftpd ftpd \\
telnet & stream & tcp & nowait & root & \multicolumn{2}{c}{$/$ etc/telnetd telnetd } \\
login & stream & tcp & nowait root & /etc/rlogind & rlogind \\
tftp & dgram & udp & wait nobody & /etc/tftpd tftpd \\
...... & & & & & &
\end{tabular}




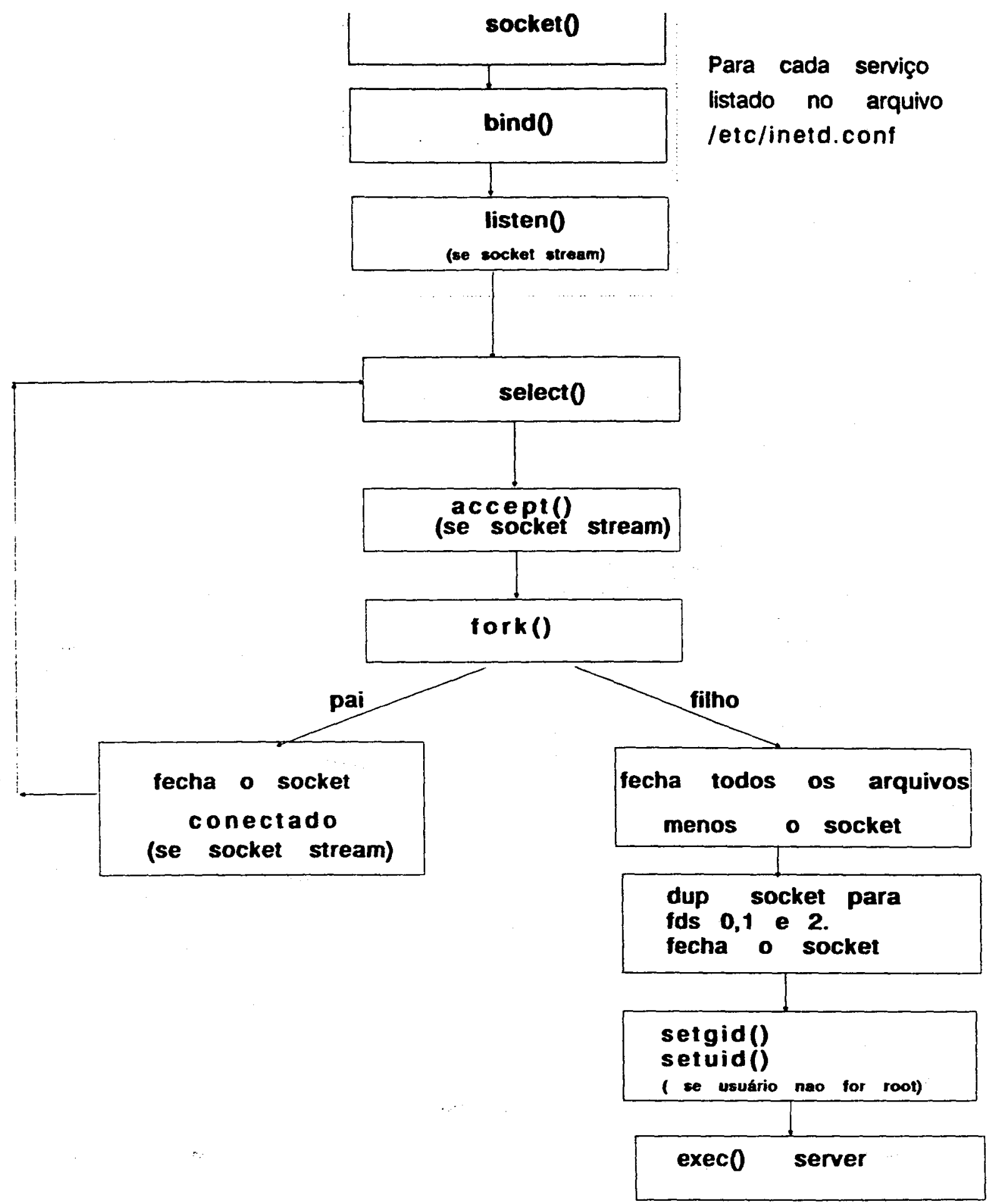

Figura 5.11 Passos executados pelo "inetd".

O nome atual do servidor é sempre passado como o primeiro argumento para o programa quando ele é executado (via "exec"). A figura 5.11 descreve a forma típica de 
funcionamento do daemon inetd. A seguir é fornecida uma explicação detalhada sobre a figura 5.11 .

- A principio, é lido o arquivo /etc/inetd.conf e criado um "socket" do tipo apropriado (stream ou datagrama) para cada serviço especificado no arquivo. Existe um limite para o número de servidores que o "inetd" pode atender, assim como o número total de descritores de arquivos usados pelo "inetd" não pode exceder o limite do sistema por processo. Em muitos sistemas BSD o limite é 64 mas pode ser mudado reconfigurando-se o kernel;

- Para cada "socket" criado, um bind é executado especificando um endereço bem conhecido para o servidor. Este número de porto TCP ou UDP é obtido verificando o campo "service_name" do arquivo de configuração/etc/services. Alguns valores típicos deste arquivo - correspondendo ao exemplo das linhas de configuração do arquivo/etc/inetd.conf - são mostrados abaixo:

$\begin{array}{ll}\text { ftp } & 21 / \text { tcp } \\ \text { telnet } & 23 / \text { tcp } \\ \text { tftp } & 69 / \mathrm{udp} \\ \text { login } & 513 / \text { tcp }\end{array}$

Os campos "service_name" e "protocol", do arquivo de configuração do "inetd", são passados como argumentos para a função de biblioteca "getservbyname" para localizar o número correto do porto para a chamada "bind";

- Para "sockets" stream uma chamada listen é executada especificando a disposiçâo para receber conexôes sobre o "socket" e o tamanho da fila para conexões que chegam. Este passo não é feito para "sockets" datagrama;

- Um "select" é então executado para esperar pelo primeiro "socket" a chegar pronto para leitura (um "socket" stream é considerado pronto para leitura quando um datagrama chega para aquele "socket"). Até este ponto o serviço "inetd" espera exatamente pela chamada do sistema "select" para retornar;

- Quando um "socket" está pronto para leitura, se for um "socket stream", uma chamada de sistema "accept" é executada para aceitar a conexão;

- O servidor "inetd" bifurca ("forks") e o processo filho manipula a requisição de serviço. $O$ processo filho fecha todos os descritores de arquivo, todos os descritores de "socket" que estava manipulando e então chama "dup2" para forçar que o descrjtor do "socket" seja duplicado sobre os descritores de arquivo 0, 1 e 2 (stdin, stdout e stderr). Então, o descritor do "socket" original é fechado. Feito isto, somente descritores de arquivos abertos pelo filho são 0, 1 e 2. Ele chama o "getpwnam" para colocar a senha do arquivo de entrada para o "login_name" que é especificada no arquivo /etc/inetd.conf. Se esta entrada não tiver uma identificaçâo do usuário ("user ID") de zero (super usuário) então o processo filho torna_se o usuário especificado pela execuçào das chamadas do sistema setgid e setuid. O processo 
filho agora faz um "exec" para executar o programa servidor apropriado para manipular a requisição passando os argumentos que estão especificados no arquivo de configuraçâo;

- Se o "socket" é um "socket stream", o processo paj deve fechar o "socket" conectado. O processo pai retorna e executa uma chamada "select" de novo esperando pelo próximo "socket" que tornar_se pronto para leitura.

O painel descrito manipula o caso onde o arquivo de configuração especifica "nowait" para o servidor. Isto é típico de todos os serviços TCP. Se outra requisição de serviço chega para o mesmo servidor, ele é retornado para o processo pai assim que ele executar - "select". Os passos mostrados acima sâo executado novamente e outro processo filho manipula esta nova requisição de serviço.

Assim, o servidor "inetd" é o processo que faz o "accept" de uma conexão stream. $O$ servidor que é invocado pelo "inetd" tem que executar a chamada de sistema "getpeername" - que retorna o endereço do processo par conectado - para obter o endereço do cliente. Isto é feito, por exemplo, por servidores que queiram verificar se o processo cliente esta usando um porto reservado. Para servidores datagrama o endereço do cliente é retornado para o servidor quando ele executa uma das chamadas do sistema para recebimento.

\section{"Portmapper"}

O protocolo "portmapper" define um serviço de rede que fornece um caminho padrão para clientes procurarem o número do porto de algum programa remoto em um servidor. O programa "portmapper" mapeia o número e a versão do programa RPC para um número especifico do porto. Este programa permite a associação dinâmica com os possiveis programas remotos. Novos serviços podem ter associados seus números de portos estaticamente ou dinamicamente de acordo com a forma como registraram seus portos no "portmapper" local [SUN90a]. O "portmapper" é iniciado automaticamente quando a máquina é ligada. Como mostra a figura 5.12, ambos os programas - cliente e servidor - usam chamadas de procedimentos do "portmapper" (via RPCs [SUN90a]).

O número do porto 111 está associado ao "portmapper" em todos os hospedeiros. Este é um dos poucos serviços de rede que tem um número do porto bem conhecido e dedicado. Para encontrar o porto de um programa remoto, o cliente envia uma mensagem RPC para o servidor "portmapper". Se o programa remoto estiver registrado, o "portmapper" retorna o número do porto na mensagem resposta. O programa cliente pode então enviar mensagens RPC para o porto do programa remoto. O "portmapper" também auxilia com uma "broadcast-rpc". Para transmitir para um dado programa, o cliente envia suas mensagens para o "portmapper" localizado no endereço transmitido. Cada "portmapper" que seleciona a transmissão chama o serviço local especificado pelo cliente. Quando o "portmapper" recebe a resposta do serviço local, ele envia a resposta de volta para. o cliente. 


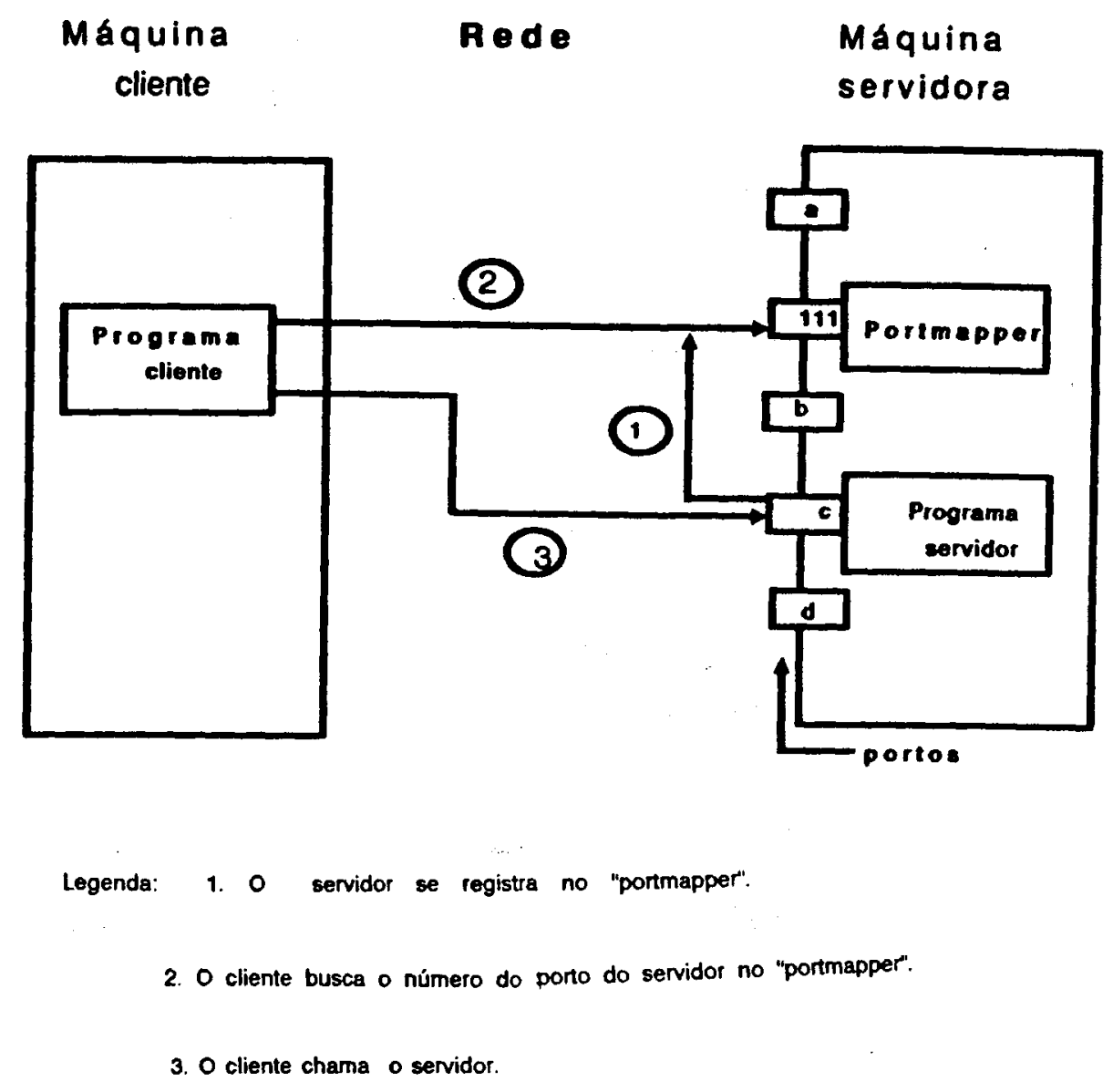

Figura 5.12 Passos para o estabelecimento de conexão entre o par cliente/servidor usando "portmapper" [SUN90a].

\subsection{Considerações finais}

Vários serviços fornecidos por sistemas operacionais em arquiteturas centralizadas são implementados em sistemas distribuídos através de servidores remotos [LEF89]. A maior conseqüência desse método é a redução da complexidade do núcleo do sistema operacional com influência direta na maior confiabilidade do sistema. A utilização do modelo cliente/servidor apresenta a possibilidade de crescimento modular, pois tanto clientes como servidores podem ser introduzidos gradualmente.

A interface "socket" de Berkeley é um mecanismo de comunicação entre processos e protocolos de rede. Na rede TCP/IP estão disponiveis dois tipos de conexão com a rede através de circuito virtual e entrega de datagramas. As mensagens são enviadas para portos e, em geral, contêm a identificaçâo da rede, do hospedeiro e o número do porto. Processos implementados usando protocolos utilizam portos.

Servidores recebem pedidos que podem chegar pela rede, os processam e retornam os resultados aos requisitantes. Um processo servidor normalmente atende às requisições de serviço através de um endereço bem conhecido. $O$ processo servidor permanece inativo até 
que uma requisição de conexão do cliente chegue no endereço do servidor. Neste momento, o servidor se torna ativo e serve ao cliente executando a ação apropriada a requisição do cliente. Um esquema alternativo é usar o servidor "inetd" para servidores Internet. Quando uma conexão é requisitada a um porto que o "inetd" está atendendo, o "inetd" executa o programa servidor apropriado para atender o cliente. Com este método o cliente não se apercebe que um intermediário, o "inetd", está fazendo uma parte da conexão. Já - "portmapper" fornece uma forma padrão para clientes procurarem o número do porto de um dos servidores registrados. $O$ "portmapper" basicamente expōe serviços - pois é um conjunto de associaçôes entre portos e serviços registrados. Isto é desejado porque a faixa de números de portos reservados é muito pequena e o número potencial de programas remotos é muito grande. Desta forma, executando somente o "portmapper" sobre um porto reservado o número dos portos de outros programas remotos pode ser determinado através de questionamento do "portmapper". 


\section{Capítulo 6}

\section{O projeto do servidor de modem}

\subsection{Introdução}

O projeto de servidor de modem considera o ambiente de rede de SUNs existente no Departamento de Ciências de Computação e Estatística do ICMSC-USP. Através da implementação do projeto pretende-se ilustrar a implantação de novos serviços neste ambiente. $\mathrm{O}$ projeto do servidor de modem segue o modelo cliente/servidor. $\mathrm{O}$ servidor "inetd" atende pedidos feitos ao servidor de modem, ativa o processo servidor que processa o pedido e estabelece a conexão com o sistema remoto, se for possivel.

O módulo cliente estabelece a comunicaçâo com o programa servidor enviando um pedido ao porto do servidor. O servidor "portmapper" permite que o processo cliente estabeleça a conexão com o processo servidor, pois fornece um modo de descobrir o número do porto do servidor. A interface "socket" é usada como mecanismo de comunicação entre os processos. Já os aspectos relacionados às características necessárias para a interconexão na rede SUN, com sistemas remotos utilizando modem, via linha telefônica, são atendidos pelo utilitário tip.

\subsection{A função do servidor}

O sistema proposto pode ser visto como mostra o diagrama da figura 6.1. A funçâo básica do par cliente/servidor é fornecer um serviço de transporte entre o processo do usuário e o modem, de modo que o usuário tenha a impressão que o modem está conectado à sua própria máquina. Os pontos principais do projeto são:

- Como os processos cliente e servidor conectam-se à rede;

- Como o processo cliente "descobre" o servidor; 
- Como o processo servidor controla pedidos de clientes;

- Como o processo servidor direciona os dados oriundos da rede para o modem;

- Como o processo cliente recebe os dados oriundos do usuário e como passa os dados recebidos da rede para ele.

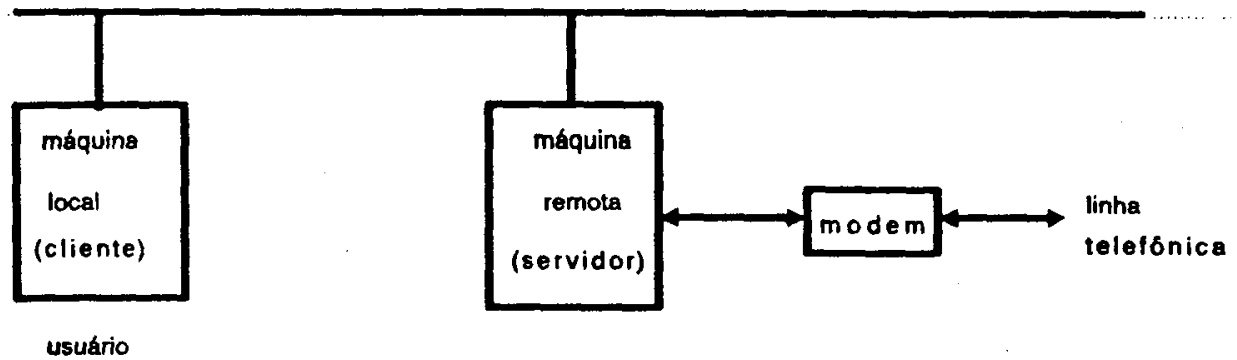

Figura 6.1 Diagrama do sistema.

O diagrama da figura 6.2 mostra um sistema que fornece blocos diferentes para resolver cada uma das questōes colocadas. Os módulos do par cliente/servidor são descritos a seguir:

- A interface com o usuário: possibilita ao usuário a utilização dos serviços oferecidos pelo servidor de modem e pela rede, propiciando meios para que esta utilização se dê dạ forma mais transparente possível.

- O armazenamento: módulo de armazenamento de massa. 0 sistema prevê a transferência de arquivos de sistemas remotos, através de algum protocolo disponível entre as duas máquinas comunicantes ou através de simples captura dos dados encontrados na tela.

- O "display": este módulo implementa todas as operações com a interface de saída padrão, gerenciadas pelo módulo de Controle/Cliente.

- O controle/Cliente: tem por funçâo controlar e reconhecer o fluxo entre o usuário e o módulo de acesso à rede. Também se encarregará do acesso aos dispositivos de armazenamento e "display", alocando-os conforme a necessidade das funções requisitadas pelo usuário.

- O controle/Servidor: módulo que faz interfaceamento entre o modem e a rede. Este módulo deve controlar o acesso dos clientes, por exemplo, recusando os pedidos feitos por estaçôes quando o modem não puder atender o pedido do cliente.

- $O$ acesso ao modem: este módulo implementa as operações para a utilização do modem, pois para se comunicar é necessário que a estação servidora tenha mecanismos de comunicação que controlem a interconexão do modem a sistemas remotos. 
- O acesso à rede: este módulo deve implementar o acesso à rede utilizando os serviços disponiveis do TCP/IP para fazer a conexão entre o cliente e o servidor.

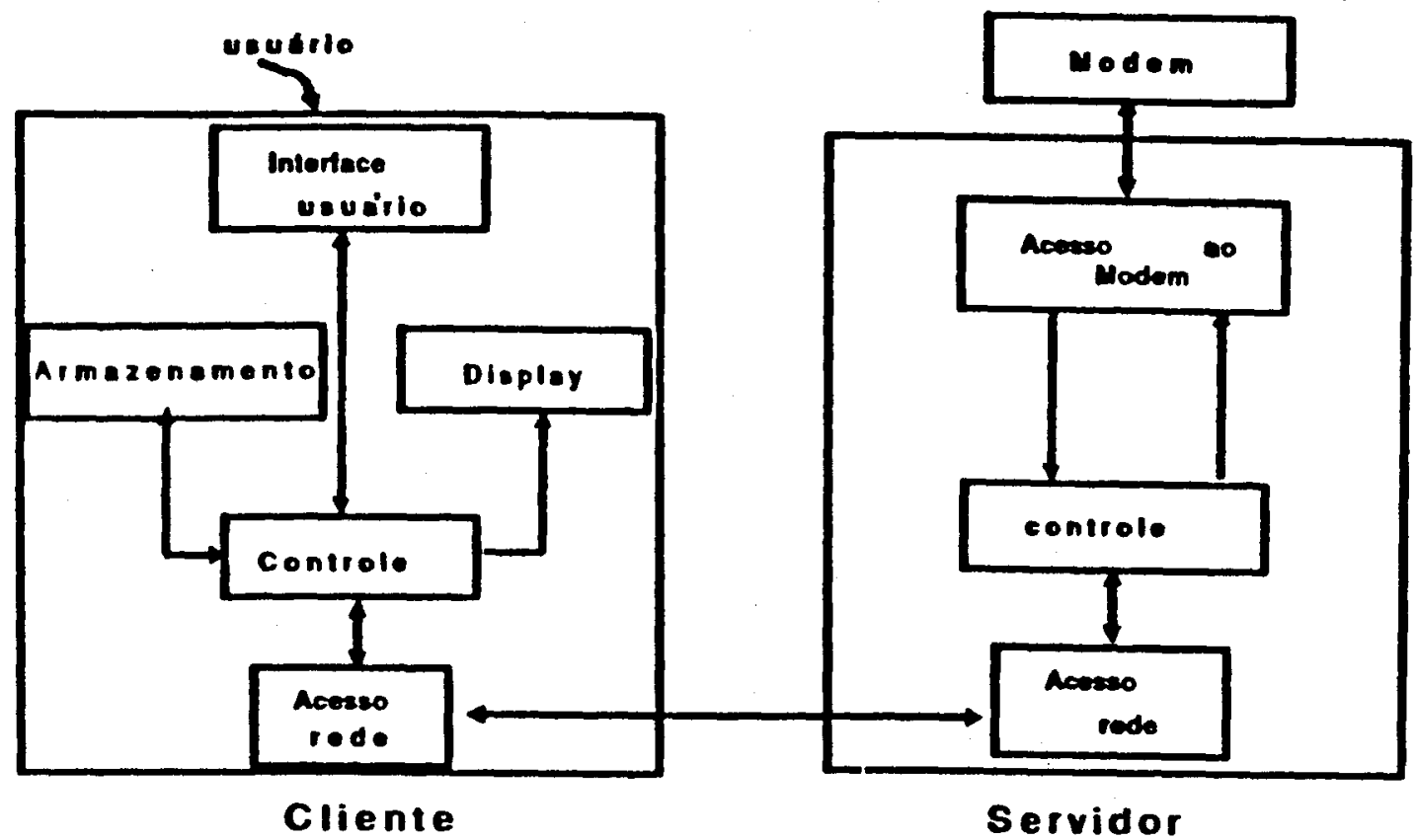

Figura $6.2 \mathrm{O}$ par cliente/servidor.

\subsection{Comandos disponíveis}

O projeto descrito visa permitir que qualquer estação da rede tenha acesso a serviços (centralizados no servidor) que estão disponiveis via telefone. Abajxo são apresentadas algumas possibilidades de utilização do servidor de modem:

- Entre uma rede local e uma rede pública (por exemplo, com a utilização do RENPAC 2000, figura 1.1);

- Entre uma rede local e um servidor localizado remotamente (base de dados, supercomputadores, etc., figura 1.2);

- Eventualmente, pode-se permitir que usuários remotos tenham acesso aos recursos oferecidos pela rede local (figura 1.3).

Alguns dos serviços desejáveis, no cliente e no servidor, são citados abaixo:

No cliente:

- help: mostra um resumo dos comandos disponiveis. A opção help command fornece uma mensagem com a sintaxe do comando command. 
- hosts: mantém a relação de alguns dos sistemas remotos e suas características. A comunicação com estes sistemas podem ser feita através de "apelidos".

- connect: estabelece a conexão inicial entre o cliente e o servidor.

- seqüencia de "escape": interrupção momentânea do cliente, através de sequaências especiais de caracteres. Algumas das possibilidades de "escape" são:

- imprime a tela;

- volta para o sistema operacional local;

- sai do sistema remoto mas continua utilizando o servidor;

- captura da tela (armazenamento da tela).

- macro: executa uma seqüência de comandos definidos em um arquivo que possibilita a conexão direta com o sistema remoto.

- get: possibilita a recepção de arquivos.

- put: envia arquivo.

- quit: encerra o processo.

Uma vez conectado ao servidor, as seguintes opções estão disponíveis ao usuário:

- help: mostra um breve resumo dos comandos disponíveis.

- status: mostra a configuraçào atual.

- configure: configura a comunicaçâo com o sistema remoto. Exemplo de parâmetros:

- speed: velocidade da transmissão.

- parity: paridade.

- modo: "half-duplex" ou "full-duplex".

- connect: estabelece a conexão entre o servidor e o sistema remoto.

- statistics: controla a contabilidade da utilização do sistema.

- quit: encerra o programa voltando o controle para o módulo cliente. 


\subsection{Acesso ao servidor}

A seguir é mostrada a sequência de passos do esquema de conexão do sistema:

- Inicialmente o rmodem é registrado no "portmapper" através do pmap_set;

- Depois é registrado no "inetd" pela inclusão do serviço no arquivo/etc/inetd.conf,

- Então o cliente descobre o servidor usando o pmap_getport (1) e requisita o serviço usando a chamada connect (2).

$\begin{array}{ccc}\text { Máquina } & \text { Rede } & \text { Máquina } \\ \text { cliente } & \text { servidora }\end{array}$

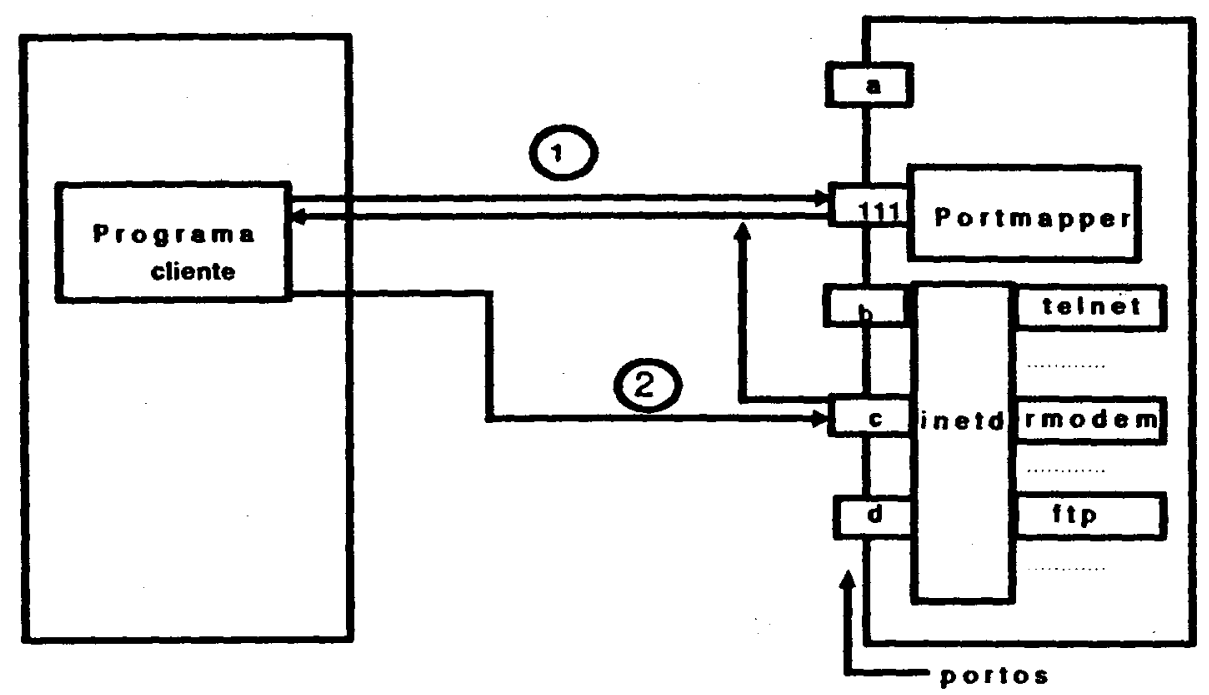

Figura 6.3 Esquema da conexão.

A interface de acesso à rede fornece dois tipos de serviços: o circuito virtual (através de SOCK_STREAM) e a entrega de datagramas (através de SOCK_DGRAM). A escolha de socket stream é justificada pela necessidade de manter uma conexão virtual entre as máquinas cliente e servidor. Em ambientes que usam redes de comunicação que implementam correção e deteç̧ão de erros do meio físico de transmissão - como é o caso da rede de SUNs implantada sobre Ethernet - a utilizaçâo de socket datagrama não implica em um serviço não confiável, mas nào estabelece um circuito virtual.

Como mencionado anteriormente, o "inetd" é o responsável por manter o serviço de modem (rmodem). A figura 6.3 descreve os passos para o estabelecimento da conexâo. $O$ rmodem é registrado no "portmapper" através do procedimento pmap_set do "portmapper". Para estabelecer a conexão com o servidor através da rede o modulo de acesso à rede do processo cliente é usado. Através do procedimento pmap_getport do "portmapper" é encontrado o número do porto do programa servidor. $\mathrm{O}$ módulo de controle do processo 
cliente envia um pedido requisitando o serviço para o endereço conseguido. $O$ servidor estando registrado no "inetd" uma chamada accept aceita a conexão. Os passos seguidos pelo "inetd" (descritos no capítulo 5) são realizados e finalmente o processo servidor é ativado para a conexão com o sistema remoto.

\subsection{Gerenciamento da conexão}

Modem é um equipamento usado na transmissão de dados at ravés de rede telefônica e a máquina servidora de modem é uma estação especial que oferece acesso a linhas telefônicas (especiais ou não) para transmissão de dados via modems. Desta maneira, uma estação poderia ter acesso a serviços disponiveis, via linha telefônica, em outra rede.

A conexão cliente/servidor é iniciada pelo módulo cliente quando solicita o serviço. $\mathrm{O}$ processo cliente é composto por dois processos - transmissáo_cliente e recepção_cliente. $\mathrm{O}$ processo transmissão_cliente lê dados da entrada padrão e exceto pelas linhas começando com um caráter de controle (dirigidas à máquina cliente), passa os dados para o porto. $\mathrm{O}$ processo recep̧̧ấ_cliente recebe dados do porto e os passa para a saída padrâo. $\mathrm{O}$ servidor verifica se o modem está disponivel e sendo possível estabelece a conexão com o modem. Uma vez estabelecida a conexâo, o servidor de modem também executa através de dois processos. O processo transmissâo_servidor lê dados do porto e exceto pelas linhas começando com um caráter de controle (dirigidas à máquina servidora), passa os dados para o sistema remoto. $\mathrm{O}$ processo recepçâo_servidor aceita dados do sistema remoto e os transfere para o porto. Enquanto existir comunicação entre o servidor/sistema remoto os processos recep̧âa_servidor e transmissáa_cliente ficam ativos.

O comando tip estabelece uma conexão tipo terminal "full-duplex" para um hospedeiro remoto. Este comando permite a utilização de uma série de sequências de "escape" usadas no controle da transferência de arquivos e na manutenção da conexão. Os fontes deste comando estão disponiveis e sâo de domínio público. A idéia é utilizar este código fonte para implementar partes do sistema (o controle de fluxo de dados, o estabelecimento e controle da conexão entre o servidor e o sistema remoto). Assim que a conexão é estabelecida a sessão remota comporta-se como uma sessão interativa sobre um terminal local. $\mathrm{O}$ arquivo remote contém entradas descrevendo sistemas remotos e as velocidades das linhas usadas por tip. Cada hospedeiro tem um padrão da taxa de transmissão para a conexão.

Quando uma conexão é solicitada ao servidor, é verificado se o sistema remoto existe no arquivo de sistemas e se a configuração do modem é compatível com o seu tipo. Somente um usuário por vez pode ter acesso a cada dispositivo. Quando se disca um número de telefone o tempo de espera ("timeout") por uma conexâo já está estabelecido. Se ocorrerem problemas na linha durante a comunicação ela será desconectada. 


\subsection{Manipulação de arquivos no cliente}

A conexâo entre o cliente e o servidor é transparente para o usuário, servindo como um caminho confiável para o transporte de dados. Se ocorrer algum erro na conexão com o sistema remoto o servidor analisa o erro e se nào for recuperável envia uma mensagem de erro para o cliente. No lado do cliente, uma vez tendo sido estabelecida a comunicação os processos transmissão_cliente e recepção_servidor ficam executando até o momento de término do programa. $\mathrm{O}$ módulo cliente deve ter a capacidade de entender modos de transferência de arquivos do tipo XMODEM, YMODEM e Kermit.

Estes comandos são utilizados pelo usuário do sistema para ter acesso a máquinas remotas ou para transferêncja de arquivos. Por exemplo, quando o objetivo é ter acesso a um sistema remoto, o usuário ativa o processo cliente, conectando-se ao servidor, especifica o sistema, a configuração e solicita a conexão com o sistema remoto. No acesso a bases de dados - que é um caso particular do "login" remoto - o usuário conta com o conjunto de comandos oferecidos pela base de dados. Na transferência de arquivos, após o estabelecimento da conexão, um programa específico de comunicação (Kermit, por exemplo) que esteja disponivel deve ser utilizado. Neste caso, após ativar o programa de comunicação no sistema remoto, o usuário realiza a seqüência de "escape" que volta o controle para o cliente, permitindo a transferência de arquivos através de get e put.

\subsection{Considerações finais}

Nesta fase do projeto do sistema servidor de modem buscou-se a utilização dos mecanismos socket stream, "portmapper" e "inetd" existentes no ambiente SunOS para permitir a conexão entre os módulos cliente/servidor e partes do código fonte do utilitário tip para estabelecer a conexâo entre sistema local e o sistema remoto. Algumas das possibilidades de utilização do servidor de modem citadas, como comunicação entre a rede local e uma rede pública, e comunicação entre a rede local e um servidor localizado remotamente tornam necessários mecanismos para transferência de arquivos. $O$ servidor de modem projetado tem por finalidade ilustrar o acréscimo de novos serviços no ambiente SunOS, permitir a interconexão da rede local com outras redes remotas (via linha telefónica) e a utilização dos serviços oferecidos por outros sistemas possibilitando o compartilhamento do modem e da linha telefônica pelos usuários. Da maneira que o projeto foi desenvolvido existe uma grande transparência para o usuário da localização do servidor. A sua instalação é feita com grande facilidade e a instalação do programa cliente se resume na transferência do código à máquina cliente. 


\section{Capítulo 7}

\section{Conclusões e trabalhos futuros}

Este capítulo conclui a dissertação revisando os principais tópicos abordados, destacando as contribuições alcançadas, apresentando as conclusões finais e sugestões para a continuidade deste trabalho.

\subsection{Considerações inicias}

Fornecer serviços como servidores independentes do kernel permite o crescimento modular da oferta de serviços, além de tornar o sistema mais confiável. Os serviços geralmente são implementados através do acréscimo de servidores. Mecanismos que forneçem a implementação de serviços oferecem subsídios para tornar seu desenvolvimento o mais independente da rede possível, além de permitirem que programas aplicativos Internet raramente tenham que "tratar" diretamente com endereços.

\subsection{Contribuições deste trabalho}

Uma preocupação sempre em mente no desenvolvimento do projeto foi a de fornecer subsídios que facilitassem o desenvolvimento de um novo serviço de rede em ambiente SunOS. O estudo de facilidades que permitam o acesso aos serviços pelo nome e não pelo endereço do porto pode facilitar a utilização e o acréscimo de recursos de rede. Estas facilidades podem eliminar parte da dependência da rede, mas como para chamar um serviço (e/ou "socket") é necessário fornecer endereços de rede, então sempre existe alguma dependência. No ambiente SunOS, o servidor "portmapper" estabelece um caminho padrão para que o cliente tenha acesso ao número do porto de um programa remoto fornecido por um servidor. Já o "inetd" simplifica a implementaçâo de um servidor pois parte dos detalhes da comunicação passam a ser manipulados por ele. 
A implementação do servidor proposto foi iniciada com o desenvolvimento e testes dos programas que têm acesso aos serviços "inetd" e "portmapper", bem como aos comandos de acesso ao modem. A conclusão do projeto ainda deverá envolver algum trabalho. Com relação às facilidades fornecidas pelo sistema SunOS, por exemplo, na conexão com sistemas remotos é usado o utilitário "tip" [SUN90a] e no acesso a rede são utilizados "sockets stream" [STE90]. O projeto está inserido em uma rede local onde convivem equipamentos de vários tipos (PC-XTs, PC-ATs, SUNs SLC e SPARC2s) tendo o TCP/IP como um dos protocolos disponíveis. Em termos de software o processo cliente executa na estação de trabalho do usuário, oferecendo uma interface amigável e "escondendo" tanto quanto possivel os detalhes de implementação. Esta interface oferece funções como captura de dados e comandos de conexão com o servidor. O processo servidor, em princípio, fornece as seguintes funçôes: acesso e configuração do modem, estatísticas sobre a utilização de serviços e conexão com sistemas remotos gerenciando o atendimento dos pedidos feitos pelos usuários.

\subsection{Conclusões}

Algumas consideraçôes finais são apresentadas a seguir:

- O servidor de modem exemplifica a implementação de um serviço, oferecendo características de comunicação de dados que torna necessário usar vários tipos de mecanismos de conexão;

- Utilizando o esquema proposto, o serviço é modular. Novas funções são facilmente acrescentadas e o servidor pode ser instalado em qualquer máquina na rede;

- O servidor de modem está descrito sobre um par cliente/servidor, com ênfase na implementação do serviço em equipamento SUN SPARCstation utilizando o serviço de circuito virtual para estabelecer a conexão entre o cliente e o servidor.

\subsection{Trabalhos futuros}

Algumas outras linhas de trabalho são previstas a partir deste projeto.

- A implementaçâo do par cliente/servidor em computadores pessoais (PCs) pode ampliar as possibilidades de utilização do software, já que redes locais de microcomputadores são bastante utilizadas e que o acréscimo do conjunto de protocolos TCP/IP em tais ambientes é relativamente fácil;

- Duas implementações do TCP/IP são bem difundidas para IBM-PCs: o chamado KA9Q e o do NCSA (Nacional Center for Supercomputing Applications). 
O TCP/IP NCSA oferece o acesso interativo de um IBM-PC ou compativel, a hospedeiros telnet sobre redes TCP/IP. NCSA Telnet é uma implementação padrão do DARPA Telnet com caracteristicas adicionais que melhoram o processamento local do PC. O KA9Q (TCP/IP) Internet Packet, desenvolvido para redes de comutação de pacotes por rádio amador também pode ser usado por redes comuns de comutação de pacotes. Através do programa NET, - KA9Q oferece IP, ICMP, TCP e UDP e implementa os aplicativos FTP, TELNET E SMTP [NOV90,SAR88];

- O KA9Q poderia ser utilizado para desenvolvimento do programa cliente para PCs. Esta implementação utiliza "sockets" com chamadas muito parecidas às do UNIX, o que facilitaria o porte - contudo, a chamada do sistema pmap_getport teria que ser implementada. Também é possível a implementação do sistema para outras plataformas além de IBM-PC como Macintosh e VAX entre outros;

- Elaborar uma versão do sistema utilizando programas de comunicação como o Kermit;

- ampliar o número de primitivas, pois a medida que os usuários passem a utilizar o sistema podem detectar a necessidade de novas funções. 


\section{Bibliografia}

[ALV89] ALVES, L.. Redes locais de microcomputadores IBM PC e compativeis. São Paulo, ATLAS, 1989.

[AMP88a] AMPLUS. INFORMÁTICA S.A.- AMPLICARD AC 210/XT: manual de instalação. versão x.1, Rjo de Janeiro, Amplus Informática, 1988.

[AMP88b] AMPLUS.INFORMÁTICA S.A.- AMPLICARD AW DOS: Manual do usuário. versão 1.2, Rio de Janeiro, Amplus Informática, 1988.

[BAL89] BAL, H. E.; STEINER, J. G.; TANENBAUM, A. S.. Programming languages for distributed computing systems. ACM Computing Surveys, v. 21, n. 3, p. 261-322, september, 1989.

[BLA88] BLACK, U. Phisycal level interfaces and protocols. Washington, IEEE Computer Society Press, 1988.

[BRA90a] BRASIL. Ministério das Comunicaçôes, EMBRATEL. Serviços RENPAC: descrição funcional. Brasilia, EMBRATEL, 1990.

[BRA90b] BRASIL. Ministério das Comunicações, EMBRATEL. STM 400 um novo conceito em transmissão de mensagens. (folhetos explicativos), 1990.

[CLA78] CLARK, D. D.; POGRAN, K.T.; REED, D. P.- An introduction to local area networks. Proceedings of the IEEE, v. 66, n. 11, p. 1497-517, november, 1978.

[COM91a] COMER, D. E.. Internetworking with TCP/IP principles, protocols and architecture. $2^{\circ}$ Ed., New Jersey, Prentice-Hall, 1991.

[COM91b] COMER, D. E.; STEVENS, D. L.. Internetworking with TCP/IP design, implementation, and internals., New Jersey, Prentice-Hall, 1991.

[COU88] COULOURIS,G. F.; DOLLIMORE, J.. Distributed Systems - Concepts and design. Wokingham, Addison-Wesley, 1988.

[CRO82] CROCKER, D. H. et al. - Standard for the format of Arpa Internet text messages. In: ARPANET Working Group Request for Comments, RFC. 822, august, 1982.

[DIG88] DIGITAL. EQUIPAMENT CORPORATION - VMS general user's manual. New Hampshire, Digital Eq. Corp., 1988. 
[DIX88] DIXON, R. C.; PITT, D. A.- Addressing, bridging and source routing. IEEE Network Magazine, v. 2, n. 1, p. 25-31, january, 1988.

[DV089] DVORAK, J. C.; ANIS, N.. Dvorak's Guide to PC Telecommunications. Berkeley, McGraw-Hill, 1989.

[GET92] GETSCHKO, D.; STANTON, M. A.. A evolução de redes acadèmicas no país. In: SIMPÓSIO BRASILEIRO DE REDES DE COMPUTADORES, 10, Recife. Anais. Recife, Editora Universitária - UFPE, p. 149-65, 1992.

[GIO86] GIOZZA, W. F. et al.. Redes locais de computadores: tecnologia e aplicações. São Paulo, McGraw-Hill, 1986.

[HIN83] HINDEN, R.; HAVERTY, J.R.; SHELTZER, A. - The DARPA Internet interconnection heterogeneous computer networks with gateways. Computer, v. 16, n. 9, p. 38-48, september, 1983.

[HUT87] HUTCHISON, G.; DESMOND, C. L. - Electronic data interchange. IEEE Network Magazine, v. 1, p. 16-20, october, 1987.

[JUE87] JUENEMAN, R. R.. Electronic document authentication. IEEE Network Magazine, v. 1, n. 2, p. 17-25, april, 1987.

[LAG86] LAGES, N. A. C.; NOGUEIRA, J. M. S.. Introdução aos sistemas distribuidos. Campinas, Papirus/Unicamp, 1986.

[LAN86] LANDWEBER, L. H. ; JENNINGS, D. M.; FUCHS, I. - Research computer networks and their interconnection. IEEE Communications Magazine, v. 24, n. 6, p. 5-16, june, 1986.

[LEF89] LEFFLER, S.J., et al.. The design and implementation of the 4.3 BSD UNIX operating system. Reading, Massachusetss, Addison-Wesley, 1989.

[LEV90] LEVY, E.; SILBERSCHATZ, A.. Distributed file systems: concepts and exemples. ACM Computing Surveys, v. 22, n. 4, p. 321-74, december, 1990.

[LIC78] LICKLIDER, J. C. R. - Applications of informations networks. Proceedings of IEEE, v. 66 , n. 11 , p. 1330-46, november, 1978.

[MET76] METCALFE, R. J.,BOGGS, D. R. - Ethernet: distributed packet switching for local computer networks. Communications of the ACM. v.19, pp,395-404, july, 1976.

[MOR92] MORGADO, E. M.. Avaliação da implantação da Bitnet nas Universidades estaduais paulistas. In: SIMPÓSIO BRASILEIRO DE REDES DE COMPUTADORES, 10, Recife. Anais. Recife, Editora Universitária - UFPE, p. 80-91, 1992.

[MOU86] MOURA, J. A. B., et al.. Redes locais de computadores, protocolos de alto nivel $e$ avaliação de desempenho. Sâo Paulo, Mc Graw-Hill, 1986. 
[MUL89] MULLENDER, S. J. (ed.). - Distributed Systems. New York, Addison-Wesley. 1989.

[NEW82] NEWELL, A.; SPROULL, R. F.. Computer networks: prospècts for scientists. Science, v. 215, n. 12, february, 1982.

[NOV90] NOVELL, INC. - NETWARE: Installation Ethernet. Utah, NOVELL INC., 1990 .

[PAR88] PARKS Informática - MODEM UP 22 BIS: Manual de instalação e operação. s.i.p., PARKS Informática, 1988.

[POS81a] POSTEL, J.- Internet Protocol - DARPA internet program protocol specification. In: ARPANET Working Group Request for Comments, RFC. 791, september 1981.

[POS81b] POSTEL, J. - Transmission Control Protocol - DARPA internet program protocol specification. In: ARPANET Working Group Request for Comments, RFC. 793, september 1981 .

[POS82] POSTEL, J. - Simple mail transfer protocol. In: ARPANET Working Group Request for Comments, RFC. 821, august 1982.

[POS83] POSTEL, J.; REYNOLDS, J.- Telnet protocol specification. In: ARPANET Working Group Request for Comments, RFC 854, may 1983.

[QUA86] QUARTERMAN, J. S.; HOSKINS, J. C.- Notable Computer Networks. Communications of the $A C M$, v. 29, n. 10, p. 932-71, october, 1986.

[RAV89] RAVINDRAN, K.; CHANSON, S. T.. Failure Transparency in Remote Procedure Calls. IEEE Transactions on computers, v. 38, n. 8, august, 1989.

[ROS88] ROSE, M.- ISO presentation services on top of TCP/IP - based internets. ARPANET Working Group Request for Comments, RFC.1085, december 1988.

[ROS90] ROSS, F.E., et al.. FDDI - A LAN among MANs. Computer Communication Review, Sigcomm, p.16-31, july 1990.

[SAR88] SARGENT,M.; SHOEMARKER, R. L.. The IBM PC from the inside out. 5 ed., Massachusetts, Addison-Wesley, 1988.

[SCH89] SCHROEDER, M. D.; BURROWS, M.. Performance of firefly RPC. $A C M$, p. 83-90, 1989.

[SHO78] SHOCH, J. F.- Inter-network naming, adressing, and routing. In: Lam, S. S. - Tutorial: Principes of Communication and the networking protocols. Los Angeles, 1984, p. 389-96.

[SHR82] SHRIVASTAVA, S. K.; PANZIERE, F.- The Design of a reliable remote procedure call mechanism. IEEE Transactions on computers, v. 31, n. 7, july, 1982. 
[SIL92] SILVA, R.M.; MOREIRA, E.S.. Um protótipo de servidor de modem sobre uma rede TCP/IP. In: SIMPÓSIO BRASILEIRO DE REDES DE COMPUTADORES, 10 $0^{\circ}$ Recife. Anais. Recife, Editora Universitária - UFPE, p. 375-384, 1992.

[SLO78] SLOMAN,M. S. - X.25 explained. Computer Communications. v.1, n.6, p.310-28, december, 1978.

[SOA86] SOARES, F. G.. Redes locais. Rio de Janeiro, Campus. 1986.

[STA84] STALLINGS, W. - Local networks. ACM Computing Surveys, v. 16, n. 1, p. 3-41, march, 1984.

[STA84b] STANKOVIC, J. A. ; A perspective on distributed computer systems. IEEE Transactions on Computer, v. 33, n. 12, p 1102-15, december 1984.

[STA92] STANTON, M. A.. A rede interna da PUC-RIO. In: SIMPÓSIO BRASILEIRO DE REDES DE COMPUTADORES, 10, Recife. Anais. Recife, Editora Universitária - UFPE, p. 93-105, 1992.

[STE90] STEVENS, M. UNIX network programming. Englewood Clifs, Prentice-Hall, 1990.

[SU82] SU, Z.; POSTEL, J.- The domain naming convention for Internet user applications. RFC 819. In: ARPANET Working Group Request for Comments, RFC. 819, august 1982 .

[SUN90a] SUN MICROSYSTEMS, INC - SunOS Networking Programming Guide. California, 1990.

[SUN90b] SUN MICROSYSTEMS, INC - SunOS System and Network Administration. California, 1990.

[SUN91a] SUN MICROSYSTEMS, INC - SPARC Desket Reference Guide. California, 1991.

[TAN85] TANENBAUM, A. S.; RENESSE, R. V.- Distributed operating systems. Computing Surveys, v. 17, n.4, p. 419-69, december, 1985.

[TAN89] TANENBAUM, A. S.. Computer Networks. 2 ed.,Englewood Cliffs, PrenticeHall, 1989.

[TAR86] TAROUCO, L. M. R.. Redes de computadores locais e de longa distância. São Paulo, McGraw-Hill, 1986.

[TAR92] TAROUCO, L. M. R.. Integração de redes acadêmicas: aplicações e gereciamento cooperantes. In: SIMPÓSIO BRASILEIRO DE REDES DE COMPUTADORES, 10, Recife. Anais. Recife, Editora Universitária - UFPE, p. 361-74, 1992.

[TRI91] TRINDADE, O. J.. Servidor de processamento paralelo baseado em banco de transputers. São Carlos, IFQSC, 1991. 
A gravidade

é a raiz da leveza;

a quietude,

a norma do movimento.

Mueller 